Universidade de São Paulo

Instituto de Física

\title{
O Modelo de Cluster-alfa Aplicado ao ${ }^{94} \mathrm{Mo}$
}

\author{
Marco Antonio de Souza
}

Orientador: Prof. Dr. Hideaki Miyake

Dissertação de mestrado apresentada ao Instituto de Física para a obtenção do título de Mestre em Ciências.

Banca examinadora:

Prof. Dr. Hideaki Miyake (IFUSP)

Prof. ${ }^{a}$ Dr. a Thereza Borello-Lewin (IFUSP)

Prof. Dr. Diógenes Galetti (IFT / UNESP) 


\section{FICHA CATALOGRÁFICA}

Preparada pelo Serviço de Biblioteca e Informação do Instituto de Física da Universidade de São Paulo

Souza, Marco Antonio de

O Modelo de Cluster-alfa aplicado ao ${ }^{94} \mathrm{Mo}$.

São Paulo, 2005.

Dissertação (Mestrado) - Universidade de São Paulo Instituto de Física - Depto. de Física Experimental

Orientador: Prof. Dr. Hideaki Miyake

Área de Concentração: Física

Unitermos:

1. Física Nuclear;

2. Estrutura Nuclear;

3. Modelo Nuclear.

USP/IF/SBI-073/2005 


\section{Agradecimentos}

Ao Prof. Hideaki Miyake, cuja colaboração foi fundamental para a realização deste trabalho.

A Leny Florêncio da Silva, por suas importantes sugestões na revisão gramatical do texto.

À CAPES, pela bolsa concedida para a realização deste trabalho. 


\section{Sumário}

$\begin{array}{lr}\text { Resumo } & 3\end{array}$

$\begin{array}{ll}\text { Abstract } & 4\end{array}$

1 Aspectos do modelo de cluster- $\alpha$ aplicado ao ${ }^{94} \mathrm{Mo} \quad 5$

1.1 Introdução . . . . . . . . . . . . . . . . . . . . . 5

1.2 Descrição do modelo de cluster- $\alpha$. . . . . . . . . . . . . . . 7

1.3 Potencial de interação do sistema $\alpha^{-}{ }^{90} \mathrm{Zr}$. . . . . . . . . . . . . . . 9

2 Processo de determinação da banda do estado fundamental do $\begin{array}{ll}\text { sistema } \alpha-{ }^{90} \mathrm{Zr} & 13\end{array}$

2.1 Procedimento escolhido para a resolução do sistema . . . . . . . . . 13

2.2 Escolha do método numérico para a resolução do sistema . . . . . . . 14

2.3 Algumas implicações do método RKF com passo positivo . . . . . . 15

2.4 Adaptação do método RKF para a resolução do sistema $\alpha^{-9}{ }^{90} \mathrm{Zr}$. . . 18

2.5 Cálculo e identificação das auto-funções radiais $u \quad(r)$. . . . . . . 22

2.6 Aproximação de estado ligado para $E>0 \ldots \ldots$. . . . . . . . 23

3 Propriedades da banda do estado fundamental do sistema $\alpha-{ }^{90} \mathrm{Zr} \quad 25$

3.1 Espectro da banda e auto-funções radiais . . . . . . . . . . . . . . 25

3.2 Raios intercluster rms . . . . . . . . . . . . . . . . . 27

3.3 Taxas de transição $B(E 2) \ldots \ldots \ldots . \ldots . \ldots . \ldots 28$

3.4 Comparação com auto-estados de oscilador harmônico . . . . . . . . 29

4 Identificação de bandas superiores no sistema $\alpha-{ }^{90} \mathrm{Zr} \quad 36$

4.1 Procedimento para o cálculo de níveis de energia ressonantes . . . . 36

4.1.1 Localização preliminar das bandas superiores . . . . . . . . . 36

4.1.2 Tratamento para estados ressonantes . . . . . . . . . . 37

4.2 Propriedades dos níveis ressonantes calculados . . . . . . . . . . . . 40

$\begin{array}{ll}\text { Conclusões e perspectivas } & 46\end{array}$

A Funções de onda radiais da banda do estado fundamental $\quad 49$ 
B Expansão das funções de onda radiais da banda fundamental na base de $\mathrm{OHE}$

C Funções de deslocamento de fase $\delta(E) \quad 57$

Referências Bibliográficas $\quad 62$ 


\section{RESUMO}

O modelo de cluster de partícula- $\alpha$, o qual já foi bem-sucedido na descrição de dados espectroscópicos em núcleos leves próximos das duplas camadas fechadas no ${ }^{16} \mathrm{O}$ e ${ }^{40} \mathrm{Ca}$, é aplicado ao núcleo ${ }^{94} \mathrm{Mo}$ da região de massa dos meio-pesados. Para este propósito, vários esta-

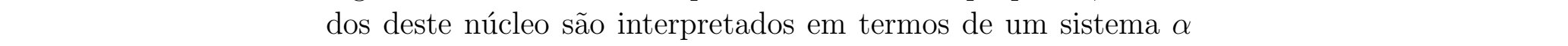




\begin{abstract}
The $\alpha$-particle cluster model, which has already been successful in describing the spectroscopic data in light nuclei near to the double shell closures at ${ }^{16} \mathrm{O}$ and ${ }^{40} \mathrm{Ca}$, is applied to the ${ }^{94} \mathrm{Mo}$ nucleus of the medium-heavy mass region. For this purpose, various states of this nucleus are interpreted in terms of an $\alpha+{ }^{90} \mathrm{Zr}$ system where an $\alpha$-cluster interacts with an inert ${ }^{90} \mathrm{Zr}$ core through a local phenomenological potential. The energy levels of the ground state band and the respective $B(E 2)$ transition rates are calculated, in good agreement with available experimental data. The intercluster rms radii calculated for the levels of the ground state band indicate that such band presents a compact $\alpha$-cluster structure. The comparison between harmonic oscillator eigenfunctions adapted to the system and the radial wave functions of the ground state band provides the estimate in which there is a significant contribution of the shell model in the formation of the states of this band. The cluster-core interaction potential predicts the existence of a negative parity band that starts at a few $\mathrm{MeV}$ above the $\alpha+{ }^{90} \mathrm{Zr}$ threshold, where the bound state approximation is very appropriate. In the same way, it is predicted that an excited positive parity band starts just below the Coulomb barrier, showing a typical feature of resonance.
\end{abstract}




\section{Capítulo 1}

\section{Aspectos do modelo de cluster- $\alpha$ aplicado ao ${ }^{94} \mathrm{Mo}$}

Este capítulo discute as motivações para a aplicação do modelo de cluster- $\alpha$ na descrição de propriedades espectroscópicas do núcleo ${ }^{94} \mathrm{Mo}$, recorrendo a estudos anteriores relacionados a este modelo. A seguir, é feita uma descrição das propriedades principais do modelo de cluster e dos aspectos específicos para a sua aplicação no estudo do sistema $\alpha-{ }^{90} \mathrm{Zr}$.

\subsection{Introdução}

A estrutura de cluster- $\alpha$ é uma característica importante na interpretação de dados espectroscópicos de núcleos leves. O modelo de cluster- $\alpha$ mostrou bom êxito na reprodução de vários níveis dos espectros de energia, propriedades eletromagnéticas, larguras de emissão- $\alpha$ e dados referentes ao espalhamento elástico de partículas- $\alpha$ em núcleos próximos daqueles com dupla camada fechada, tais como ${ }^{16} \mathrm{O}$ e ${ }^{40} \mathrm{Ca}$. Diante disto, uma questão que desperta interesse é a possibilidade de existência da mesma estrutura na região dos núcleos meio-pesados e pesados. Estudos recentes sobre este tema $[5,4,6]$ indicam a persistência da estrutura de cluster- $\alpha$ na região de massa $A=90 \mathrm{com}$ base em dados experimentais. O presente trabalho visa descrever as propriedades de tal estrutura no ${ }^{94} \mathrm{Mo}$, o qual é o principal núcleo desta região onde a aglomeração- $\alpha^{1}$ é estudada.

De acordo com o modelo de cluster, propõe-se que certos núcleos apresentam uma condição favorável para o surgimento de estados associados a movimentos coletivos de dois ou mais agrupamentos de núcleons, constituindo um sistema de aglomerados no núcleo total. Tal sistema corresponde à chamada estrutura de cluster do núcleo. Esta interpretação representa uma alternativa simples para o tratamento de estados nucleares que também podem ser descritos, em princípio, por tratamentos microscópicos mais complicados como o produzido através do

\footnotetext{
${ }^{1} \mathrm{O}$ termo aglomeração- $\alpha$ é usado neste trabalho como o equivalente ao termo $\alpha$-clustering que é freqüentemente citado nas publicações em Inglês.
} 
modelo de camadas. No caso da aglomeração- $\alpha$, a procura por estes estados é feita preferencialmente nos núcleos onde o cluster- $\alpha$, que é conhecidamente estável, seja constituído por núcleons situados em orbitais acima da dupla camada fechada ou de subcamadas completas. Como é favorecida a estabilidade do conjunto de núcleons restantes, as propriedades do núcleo total são então descritas a partir de um sistema $\alpha$-caroço.

A estrutura de cluster- $\alpha$ já foi estudada em detalhes nos núcleos ${ }^{20} \mathrm{Ne}[1]$ e ${ }^{44} \mathrm{Ti}$ $[2,3]$, considerando respectivamente os sistemas $\alpha^{-16} \mathrm{O}$ e $\alpha-{ }^{40} \mathrm{Ca}$. Os resultados obtidos demonstraram a eficiência do modelo de cluster- $\alpha$ na reprodução do comportamento quase-rotacional das bandas de níveis experimentais de mais baixa energia nos dois núcleos. O modelo de cluster- $\alpha$ também foi usado na reprodução das taxas de transição $B(E 2)$ entre os níveis das bandas de estado fundamental dos dois núcleos, havendo boa concordância com dados experimentais sem o uso excessivo de cargas efetivas. Em contraposição a isto, os valores de $B(E 2)$ calculados através do modelo de camadas para os dois núcleos encontram-se bastante afastados dos dados experimentais, sendo necessárias altas cargas efetivas para que valores teóricos e experimentais se aproximem. As larguras de decaimento- $\alpha$ calculadas por meio de diferentes formas de potenciais de interação $\alpha+{ }^{16} \mathrm{O}$ no ${ }^{20} \mathrm{Ne}[1,5]$ fornecem uma boa reprodução das grandezas das respectivas larguras experimentais. Em adição às comparações com dados experimentais, os cálculos já desenvolvidos indicam a existência de um grau significativo de aglomeração- $\alpha$ nas bandas de mais baixa energia nos núcleos ${ }^{20} \mathrm{Ne}$ e ${ }^{44} \mathrm{Ti}$.

Os resultados favoráveis obtidos para os núcleos ${ }^{20} \mathrm{Ne},{ }^{44} \mathrm{Ti}$ e outros núcleos próximos motivaram a procura por estados de cluster- $\alpha$ nos núcleos mais pesados. Seguindo a lógica adotada para os núcleos leves, os núcleos seguintes a serem estudados são aqueles próximos das duplas camadas fechadas no ${ }^{90} \mathrm{Zr}$ e ${ }^{208} \mathrm{~Pb}$. Com isso, alguns trabalhos já foram publicados sobre a estrutura de cluster- $\alpha$ no ${ }^{94} \mathrm{Mo} \mathrm{e}{ }^{212} \mathrm{Po}$, analisando respectivamente as propriedades dos sistemas $\alpha^{-}{ }^{90} \mathrm{Zr}$ e $\alpha-{ }^{208} \mathrm{~Pb}$. Em ambos os sistemas, a interação $\alpha$ +caroço foi simulada através de potenciais locais fenomenológicos os quais são determinados por ajustes de parâmetros $[5,6]$, podendo alternativamente incluir uma relação explícita com a interação núcleon-núcleon $[4,7]$. Tais ajustes visam principalmente a reprodução dos níveis de energia experimentais onde a estrutura de cluster- $\alpha$ é esperada e/ou dados experimentais de espalhamento elástico nos respectivos sistemas $\alpha+$ caroço. Os resultados obtidos nos diferentes trabalhos são geralmente compatíveis. No caso do ${ }^{94} \mathrm{Mo}$, os diferentes potenciais de interação $\alpha+{ }^{90} \mathrm{Zr}$ fornecem uma boa descrição geral do espectro da banda do estado fundamental, mas o uso de cargas efetivas na reprodução quantitativa das taxas $B(E 2)$ ainda é necessário (em torno de $0,2 e[4]$ ). Assim como nos núcleos leves, o modelo de cluster- $\alpha$ prevê que as bandas de estado fundamental dos núcleos ${ }^{94} \mathrm{Mo} \mathrm{e}{ }^{212}$ Po apresentam uma condição de cluster- $\alpha$ substancial.

Um assunto pouco explorado no ${ }^{94} \mathrm{Mo}$ é a possível existência de bandas superiores de estados associados à estrutura de cluster- $\alpha$. Não há atualmente menção sobre níveis de energia experimentais do ${ }^{94}$ Mo que possam ser relacionados a tais 
bandas. O modelo de cluster- $\alpha$ pode ser importante na identificação destes estados até agora desconhecidos.

\subsection{Descrição do modelo de cluster- $\alpha$}

A aglomeração- $\alpha$ é um caso particular entre as diferentes estruturas de cluster nos núcleos. O modelo de cluster deve ser aplicado aos núcleos onde a estabilidade dos aglomerados seja favorecida. Tal estabilidade é geralmente procurada nos aglomerados que apresentam camadas fechadas ou subcamadas completas de prótons e nêutrons ou que estão próximos da condição de dupla camada fechada, mas outras considerações a respeito da energia de ligação nos aglomerados podem ser aplicadas para a determinação da estrutura de cluster mais estável num certo núcleo [8]. Com isso, os trabalhos relacionados às estruturas de cluster freqüentemente utilizam a aproximação onde os aglomerados do sistema são tratados como inertes, isto é, sem excitação interna. Os termos relevantes na Hamiltoniana do sistema então são aqueles associados aos movimentos dos centros de massa dos aglomerados ou aos movimentos relativos entre os aglomerados.

No caso da estrutura de cluster- $\alpha$ no ${ }^{94}$ Mo trata-se o movimento relativo entre cluster- $\alpha$ e ${ }^{90} \mathrm{Zr}$. O núcleo ${ }^{90} \mathrm{Zr}$ apresenta camada fechada para nêutrons e subcamadas de prótons completas até $2 p_{12}$, sendo favorecido o seu tratamento como um caroço inerte. A interação entre $\alpha$ e ${ }^{90} \mathrm{Zr}$ é simulada por um potencial local $V(r)$ (mais detalhes na próxima seção), onde $r$ é o raio intercluster (o raio associado à distância entre os centros de massa do cluster e do caroço). A resolução deste sistema nos fornece o espectro de energias e as funções de onda associadas. Outras propriedades do sistema podem ser calculadas através das funções de onda.

Tomando o modelo de camadas como referência, os núcleons constituintes do cluster- $\alpha$ devem se situar em orbitais acima daqueles já preenchidos pelo caroço, respeitando-se o princípio de Pauli. Assim, os números quânticos que caracterizam o movimento relativo devem ser compatíveis com esta restrição. Os auto-estados $|N, L, M\rangle$ do sistema cluster-caroço são identificados pelos números quânticos $N$, $L$ e $M$, onde $N$ é o número de nós internos da auto-função radial (detalhes no Capítulo 2) e $L$ e $M$ são os números tradicionalmente relacionados com o momento angular orbital. Uma relação usada freqüentemente para os sistemas cluster-caroço estabelece que

$$
2 N+L=\sum_{=1}^{c}(2 n+l),
$$

onde $n$ e $l$ são os números quânticos associados ao orbital ocupado pelo $i$-ésimo núcleon constituinte do cluster, sendo $A$ o número de núcleons do cluster. As definições de $n$ e $l$ são análogas às mencionadas respectivamente para $N$ e $L$. A equação (1.1) costuma ser mencionada como a Condição de Wildermuth. Esta fórmula é obtida através da relação de equivalência entre a Hamiltoniana dos núcleons individuais, que é descrita pelo modelo de camadas de oscilador harmônico 
e considera $A$ núcleons de valência ocupando os orbitais acima das camadas fechadas, e a Hamiltoniana do sistema cluster-caroço, que leva em conta a não excitação interna dos dois aglomerados. Detalhes sobre a construção de tais funções Hamiltonianas e os princípios que originam a eq. (1.1) encontram-se nas Refs. [9] e [10]. O uso de (1.1) permite a determinação aproximativa dos auto-estados do sistema cluster-caroço cuja existência é permitida pelo princípio de Pauli. Os autoestados do sistema formam conjuntos identificados pelo número quântico global

$$
G=2 N+L
$$

o qual identifica uma banda de níveis de energia. O número de banda $G$ exerce uma função semelhante à do número quântico principal do oscilador harmônico, pois determina a localização média dos níveis da banda dentro do espectro de energia; porém, os auto-estados de uma mesma banda $G$ com diferentes números $L$ não são degenerados.

No caso do sistema $\alpha^{-90} \mathrm{Zr}$ no seu estado fundamental, o cluster- $\alpha$ é formado de dois prótons situados no nível $1 g_{9} 2(n=0$ e $l=4)$ e dois nêutrons no nível $1 g_{7} 2$ $(n=0$ e $l=4)$. Aplicando estes valores em (1.1) e recorrendo a (1.2), teremos o número quântico global $G=16$ para a banda do estado fundamental do sistema $\alpha^{-}{ }^{90} \mathrm{Zr}$. O número $G=16$ é adotado em diferentes trabalhos sobre a estrutura de cluster- $\alpha$ no ${ }^{94}$ Mo $[5,4,6]$ e mostra-se adequado para uma reprodução satisfatória dos níveis de energia experimetais que constituem a banda do estado fundamental no ${ }^{94}$ Mo. Desta forma, as bandas fisicamente permitidas para este sistema são aquelas que satisfazem a condição $G \geq 16$. Seguindo a mesma idéia empregada para o sistema $\alpha^{-}{ }^{90} \mathrm{Zr}$, temos $G \geq 8$ para o sistema $\alpha^{-}{ }^{16} \mathrm{O}, G \geq 12$ para o sistema $\alpha-{ }^{40} \mathrm{Ca}$, etc.

Nos sistemas onde cluster e caroço apresentam spins totais nulos, tais como $\alpha^{-90} \mathrm{Zr}$, não são esperados efeitos de interação spin-órbita na Hamiltoniana do movimento relativo. Para estes sistemas, os números $G$ pares correspondem a bandas formadas por estados com $J$ inteiro e paridade positiva $\left(0^{+}, 2^{+}, 4^{+}, \ldots\right)$ enquanto os números $G$ ímpares correspondem a bandas formadas por estados com $J$ inteiro e paridade negativa $\left(1^{-}, 3^{-}, 5^{-}, \ldots\right)$.

A equação (1.1) é eficiente na identificação das bandas de estado fundamental de diferentes sistemas de cluster em núcleos leves e meio-pesados, em particular nos sistemas $\alpha$-caroço. Contudo, a mesma não deve ser entendida como uma condição exata, pois torna-se um tanto imprecisa na determinação dos números quânticos $G$ mais apropriados para a descrição de bandas de estado fundamental em núcleos pesados ou em sistemas que apresentam clusters mais pesados que $\alpha$ [8]. A Condição de Wildermuth se baseia no modelo de camadas de oscilador harmônico, o qual fornece uma boa aproximação quando os núcleons constituintes do cluster ocupam orbitais de baixo spin; porém, tal condição perde eficiência quando os núcleons do cluster ocupam orbitais com altos spins, pois o efeito da interação spin-órbita provoca um forte desvio entre os níveis previstos pelo oscilador harmônico e os níveis do modelo de camadas mais realista. Portanto, de uma forma geral, a equação (1.1) serve como um guia para a estimativa da grandeza do 
número quântico $G$ associado à banda do estado fundamental de um certo sistema de cluster.

\subsection{Potencial de interação do sistema $\alpha{ }^{90} \mathrm{Zr}$}

Diferentes formas de potencial de interação nuclear cluster-caroço foram usadas nos trabalhos que tratam das estruturas de cluster. Algumas formas se baseiam em variações dos potenciais do tipo Woods-Saxon, Gaussiano e "cosseno hiperbólico", enquanto outras tentam levar em conta a interação núcleon-núcleon de maneira mais explícita. No último exemplo mencionado, são usados os potenciais do tipo folding ou double folding [11] onde também são incluídas as funções de densidade de matéria do cluster e do caroço para a simulação da interação entre ambos.

Nos trabalhos envolvendo a estrutura de cluster- $\alpha$ no ${ }^{94} \mathrm{Mo}$, as diferentes formas empregadas para o potencial nuclear fornecem resultados quantitativamente semelhantes. O potencial double folding usado por Ohkubo [4] possui uma interação núcleon-núcleon do tipo DDM3Y [14] e apresenta uma fraca dependência do número quântico $L$ para uma reprodução mais eficiente do espectro da banda fundamental no ${ }^{94} \mathrm{Mo}$. O potencial nuclear adotado por Michel, Reidemeister e Ohkubo [6] é o resultado da razão entre um termo do tipo Gaussiano e outro do tipo Woods-Saxon quadrático, apresentando mais parâmetros de ajuste em comparação com potenciais derivados apenas do tipo Woods-Saxon. Ambos os potenciais fornecem uma boa reprodução do espectro da banda $G=16$ e de dados experimentais de espalhamento elástico de partículas- $\alpha$ em alvos de ${ }^{90} \mathrm{Zr}$.

O potencial nuclear usado neste trabalho foi desenvolvido por Buck, Merchant e Perez [5] e apresenta a forma

$$
V(r)=-V_{0}\left\{\frac{b}{1+\exp \left(-\frac{-}{-}\right)}+\frac{1-b}{\left[1+\exp \left(\frac{-}{3}\right)\right]^{3}}\right\} .
$$

Foi verificado que esta forma de potencial é eficiente na descrição de dados experimentais de diferentes núcleos onde a estrutura de cluster- $\alpha$ é esperada. Para a interação $\alpha_{-}{ }^{90} \mathrm{Zr}$, temos $V_{0}=220 \mathrm{MeV}, a=0,65 \mathrm{fm}, b=0,3$ e $R=5,793 \mathrm{fm}$. Em adição à interação nuclear, é incluído o potencial coulombiano

$$
V(r)= \begin{cases}\left(\frac{e^{2}}{4 \pi \varepsilon_{0}}\right) \frac{Z Z_{\mathrm{Zr}}}{2 R}\left(3-\frac{r^{2}}{R^{2}}\right) & \text { para } r<R \\ \left(\frac{e^{2}}{4 \pi \varepsilon_{0}}\right) \frac{Z Z_{\mathrm{Zr}}}{r} & \text { para } r \geq R\end{cases}
$$

simulado pela interação entre uma partícula- $\alpha$ e uma esfera uniformemente carregada de raio $R$, sendo $Z$ e $Z_{\mathrm{Zr}}$ respectivamente os números atômicos da partícula- $\alpha$ e do ${ }^{90} \mathrm{Zr}$, enquanto $R$ é o mesmo parâmetro usado em $V(r)$. O potencial total então será 


$$
V(r)=V(r)+V(r) .
$$

A inclusão do termo associado à barreira centrífuga resulta no potencial efetivo

$$
V(r)=V(r)+\frac{L(L+1) \hbar^{2}}{2 \mu r^{2}},
$$

onde $\mu$ é a massa reduzida do sistema $\alpha{ }^{90} \mathrm{Zr}$.

Os potenciais $V(r)$ e $V(r)$ são mostrados graficamente na Figura 1.1. De acordo com a Ref. [5], os parâmetros $V_{0}, a$ e $b$ foram ajustados visando uma reprodução satisfatória das energias de excitação experimentais pertencentes às bandas de estado fundamental nos núcleos ${ }^{20} \mathrm{Ne},{ }^{44} \mathrm{Ti},{ }^{94} \mathrm{Mo} \mathrm{e} \mathrm{e}{ }^{212} \mathrm{Po}$, assim como das meias-vidas de decaimento- $\alpha$ em vários núcleos pesados par-par. Diferentemente dos outros parâmetros, $R$ foi ajustado especificamente para cada núcleo no qual a mesma forma de potencial foi empregada, sendo $R=5,793 \mathrm{fm}$ o valor correspondente ao ${ }^{94}$ Mo. A forma escolhida para $V(r)$ (uma combinação entre um termo de WoodsSaxon simples e outro de Woods-Saxon cúbico) foi justificada pela similaridade dos potenciais ajustados para o ${ }^{20} \mathrm{Ne}$ e ${ }^{44} \mathrm{Ti}$ com as partes reais dos potenciais ópticos determinados a partir do espalhamento elástico de núcleos- $\alpha$ em alvos de ${ }^{16} \mathrm{O}$ e ${ }^{40} \mathrm{Ca}$, respectivamente (ver Figura 1.2). Convém lembrar que, apesar de $R$ ser aproximadamente proporcional ao raio do caroço, este parâmetro não é dado pelo raio do ${ }^{90} \mathrm{Zr}$ no caso do potencial ajustado para o ${ }^{94} \mathrm{Mo}$. 

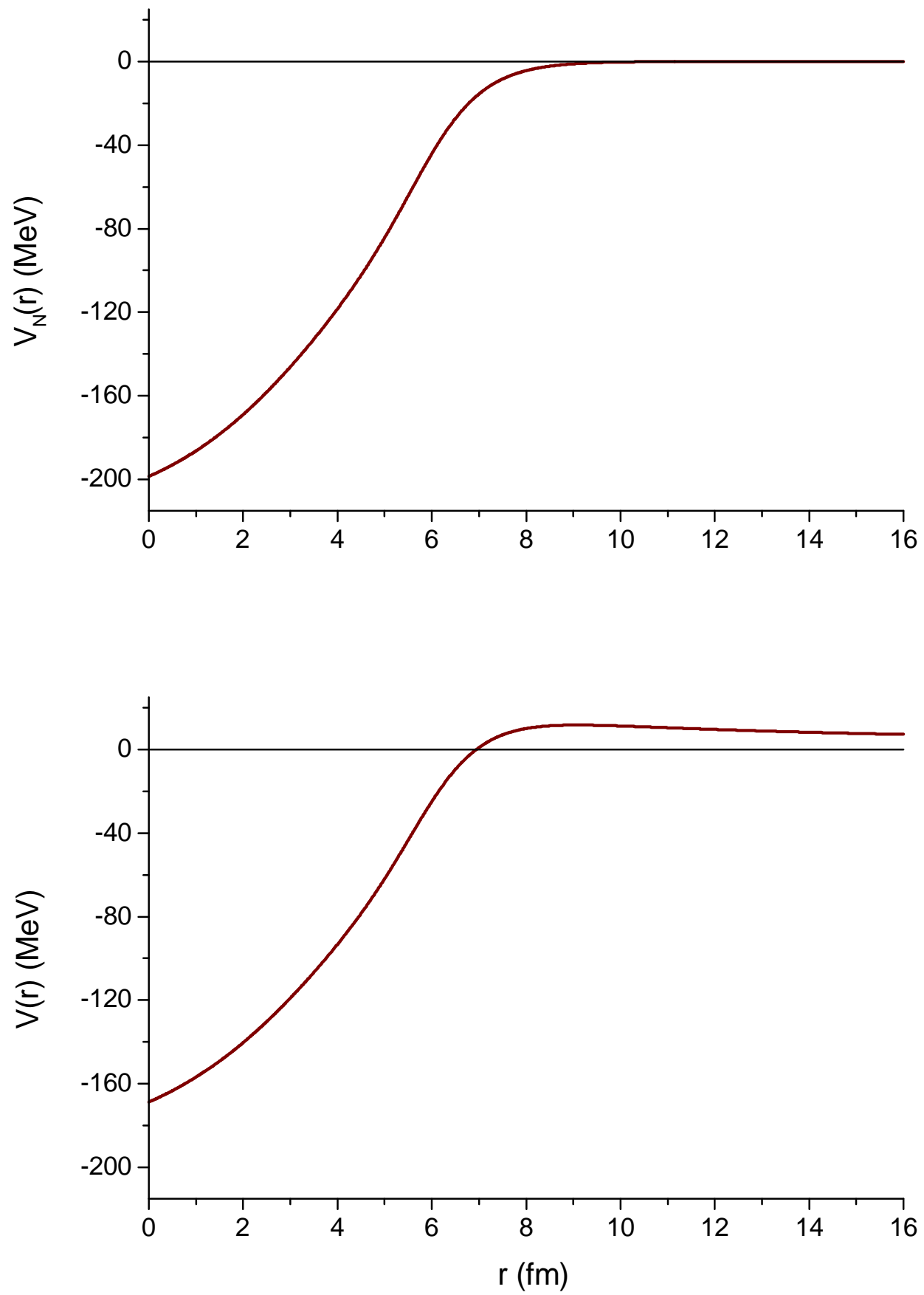

Figura 1.1: Potencial nuclear $V_{N}(r)$ e potencial total $V(r)$ usados para a interação $\alpha-{ }^{90} \mathrm{Zr}$. 

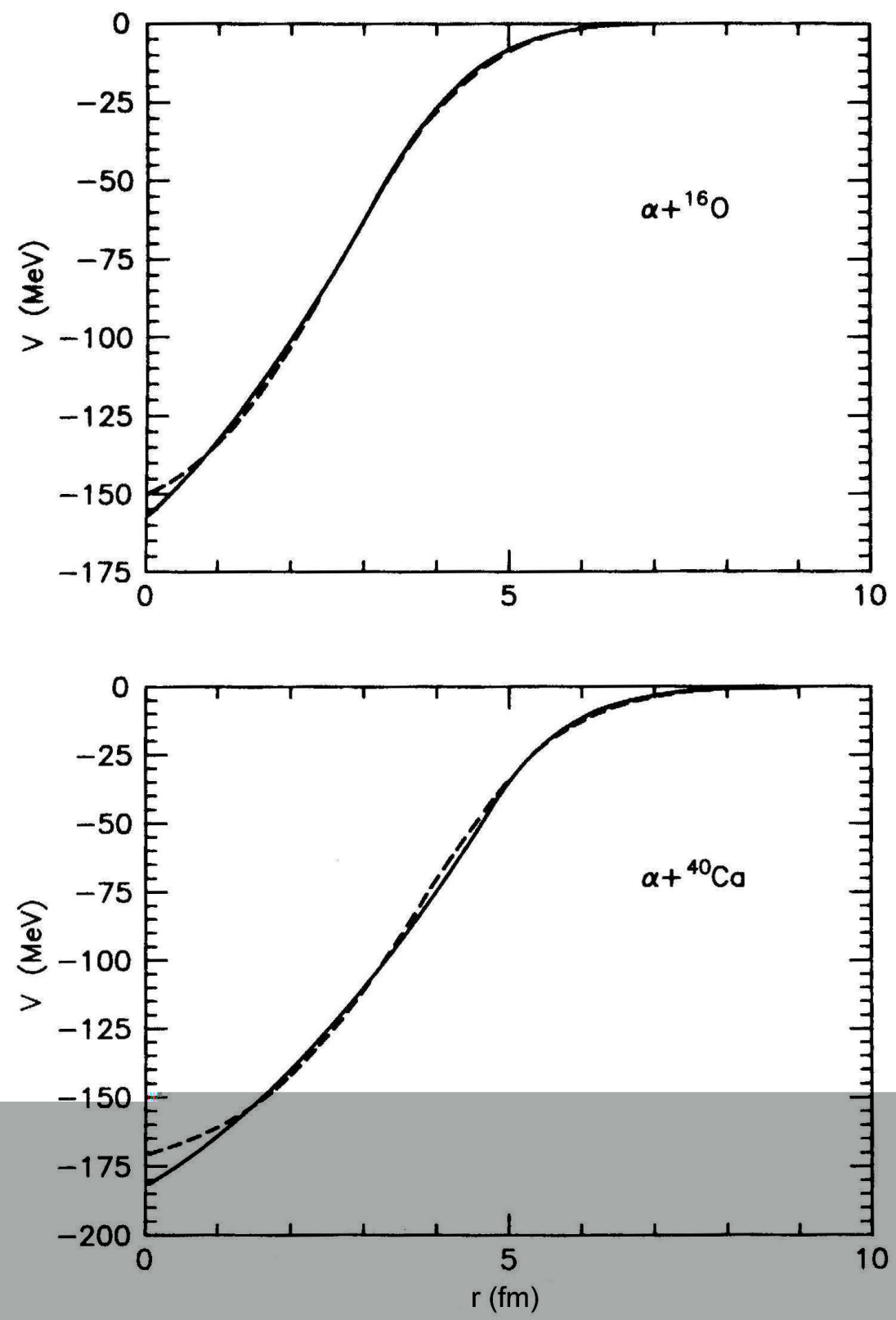

Figura 1.2: Comparação das partes reais dos potenciais ópticos determinados a partir do espalhamento- $\alpha$ elástico nos alvos de ${ }^{16} \mathrm{O}$ e ${ }^{40} \mathrm{Ca}$ (linhas tracejadas) com os potenciais nucleares desenvolvidos na forma da eq. (1.3) para a descrição das bandas de cluster- $\alpha$, respectivamente, no ${ }^{20} \mathrm{Ne}$ e ${ }^{44} \mathrm{Ti}$ (linhas contínuas). Esta figura foi extraída da Ref. [5]. 


\section{Capítulo 2}

\section{Processo de determinação da banda do estado fundamental do sistema $\alpha{ }^{90} \mathbf{Z r}$}

Neste capítulo são detalhados os procedimentos para a determinação dos níveis de energia e as respectivas auto-funções da banda do estado fundamental do sistema $\alpha^{-}{ }^{90} \mathrm{Zr}$, a qual é identificada pelo número quântico global $G=16$. Dentro destes procedimentos estão o desenvolvimento e aplicação do método numérico para a caracterização dos estados ligados e o uso da aproximação de estado ligado para os níveis acima do limiar $\alpha+{ }^{90} \mathrm{Zr}$.

\subsection{Procedimento escolhido para a resolução do sistema}

Uma tarefa inicial deste trabalho é a procura por um método numérico adaptado para a resolução da equação que descreve o sistema $\alpha^{-90} \mathrm{Zr}$. Assim, seguimos o procedimento no qual as funções de onda e o espectro de energias do sistema são determinados diretamente pela resolução da equação de Schrödinger independente do tempo

$$
\nabla^{2} \psi+\frac{2 \mu}{\hbar^{2}}[E-V(r)] \psi=0
$$

no caso de uma partícula de massa $\mu$ submetida a um potencial radial $V(r)$.

Deve-se considerar as características do sistema para a interpretação do significado das funções de onda. Em concordância com as discussões do Capítulo 1, os únicos termos relevantes na função Hamiltoniana do sistema são aqueles associados ao movimento relativo entre os centros de massa do cluster- $\alpha$ e do caroço. Com isto, as propriedades do sistema são determinadas através das funções de onda que descrevem tal movimento relativo. A eq. (2.1) é usada para o cálculo das funções 
de onda $\psi(r, \theta, \phi)$, sendo $r, \theta$ e $\phi$ as coordenadas do movimento relativo, $\mu$ a massa reduzida do sistema cluster-caroço e $V(r)$ o potencial intercluster.

Para que sejam obtidas as soluções $\psi(r, \theta, \phi)$, deve ser aplicado o método de separação de variáveis em (2.1). As soluções terão a forma

$$
\psi \quad(r, \theta, \phi)=\frac{1}{r} u \quad(r) Y \quad(\theta, \phi) .
$$

Como o potencial $V(r)$ possui simetria radial, a parte angular $Y \quad(\theta, \phi)$ será dada pelos harmônicos esféricos, onde os números quânticos $L$ e $M$ são aqueles usados na definição do momento angular orbital. A parte $u \quad(r)$ é a função radial que depende dos números quânticos $N$ e $L$, onde $N$ é o número de nós internos desta função radial. Como a parte angular já é conhecida analiticamente, resta determinar a parte radial $u \quad(r)$ através da resolução da equação radial

$$
\frac{d^{2} u}{d r^{2}}+\left\{\frac{2 \mu}{\hbar^{2}}[E-V(r)]-\frac{L(L+1)}{r^{2}}\right\} u=0
$$

que é conseqüência da aplicação do método de separação de variáveis em (2.1). A resolução de (2.3) nos fornece o espectro de energias do sistema e as auto-funções associadas a estas energias.

\subsection{Escolha do método numérico para a resolução do sistema}

Diante do problema estabelecido, é necessário o uso de um método numérico eficiente para a resolução da eq. (2.3). Após uma pesquisa pelas formas mais usuais, foi escolhido o método Runge-Kutta-Fehlberg (RKF) para equações diferenciais de segunda ordem. Este método produz uma solução $f(x)$ gerada por uma aproximação do tipo Runge-Kutta de quinta ordem, porém, o erro cometido nos pontos de $f(x)$ é definido como a diferença entre os resultados obtidos pelas aproximações de quinta e quarta ordem. Desta forma, a definição do erro está relacionada à aproximação de quarta ordem e o método RKF então é associado a esta ordem de aproximação. O método RKF diferencia-se do Runge-Kutta tradicional por incluir um processo de refinamento da solução onde o passo de integração $h$ é ajustado conforme são calculados consecutivamente os pontos da função no processo iterativo. O propósito deste refinamento é adaptar $h$ para que o erro numérico cometido na derivada da função nunca ultrapasse um limite pré-estabelecido em cada passo da integração. O recurso do refinamento torna-se útil para uma padronização da grandeza do erro cometido ao longo da função $f(x)$, além de evitar o aumento excessivo do erro em trechos da função onde há um comportamento exponencial. O método RKF é descrito em detalhes na Ref. [15].

O grau de eficiência do método RKF foi verificado através da resolução da eq. (2.3) com um potencial do tipo oscilador harmônico $V(r)=(1 / 2) \mu \omega^{2} r^{2}$ apenas com finalidade ilustrativa. Para que fossem usadas grandezas semelhantes às do 
sistema $\alpha^{-90} \mathrm{Zr}$, foi aplicado $\hbar \omega=41 A^{-13} \mathrm{MeV}$, que é o parâmetro típico do modelo de camadas, e $A=94$, que é o número de massa do núcleo total. A massa reduzida $\mu$ do sistema $\alpha{ }^{9}{ }^{90} \mathrm{Zr}$ foi obtida através das massas da partícula- $\alpha(m \approx$ $4,003 \mathrm{u})$ e do ${ }^{90} \mathrm{Zr}(m \approx 89,905 \mathrm{u})$ na unidade atômica de massa $\mathrm{u}=931,494$ $\mathrm{MeV} / \mathrm{c}^{2}$ (valores extraídos da Ref. [16]). Com isso, obtém-se

$$
\mu=\frac{m m}{m+m} \approx 3569,49 \mathrm{MeV} / \mathrm{c}^{2} .
$$

O valor indicado em (2.4) é o mesmo usado em todos os cálculos deste trabalho. O erro numérico máximo $\varepsilon$ (erro absoluto associado a cada passo de integração) para a derivada de $u(r)$ foi estabelecido como $5 \times 10^{-9} \mathrm{fm}^{-3} 2$ dentro do método RKF, enquanto o passo $h$ foi limitado por um valor mínimo de $10^{-4} \mathrm{fm}$ e um valor máximo de $10^{-2} \mathrm{fm}$. Levando em conta que as auto-funções do oscilador harmônico esférico são conhecidas analiticamente, foi possível fazer uma comparação entre as soluções analíticas e numéricas da eq. (2.3) nos auto-estados 1s, 1p, 1d e 2s. Esta comparação é feita calculando-se o erro relativo

$$
\operatorname{Err} \quad=\left|\frac{u \quad(r)-u \quad(r)}{u}\right|
$$

no intervalo de 0 a $5 \mathrm{fm}$, onde praticamente toda a densidade de probabilidade está distribuída. Este intervalo compreende a região interna do poço de potencial efetivo $V(r)$ (definição em (1.6)), o trecho externo mais próximo de $r=0$ (provocado pela ação da barreira centrífuga) e um trecho de 2 a 3 fm além do poço. Foi constatado que o erro relativo das funções radiais analisadas varia entre as ordens de grandeza de $10^{-14}$ e $10^{-8}$ nesta região, sendo que os maiores valores registrados situam-se em torno de $5 \mathrm{fm}$, onde a amplitude das funções radiais é praticamente desprezível. Tais resultados são suficientemente satisfatórios para que o método RKF seja aplicado com outros potenciais associados ao sistema $\alpha^{-9} \mathrm{Zr}$, adotando parâmetros semelhantes aos mencionados anteriormente.

\subsection{Algumas implicações do método RKF com passo positivo}

Após os testes de verificação da eficiência do método RKF dentro do poço de oscilador harmônico e nas suas proximidades, o procedimento seguinte é aplicá-lo na resolução da eq. (2.3) com o potencial de interação $V(r)$ do sistema $\alpha^{-}{ }^{90} \mathrm{Zr}$. Porém, são necessárias adaptações para este caso. As soluções $u(r)$ podem apresentar um comportamento de divergência em $r \gg 0$ devido a pequenas imprecisões provocadas pelo próprio método numérico e pequenos desvios nos auto-valores de energia. Para que este problema seja melhor explicado, é feita a seguir uma descrição mais detalhada da resolução numérica da equação radial para o oscilador harmônico esférico. 
O uso do método RKF implica na escolha de uma condição inicial para a função numérica $u(r)$ e para a sua derivada $u^{\prime}(r)$ num certo raio $r_{0}$. No caso da resolução da eq. (2.3) para o oscilador harmônico esférico (OHE) citado na seção anterior, a condição inicial foi aplicada em $r_{0}=0$ para $L=0$ e $r_{0}=0,01 \mathrm{fm}$ para $L>0$. No caso de $L>0$, o termo associado à barreira centrífuga na eq. (2.3) provocaria uma divisão do tipo $L(L+1) / 0$ caso utilizássemos $r_{0}=0$, o que é impraticável do ponto de vista computacional. Portanto, justifica-se a utilização de um valor não nulo para $r_{0}$ no último caso. As condições iniciais $u\left(r_{0}\right)$ e $u^{\prime}\left(r_{0}\right)$ foram obtidas das soluções analíticas $u \quad(r)$ para o OHE, pois esta é a escolha ideal para que as soluções numéricas do OHE tenham a maior proximidade possível com as soluções analíticas correspondentes, incluindo o fato de que estas já são normalizadas. Pelo mesmo motivo anterior, também aplicamos em (2.3) as auto-energias conhecidas analiticamente para o OHE. O passo de integração $h$ foi estabelecido como positivo em todo o processo iterativo, de modo que a equação foi resolvida no sentido de $r$ crescente.

Seguindo os detalhes citados no parágrafo anterior, foram obtidas soluções numéricas $u(r)$ muito próximas das respectivas soluções analíticas do OHE no intervalo de 0 a $5 \mathrm{fm}$, de acordo com os números já mencionados na Seção 2.2. Porém, o erro relativo (ver definição em (2.5)) torna-se muito significativo além de $7 \mathrm{fm}$, isto é, fora do poço de potencial efetivo do OHE. A partir deste raio, Err tende a $100 \%$ e continua a aumentar exponencialmente com $r$. Este fato ocorre devido aos erros numéricos associados às iterações do método RKF. Mesmo sendo relativamente muito pequenos entre 0 e $5 \mathrm{fm}$, estes erros provocam o surgimento de uma componente exponencial crescente (em módulo) na função numérica $u(r)$. Esta componente divergente se manifesta logo que a função radial ultrapassa o poço de potencial efetivo do OHE, de modo que ela predomina sobre a componente exponencial decrescente (aquela que respeita a condição de contorno onde $u(r \rightarrow \infty)=0)$. Com isso, constata-se que o método RKF com passo positivo é bastante eficiente dentro do poço de potencial efetivo e na parte externa mais próxima de $r=0$, mas resulta na divergência da função radial para $r \gg 0$.

O comportamento de divergência fora do poço de potencial efetivo torna-se ainda mais significativo quando ocorrem pequenos desvios nos auto-valores de energia. A Figura 2.1 mostra as funções radiais do OHE previstas analiticamente nos estados 1s e 2 s e as respectivas funções determinadas através do método RKF com um acréscimo de $0,001 \mathrm{MeV}$ nas energias que caracterizam estes dois níveis. Os outros parâmetros envolvidos no cálculo numérico são os mesmos antes mencionados. No auto-estado 1s, o erro Err alcança a ordem de $10^{2}$ em $r \approx 4,8$ $\mathrm{fm}$, enquanto no auto-estado $2 \mathrm{~s}$ ocorre a mesma ordem de grandeza a partir de $r \approx 5,5 \mathrm{fm}$. Por outro lado, verificando os estados $1 \mathrm{~s}$ e $2 \mathrm{~s}$ com um desvio 5 vezes maior $(0,005 \mathrm{MeV})$, constata-se que Err varia entre as ordens de grandeza de $10^{-8}$ e $10^{-3}$ dentro do poço de potencial efetivo. Demonstra-se que pequenos erros cometidos nos auto-valores de energia não causam efeitos significativos dentro do poço de potencial efetivo; porém, podem aumentar em ordens de grandeza o erro relativo da função radial numérica $u(r)$ fora do poço de potencial efetivo. 


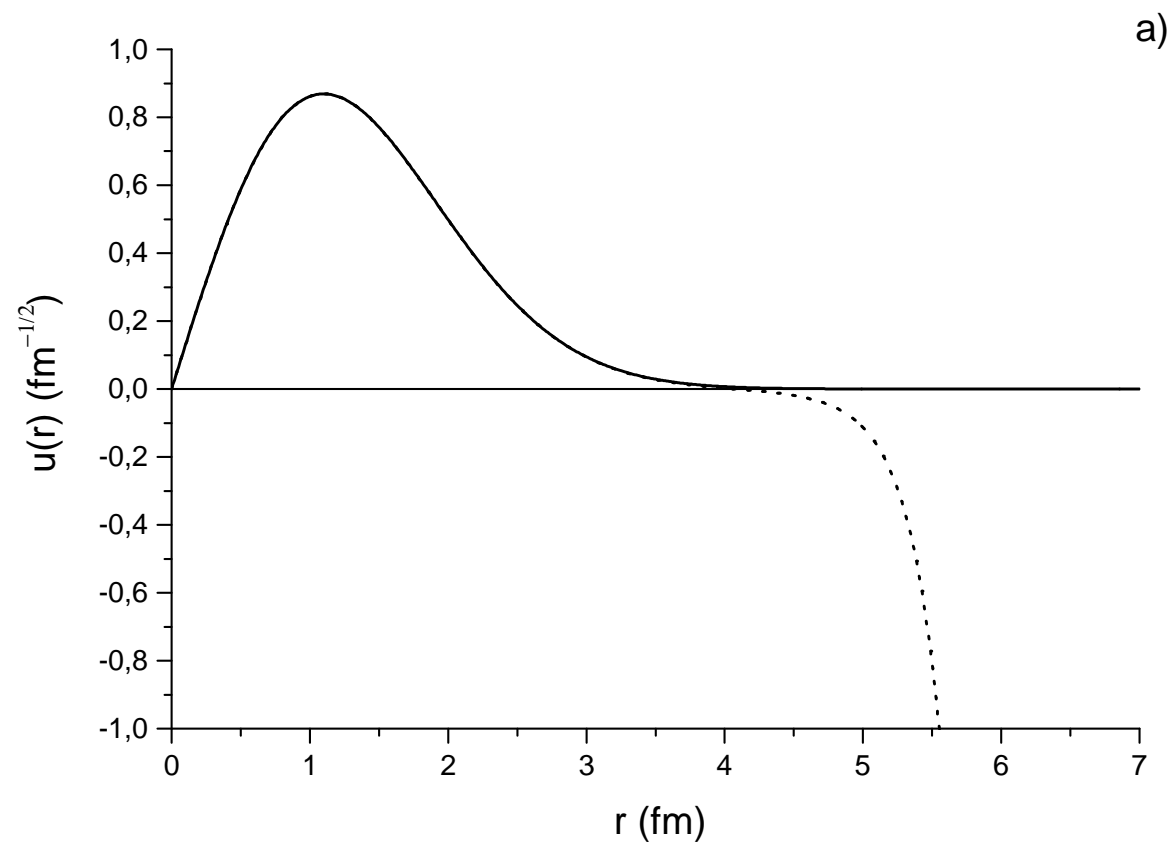

a) $1 \mathrm{~s}$

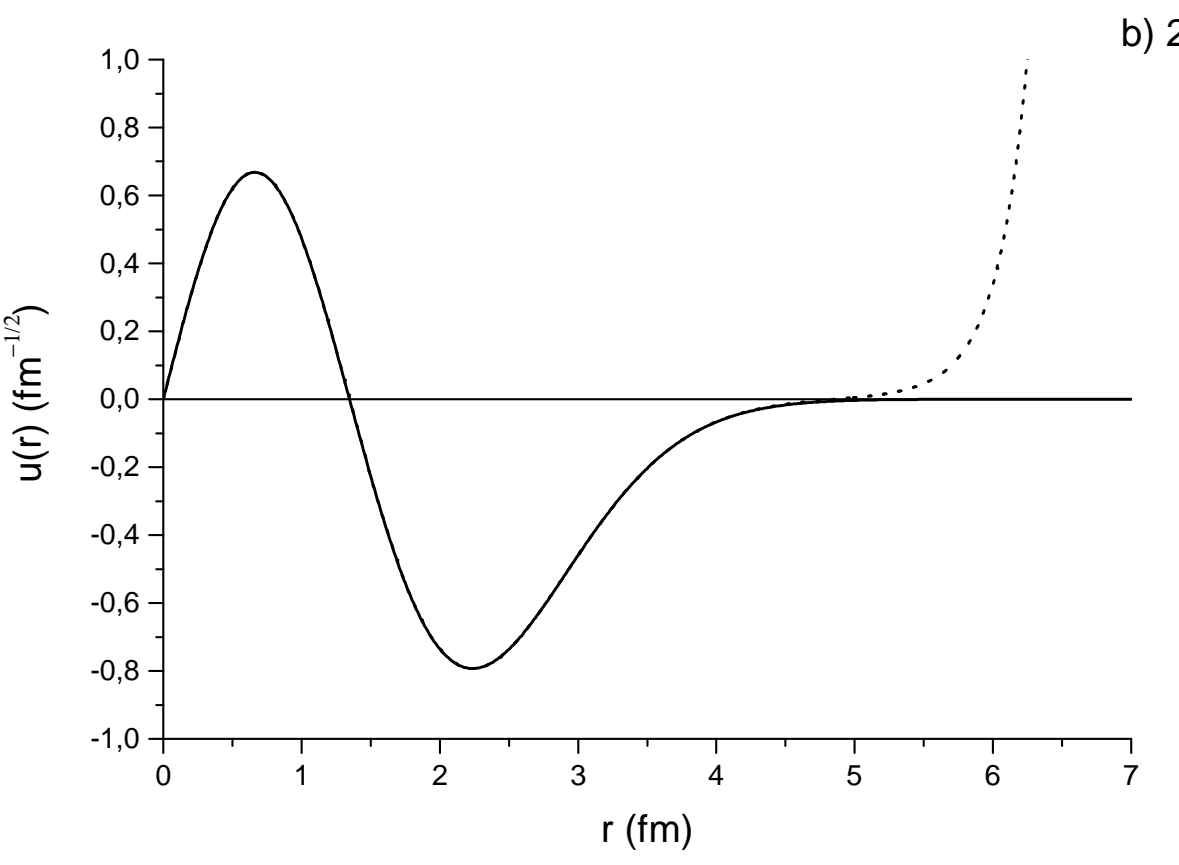

Figura 2.1: Comparação entre funções radiais $u(r)$ analíticas do OHE (linhas contínuas) e as respectivas funções radiais calculadas pelo método RKF com passo positivo e desvio nos autovalores de energia (linhas pontilhadas). Os gráficos referem-se aos auto-estados $1 \mathrm{~s}$ (a) e 2s (b) do OHE com parâmetro $\hbar \omega=41 A^{-1 / 3} \mathrm{MeV}$, sendo $A=94$, e massa $\mu$ indicada em (2.4). O desvio nas auto-energias é de $0,001 \mathrm{MeV}$, de modo que as energias aplicadas na resolução numérica da equação radial são $E_{1 s}=[(3 / 2) \hbar \omega+0,001] \mathrm{MeV}$ e $E_{2 s}=[(7 / 2) \hbar \omega+0,001] \mathrm{MeV}$. 


\subsection{Adaptação do método RKF para a resolução do sistema $\alpha-{ }^{90} \mathrm{Zr}$}

O método RKF necessita de adaptações para que seja evitado o comportamento de divergência da função radial em $r \gg 0$. No caso da resolução do sistema $\alpha^{-}{ }^{90} \mathrm{Zr}$, deve-se levar em conta que não há soluções analíticas da eq. (2.3) com o potencial intercluster $V(r)$, significando que as condições iniciais $u\left(r_{0}\right)$ e $u^{\prime}\left(r_{0}\right)$ devem ser escolhidas por um critério diferente daquele mencionado na Seção 2.3 para o OHE. Além disto, os auto-valores de energia do sistema não são conhecidos previamente, de modo que as auto-funções correspondentes não podem ser determinadas pelo procedimento adotado para o OHE.

O procedimento escolhido para evitar a divergência da função radial consiste em calcular separadamente as partes interna e externa da função $u(r)$ em relação ao limite do poço de potencial efetivo. Como foi citado na Seção 2.2, o método RKF com passo positivo é bastante eficiente na parte interna do poço de potencial efetivo e na parte externa mais próxima de $r=0$, de modo que a parte interna de $u(r)$ pode ser calculada pela mesma forma já adotada para o OHE, isto é, com passo positivo e $r_{0}=0$ ou próximo de 0 . Como a parte externa de $u(r)$ sofre o efeito de divergência por este procedimento, pode-se determiná-la usando o método RKF com passo negativo e condição inicial em $r_{0} \gg 0$. Neste caso, as condições iniciais $u\left(r_{0}\right)$ e $u^{\prime}\left(r_{0}\right)$ devem ser escolhidas adequadamente em $r_{0} \gg 0$ para que sejam compatíveis com a condição de contorno $u(r \rightarrow \infty)=0$.

O desconhecimento dos auto-valores de energia do sistema $\alpha^{-9}{ }^{90} \mathrm{Zr}$ torna necessário determiná-los por tentativas, isto é, fazendo uma varredura em todo o intervalo de energia onde é possível a existência destes auto-valores. De acordo com a Ref. [5], os parâmetros do potencial intercluster (definição no Capítulo 1) são ajustados levando-se em conta a energia de separação da partícula- $\alpha$ originária do núcleo total, significando que a energia do estado fundamental do sistema (a energia do nível $0^{+}$da banda do estado fundamental) deve localizar-se em torno de $2 \mathrm{MeV}$ abaixo do limiar do sistema $\alpha^{-90} \mathrm{Zr}$. Por isto, o estado fundamental do sistema $\alpha^{-90} \mathrm{Zr}$ é considerado ligado e os outros níveis da banda fundamental devem situar-se acima do nível $0^{+}$.

A Figura 2.2 mostra o comportamento do potencial efetivo e as regiões interna e externa em relação à fronteira do poço na energia $E$. Desta forma, é convencionado que a região I compreende o trecho interno do poço de potencial efetivo e o trecho externo bem próximo de $r=0$, enquanto a região II compreende toda a parte externa restante além da fronteira do poço. Esta fronteira é delimitada pelo raio $r_{\mathrm{f}}$ que varia de acordo com a energia $E$. A solução da equação radial (2.3) na região I é chamada $u_{\mathrm{I}}(r)$, enquanto na região II é chamada $u_{\mathrm{II}}(r)$. Estas soluções ainda não incluem constantes de normalização, como é justificado posteriormente nesta seção.

Outro procedimento escolhido para a resolução do sistema $\alpha^{-90} \mathrm{Zr}$ consiste no uso de condições iniciais para o método RKF as quais se baseiam nas soluções 


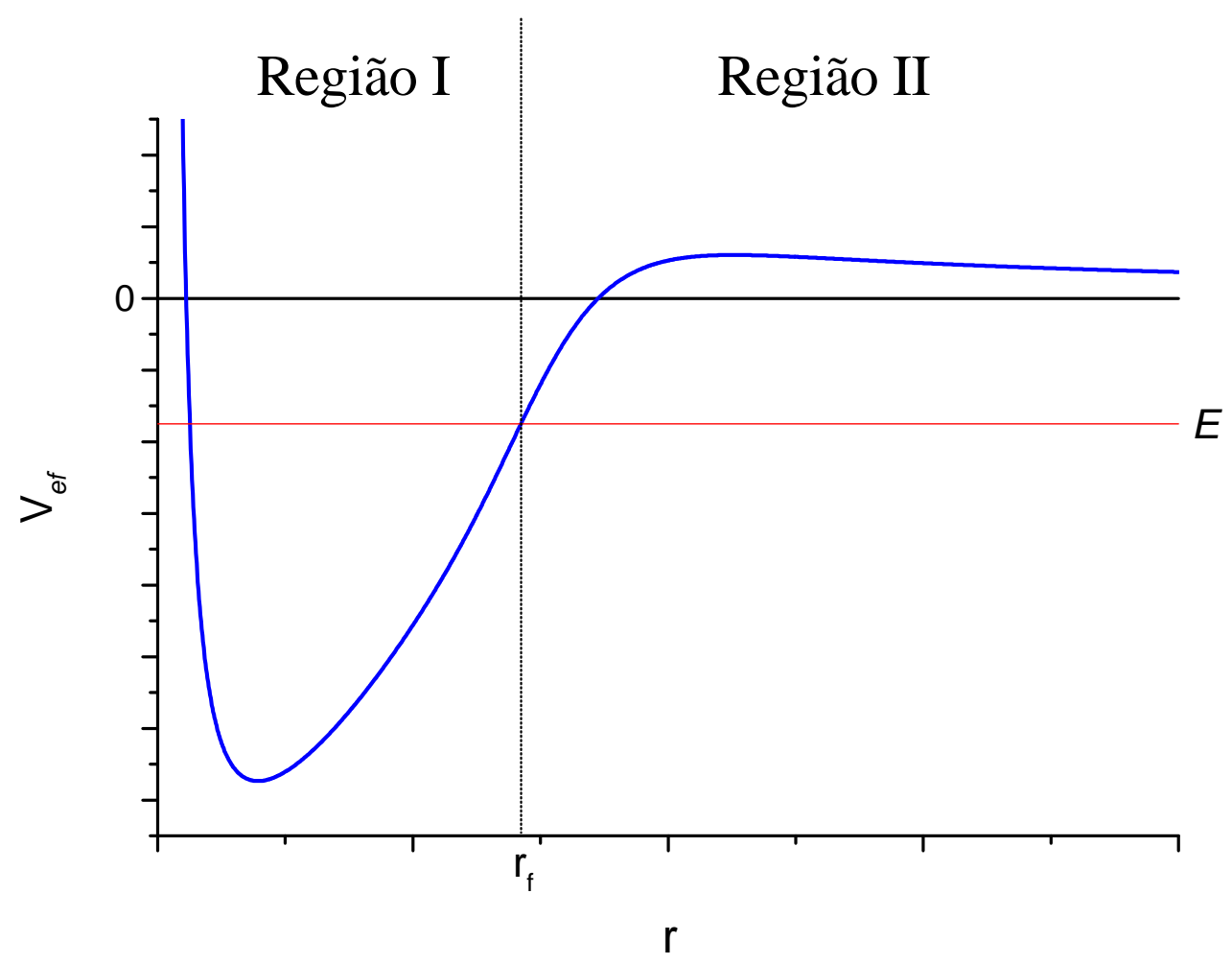

Figura 2.2: Representação em escala arbitrária do potencial efetivo $V_{e f}(r)$ com a delimitação entre as regiões I e II no caso onde a equação radial (2.3) é resolvida com energia $E$. As soluções $u_{\mathrm{I}}(r)$ e $u_{\mathrm{II}}(r)$, obtidas respectivamente nas regiões I e II, são calculadas de forma independente. $\mathrm{O}$ raio de fronteira $r_{\mathrm{f}}$ delimita as duas regiões.

analíticas da equação radial para o poço de potencial quadrado. Tal procedimento é justificado através da aproximação do potencial intercluster como uma justaposição de potenciais quadrados que acompanham a variação de profundidade de $V(r)$, desde que cada um destes potenciais quadrados seja bastante estreito na sua extensão $\Delta r$. Contudo, esta aproximação é utilizada apenas como condição inicial para que a eq. (2.3) seja resolvida com o próprio potencial intercluster $V(r)$. Desta forma, $V(r)$ é aproximado como $V_{0}=V\left(r_{0}\right)$ somente numa pequena extensão delimitada por $r_{0}-(\Delta r) / 2$ e $r_{0}+(\Delta r) / 2$.

A aproximação de poço quadrado é aplicada tanto para $r_{0}=0$ (ou $r_{0} \approx 0$ ) quanto para $r_{0} \gg 0$ (no caso de estados ligados ou quase-ligados), considerando as devidas adaptações em cada situação. Tal aproximação deve reproduzir com suficiente acurácia as condições iniciais ideais, isto é, aquelas que resultam numa derivada logarítmica inicial $u^{\prime}\left(r_{0}\right) / u\left(r_{0}\right)$ compatível com a verdadeira solução da eq. (2.3) em $r_{0}$, levando-se em conta as condições de contorno $u(0)=0 \mathrm{e}$ $u(r \rightarrow \infty)=0$ e a energia $E$ do sistema.

No cálculo de $u_{\mathrm{I}}(r)$ com $L=0$ e uma certa energia $E$, a condição inicial de poço quadrado é aplicada em $r_{0}=0$, visto que não há o termo associado à barreira centrífuga na eq. (2.3). Assim, as condições iniciais são $u_{\mathrm{I}}\left(r_{0}\right)=u \quad\left(r_{0}\right)$ e $u_{\mathrm{I}}^{\prime}\left(r_{0}\right)=u^{\prime} \quad\left(r_{0}\right)$, onde $u \quad(r)$ é a solução analítica da equação radial com ener- 
gia $E$ no caso de um poço de potencial quadrado com profundidade $V_{0}=V\left(r_{0}\right)$. A função $u \quad(r)$ em $r=0$ respeita a condição de contorno $u_{\mathrm{I}}(0)=0$, tornando o valor de $u_{\mathrm{I}}^{\prime}\left(r_{0}\right)$ irrelevante, pois a derivada logarítmica de $u_{\mathrm{I}}(r)$ em $r_{0}=0$ tende a $\infty$ para qualquer valor de $u_{\mathrm{I}}^{\prime}\left(r_{0}=0\right.$ ) (o que já é previsto para as soluções regulares da equação radial (2.3)) e a derivada de $u_{\mathrm{I}}(r)$ é multiplicada posteriormente por constantes associadas à continuidade e normalização da solução completa $u(r)$.

No cálculo de $u_{\mathrm{I}}(r)$ com $L>0$, são aplicadas as mesmas condições iniciais $u_{\mathrm{I}}\left(r_{0}\right)=u \quad\left(r_{0}\right)$ e $u_{\mathrm{I}}^{\prime}\left(r_{0}\right)=u^{\prime} \quad\left(r_{0}\right)$, mas a presença do termo associado à barreira centrífuga torna impossível o uso de $r_{0}=0$. Por isso, deve ser escolhido um valor não nulo para $r_{0}$, mas que seja próximo de $r=0$. A variação do potencial $V(r)$ na região I difere muito daquela de um poço quadrado e, devido a este fato, a aproximação de poço quadrado deve ser feita de tal forma que este poço seja suficientemente estreito e tenha o seu início em $r=0$, onde as funções $u_{\mathrm{I}}(r)$ e $u \quad(r)$ compartilham da mesma condição de contorno $u_{\mathrm{I}}(0)=u \quad(0)=0$. O poço quadrado com tal descrição deve resultar numa função $u \quad(r)$ com derivada logarítmica em $r_{0}$ muito próxima daquela esperada para a verdadeira solução da eq. (2.3) com o potencial $V(r)$. Seguindo estes princípios, foi empregado o valor $r_{0}=0,003 \mathrm{fm}$ para todos os cálculos de $u_{\mathrm{I}}(r) \operatorname{com} L>0$.

No cálculo de $u_{\mathrm{II}}(r)$ para um $L$ qualquer, as condições iniciais de poço quadrado devem ser escolhidas adequadamente em $r_{0} \gg 0$ para que reproduzam o comportamento decrescente das funções radiais fora do poço de potencial. Deve-se então aplicar condições iniciais $u_{\mathrm{II}}\left(r_{0}\right)=u \quad\left(r_{0}\right)$ e $u_{\mathrm{II}}^{\prime}\left(r_{0}\right)=u^{\prime} \quad\left(r_{0}\right)$ baseadas no comportamento específico da função $u \quad(r)$ quando a energia $E$ encontra-se abaixo do potencial $V_{0}=V\left(r_{0}\right)$, isto é, na região classicamente proibida. Neste caso, não se pode aplicar $r_{0}$ próximo ao raio onde $u_{\mathrm{II}}(r)$ e $u \quad(r)$ compartilham de uma mesma condição de contorno, pois tal condição é definida em $r \rightarrow \infty$. Contudo, o potencial $V(r)$ dado em (1.5) varia muito lentamente em $r \gg 0$, visto que o potencial nuclear é praticamente nulo e apenas a barreira coulombiana se manifesta nesta região. Verifica-se que $V(r)$ varia numa taxa de $\approx-0,01 \mathrm{MeV} / \mathrm{fm}$ em $r=100 \mathrm{fm}$ e que o módulo desta taxa diminui lentamente com o aumento de $r$. Com isso, pode-se afirmar previamente que a aproximação de $V(r)$ por um potencial constante $V_{0}=V\left(r_{0}\right)$ é satisfatória se $r_{0}$ estiver muito afastado do poço atrativo da região I. Seguindo esta consideração, a derivada logarítmica da função $u \quad(r)$ caracterizada por $u \quad(r \rightarrow \infty)=0$ no caso $E<V_{0}$ deve simular eficientemente a derivada logarítmica de $u_{\mathrm{II}}(r)$ em $r_{0}$, respeitando assim o comportamento essencialmente exponencial e decrescente que a solução $u(r)$ deve apresentar em $r \gg 0$ para estados ligados. Dentro destes princípios, foram empregados valores de $r_{0}$ maiores que $100 \mathrm{fm}$ para os cálculos de $u_{\mathrm{II}}(r)$ nos auto-estados ligados, sendo que a escolha de tais valores também é dependente de restrições computacionais relacionadas ao valor mínimo aceitável para $u \quad\left(r_{0}\right)$ ou $u^{\prime} \quad\left(r_{0}\right)$ com determinados valores de $r_{0}$ e $E$.

Em concordância com as descrições dos parágrafos anteriores e usando como referência as soluções analíticas $u \quad(r)$ para o poço quadrado (mais precisamente, para um potencial constante $V_{0}=V\left(r_{0}\right)$ ), as condições iniciais aplicadas na deter- 
minação dos estados ligados ou quase-ligados são

$$
u_{\mathrm{I}}\left(r_{0}\right)=A r_{0} j\left(\kappa r_{0}\right) \quad \text { na região I }
$$

e

$$
u_{\mathrm{II}}\left(r_{0}\right)=B r_{0} h^{(1)}\left(i \alpha r_{0}\right) \quad \text { na região II, }
$$

onde

$$
\kappa^{2}=\frac{2 \mu}{\hbar^{2}}\left(E-V\left(r_{0}\right)\right) \quad \text { e } \quad \alpha^{2}=-\frac{2 \mu}{\hbar^{2}}\left(E-V\left(r_{0}\right)\right) .
$$

As funções $j$ e $h^{(1)}$ são, respectivamente, as funções de Bessel esféricas e as funções de Hankel esféricas do primeiro tipo. As condições iniciais $u_{\mathrm{I}}^{\prime}\left(r_{0}\right)$ e $u_{\mathrm{II}}^{\prime}\left(r_{0}\right)$ são obtidas com a simples derivação das funções analíticas $u \quad(r)$. Os coeficientes $A$ e $B$ devem ser calculados de tal forma que seja mantida a continuidade da solução completa $u(r)$ no raio $r_{\mathrm{f}}$, resultando em $u_{\mathrm{I}}\left(r_{\mathrm{f}}\right)=u_{\mathrm{II}}\left(r_{\mathrm{f}}\right)$. A solução completa então será

$$
u(r)=\left\{\begin{array}{lll}
u_{\mathrm{I}}(r) & \text { para } & r \leq r_{\mathrm{f}} \\
u_{\mathrm{II}}(r) & \text { para } & r>r_{\mathrm{f}}
\end{array} .\right.
$$

A solução $u(r)$ ainda não é normalizada, pois as condições iniciais dadas em (2.6) e (2.7) não incluem coeficientes com esta função. Primeiramente, é necessária a determinação dos auto-valores de energia para que as soluções correspondentes $u(r)$ sejam calculadas e em seguida normalizadas.

Uma certa energia $E$ é considerada um dos auto-valores quando resulta na continuidade da derivada logarítmica de $u(r)$ em $r_{\mathrm{f}}$. Isto pode ser descrito em termos de $u_{\mathrm{I}}(r)$ e $u_{\mathrm{II}}(r)$ por

$$
\left.\frac{1}{u_{\mathrm{I}}(r)}\left(\frac{d u_{\mathrm{I}}(r)}{d r}\right)\right|_{=\mathrm{f}}=\left.\frac{1}{u_{\mathrm{II}}(r)}\left(\frac{d u_{\mathrm{II}}(r)}{d r}\right)\right|_{=\mathrm{f}} .
$$

Assim, a equação (2.10) é usada para a determinação dos auto-valores por meio de uma varredura na faixa de energia onde devem estar localizados os níveis da banda do estado fundamental. Esta varredura é executada através da resolução numérica da eq. (2.3) com diferentes valores de energia, os quais se distanciam por um passo constante $\Delta E$. Levando em conta a precisão adotada pela Ref. [6] na indicação dos níveis de energia do sistema $\alpha^{-9} \mathrm{Zr}$, foi usado $\Delta E=0,01 \mathrm{MeV}$ em todas as varreduras referentes à banda do estado fundamental. É previsto que uma varredura de passo $\Delta E$ deve resultar em auto-energias com erros da ordem de $(\Delta E) / 2$ e, tomando como referência os testes com o OHE em condições de erro semelhantes, o uso de um passo $\Delta E$ com ordem de grandeza superior a 0,01 $\mathrm{MeV}$ pode resultar em funções $u(r)$ cujo nível de acurácia é insuficiente para os propósitos seguintes deste trabalho. Do ponto de vista do cálculo numérico, $E$ é estabelecido como um dos auto-valores de energia quando o módulo da diferença 
entre os dois membros da eq. (2.10) atinge um mínimo dentro da faixa submetida à varredura.

Sabe-se antecipadamente que a faixa de energia submetida à varredura deve conter as auto-energias associadas aos níveis da banda do estado fundamental, tomando-se a energia de separação- $\alpha$ como referência. Tais níveis podem ser identificados diretamente pelo comportamento das respectivas funções radiais $u(r)$.

\subsection{Cálculo e identificação das auto-funções radiais $u_{N, L}(r)$}

As funções $u(r)$ associadas aos auto-valores de energia dão origem às auto-funções radiais $u \quad(r)$, as quais compõem as auto-soluções $\psi \quad(r, \theta, \phi)$ da equação de Schrödinger independente do tempo. Para isso, a normalização das funções $u(r)$ torna-se necessária. Inicialmente, deve-se integrar $u^{2}(r)$ sobre todos os $r$ para a obtenção da quantidade

$$
C=\int_{0}^{\infty} u^{2}(r) d r
$$

Assim, a função normalizada $u \quad(r)$ se relaciona com $u(r)$ através da equação

$$
u \quad(r)=\frac{1}{\sqrt{C}} u(r) .
$$

A integração em (2.11) foi feita numericamente pela regra do trapézio na forma composta (detalhes na Ref. [15]). Na prática, a integração numérica foi executada entre 0 e $50 \mathrm{fm}$, visto que a amplitude de $u(r)$ além deste intervalo é desprezível no cálculo de $C$. Este método de integração foi considerado bastante satisfatório, pois o passo de integração varia da mesma forma que no cálculo de $u(r)$ através do método RKF (entre $10^{-4} \mathrm{fm}$ e $10^{-2} \mathrm{fm}$ ). O mesmo método é empregado em outros cálculos deste trabalho onde a integração numérica é necessária.

O processo de normalização resultou nas auto-funções radiais $u \quad(r)$ da banda do estado fundamental, as quais são mostradas graficamente no Apêndice A. Podese identificá-las através do número de nós internos $N$ que é obtido diretamente do comportamento das funções $u \quad(r)$. Como a banda do estado fundamental é caracterizada por $G=16$, as funções $u \quad(r)$ procuradas são aquelas que satisfazem a relação

$$
2 N+L=16
$$

conforme a definição dada na eq. (1.2). 


\subsection{Aproximação de estado ligado para $E>0$}

Os procedimentos descritos nas seções anteriores são usados em princípio para o cálculo de estados ligados $(E \leq 0)$, isto é, abaixo do limiar do sistema $\alpha^{-}{ }^{90} \mathrm{Zr}$. Nesta seção, mostra-se como os estados quase-ligados podem ser tratados por meios semelhantes.

A barreira de potencial efetivo formada por $V(r)$ possui largura limitada em energias acima do limiar do sistema $\alpha^{-}{ }^{90} \mathrm{Zr}$; desta forma, os estados que se localizam muitos $\mathrm{MeV}$ acima do limiar devem ser tratados como níveis ressonantes, conforme as discussões do Capítulo 4. Entretanto, os níveis que se encontram apenas alguns $\mathrm{MeV}$ acima do limiar podem ser tratados por uma aproximação de estado ligado. Pode-se justificar esta aproximação verificando a largura da barreira de potencial efetivo no intervalo de energia onde os níveis devem estar localizados e o quanto este intervalo está abaixo do topo da barreira.

Inicialmente, os procedimentos descritos nas seções anteriores foram executados para o cálculo dos auto-estados ligados da banda fundamental, utilizando-se o potencial intercluster proposto na Ref. [5]. Os resultados obtidos mostram que os níveis teóricos $0^{+}, 2^{+}, 4^{+}$e $6^{+}$da banda fundamental são ligados (o espectro da banda do estado fundamental é discutido em detalhes no Capítulo 3). Os níveis teóricos $8^{+}$e $10^{+}$, os quais também foram levados em conta no ajuste de parâmetros do potencial intercluster, localizam-se acima do limiar $\alpha+{ }^{90} \mathrm{Zr}$ e por isto devem ser tratados pela aproximação de estado ligado.

Em seguida, é descrito um procedimento preliminar que justifica o uso da aproximação de estado ligado na banda do estado fundamental. Com base nos dados da Ref. [5], é possível identificar no espectro experimental do ${ }^{94} \mathrm{Mo}$ [17] os níveis de energia usados como referência no ajuste de parâmetros do potencial intercluster $\alpha^{-90} \mathrm{Zr}$. Conhecendo as energias de excitação de tais níveis, foram verificadas as distâncias entre os níveis $6^{+}$e $8^{+}$e entre os níveis $6^{+}$e $10^{+}$. Assumindo que estas distâncias devem ser reproduzidas aproximadamente pelo espectro teórico e usando a energia do nível teórico $6^{+}$como referência, foi estimado que os níveis teóricos $8^{+}$e $10^{+}$devem localizar-se respectivamente $\mathrm{em} \approx 0,5 \mathrm{MeV}$ e $\approx 1,5 \mathrm{MeV}$ acima do limiar $\alpha+{ }^{90} \mathrm{Zr}$. As energias estimadas encontram-se respectivamente $\approx 16 \mathrm{MeV}$ $\mathrm{e} \approx 18 \mathrm{MeV}$ abaixo do topo da barreira de potencial efetivo, enquanto as larguras da mesma barreira em tais energias são respectivamente de $\approx 227 \mathrm{fm}$ e $\approx 75 \mathrm{fm}$. Os números mencionados mostram que a região classicamente proibida é muito extensa nos níveis teóricos $8^{+}$e $10^{+}$; junto a isso, os mesmos níveis encontramse demasiado abaixo da barreira efetiva para que apresentem um comportamento significativo de estados ressonantes. Estes fatos evidenciam que uma aproximação de estado ligado é bastante apropriada para os níveis $8^{+}$e $10^{+}$.

A aproximação de estado ligado consiste em aplicar os mesmos procedimentos já usados na resolução da equação radial para níveis ligados, contudo, considerando uma barreira de potencial com extensão limitada. Se é desejado que a função $u(r)$ apresente a característica de estado ligado em $E>0$, ela deve apresentar um comportamento exponencial decrescente fora do poço de potencial efetivo, isto 
é, o mesmo comportamento para uma barreira de potencial de extensão infinita naquela energia. A função $u(r)$ pode apresentar naturalmente esta característica exponencial nos trechos onde $E<V(r)$.

De acordo com esta necessidade, é estabelecido que a condição inicial do método RKF na região II deve ser aplicada num raio $r_{0} \gg 0$ onde $E<V_{0}$. Apesar de $r_{0}$ estar restrito ao limite externo da barreira de potencial, ainda é possível aplicá-lo num raio suficientemente distante do poço atrativo quando $E$ está poucos $\mathrm{MeV}$ acima do limiar $\alpha^{-}{ }^{90} \mathrm{Zr}$, de modo que a aproximação de poço quadrado se mantenha satisfatória em $r_{0}$.

Deste modo, a varredura de energia então é aplicada acima de $E=0$ e as condições iniciais do método RKF continuam baseadas em (2.6) e (2.7). Nas proximidades das auto-energias encontradas para os níveis $8^{+}$e $10^{+}$, foram utilizados valores de $r_{0}$ respectivamente em torno de $140 \mathrm{fm}$ e $65 \mathrm{fm}$ na região II. As funções radiais normalizadas $u \quad(r)$ para os níveis $8^{+}$e $10^{+}$são apresentadas graficamente no Apêndice A. A resolução da equação radial com a aproximação de estado ligado gera funções $u \quad(r)$ que claramente tendem a respeitar as condições de contorno para níveis ligados. 


\section{Capítulo 3}

\section{Propriedades da banda do estado fundamental do sistema $\alpha-{ }^{90} \mathrm{Zr}$}

Com os procedimentos descritos no Capítulo 2, foram obtidas várias propriedades da banda do estado fundamental do sistema $\alpha^{-}{ }^{90} \mathrm{Zr}$. Primeiramente, determinou-se o espectro de energias e as auto-funções radiais $u \quad(r)$. Estas auto-funções foram utilizadas no cálculo dos raios intercluster rms e das taxas de transição $B(E 2)$ entre os níveis da banda. Foi efetuada uma comparação entre os estados do sistema $\alpha^{-90} \mathrm{Zr}$ e auto-estados de oscilador harmônico resultantes de uma aproximação do modelo de camadas. A análise dos resultados é feita através da verificação de dados experimentais e cálculos de outras referências.

\subsection{Espectro da banda e auto-funções radiais}

O processo de varredura de energias (detalhes no Capítulo 2) resultou no espectro mostrado na Figura 3.1, onde comparamos os níveis de energia calculados para a banda fundamental e os níveis experimentais usados no ajuste de parâmetros do potencial intercluster $V(r)$, cuja forma é descrita na Seção 1.3. A escala de energia tem como referência o limiar teórico do sistema $\alpha^{-90} \mathrm{Zr}$, significando que esta escala é compatível com os níveis de energia calculados através do potencial $V(r)$. Os espaçamentos entre os níveis experimentais respeitam os dados indicados no espectro experimental do ${ }^{94} \mathrm{Mo}$ [17], sendo que o nível experimental $0^{+}$corresponde ao estado fundamental deste núcleo. Contudo, o conjunto dos níveis experimentais é posicionado na escala de energia de tal forma que a comparação com os níveis teóricos seja equivalente àquela adotada na Ref. [5].

Os níveis de energia calculados para a banda fundamental mostram um espectro quase-rotacional, o que também ocorre nos espectros calculados para os sistemas $\alpha_{-}{ }^{16} \mathrm{O}$ e $\alpha-{ }^{40} \mathrm{Ca}$ com diferentes potenciais intercluster [1,3]. O espaçamento dos níveis calculados é totalmente compatível com o espectro teórico da Ref. [5], o qual foi obtido por um método semi-clássico baseado na regra de quantização de Bohr-Sommerfeld. Verifica-se que o espectro teórico reproduz satisfatoriamente o espaçamento médio dos níveis experimentais, levando em conta que os parâmetros 


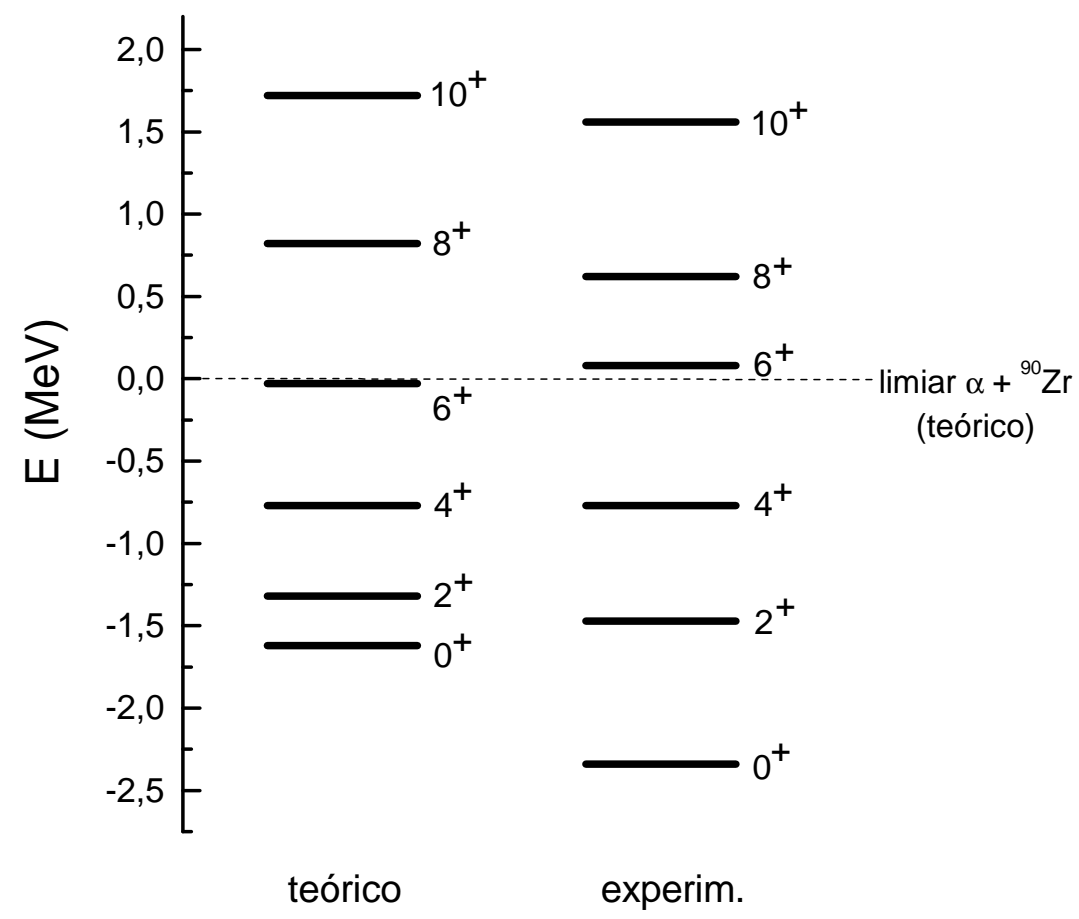

Figura 3.1: Níveis de energia calculados para a banda do estado fundamental $(G=16)$ em comparação com níveis experimentais do espectro do ${ }^{94}$ Mo. A escala de energia é dada em relação ao limiar teórico do sistema $\alpha^{-}{ }^{90} \mathrm{Zr}$. Os valores experimentais foram extraídos da Ref. [17].

do potencial intercluster $V(r)$ não são dependentes da energia de excitação do sistema ou do número quântico $L$, ao contrário de outros trabalhos que tratam da estrutura de cluster- $\alpha[3,4,7]$. Além disto, estes parâmetros foram ajustados visando a reprodução simultânea de propriedades espectroscópicas de vários núcleos onde a estrutura de cluster- $\alpha$ é esperada [5], de modo que o potencial intercluster não foi otimizado apenas para a descrição do ${ }^{94}$ Mo.

Uma deficiência a ser destacada encontra-se no espaçamento entre os níveis calculados $0^{+}$e $2^{+}$. Tomando como referência o posicionamento dos espectros teórico e experimental da Figura 3.1, verifica-se que o nível $0^{+}$teórico está $\approx 0,7$ $\mathrm{MeV}$ acima do nível $0^{+}$experimental e o intervalo de energia teórico $2^{+} \rightarrow 0^{+}$ representa $\approx 34 \%$ do respectivo intervalo experimental. A excessiva compressão do espectro teórico nos primeiros níveis também ocorre nos sistemas $\alpha_{-}{ }^{16} \mathrm{O}, \alpha_{-}{ }^{40} \mathrm{Ca}$ e $\alpha-{ }^{208} \mathrm{~Pb}$ com graus de intensidade distintos, sendo uma característica apresentada em diferentes cálculos referentes ao modelo de cluster- $\alpha$ com potencial local $[5,1,3]$. O aumento de proximidade entre o espaçamento dos níveis teóricos seguintes e o espectro experimental sugere que a adição da barreira centrífuga no potencial intercluster ameniza os efeitos da deficiência de $V(r)$. Observações da Ref. [5] registram que tal deficiência pode ter origem numa descrição inadequada da forma de $V(r)$ nas proximidades de $r=0$.

As auto-energias apresentadas estão associadas às respectivas auto-funções radiais $u \quad(r)$, as quais se encontram no Apêndice A. As funções $u \quad(r)$ são avali- 
adas pelas suas aplicações no cálculo de propriedades do sistema $\alpha^{-}{ }^{90} \mathrm{Zr}$, como é mostrado nas seções seguintes.

\subsection{Raios intercluster rms}

Com base no modelo de cluster, fizemos uma avaliação sobre a distância relativa entre o cluster- $\alpha$ e o caroço de ${ }^{90} \mathrm{Zr}$ na banda do estado fundamental. Lembrando que $r$ representa o raio intercluster do sistema, podemos calcular o raio quadrático médio intercluster de um estado $|N, L\rangle$ com o auxílio das funções $u \quad(r)$. Para isto, usamos

$$
\left\langle r^{2}\right\rangle=\int_{0}^{\infty} r^{2} u^{2} \quad(r) d r
$$

Assim, o raio intercluster rms será dado por $\sqrt{\left\langle r^{2}\right\rangle}$.

Os resultados obtidos para os raios intercluster rms encontram-se na Tabela 3.1. Nota-se que $\sqrt{\left\langle r^{2}\right\rangle}$ decresce de $5,13 \mathrm{fm}$ no estado $0^{+}$para $4,86 \mathrm{fm}$ no estado $10^{+}$. Este comportamento, chamado em alguns artigos como antistretching effect, já foi constatado em cálculos de estrutura de cluster- $\alpha$ em outros núcleos $[1,3,4]$ e no próprio ${ }^{94} \mathrm{Mo}$ [4] com diferentes formas de potencial intercluster. De acordo com observações de Buck, Dover e Vary [1], o efeito antistretching é esperado em sistemas onde o potencial $V(r)$ apresenta uma difusividade efetiva acentuada, tal como nos potenciais locais empregados no modelo de cluster- $\alpha$.

Os valores da Tabela 3.1 podem ser comparados com os raios experimentais dos núcleos envolvidos no sistema. Usando os raios rms experimentais [18] para a distribuição de carga do $\alpha(1,674 \mathrm{fm})$ e do ${ }^{90} \mathrm{Zr}(4,224 \mathrm{fm})$, podemos calcular o raio rms do ${ }^{94} \mathrm{Mo}$ de acordo com o raio intercluster previsto para um determinado estado da banda. Estes raios se relacionam por [19]

$$
\left\langle R^{2}\right\rangle_{\mathrm{Mo}}=\frac{Z}{Z+Z_{\mathrm{Zr}}}\left\langle R^{2}\right\rangle+\frac{Z_{\mathrm{Zr}}}{Z+Z_{\mathrm{Zr}}}\left\langle R^{2}\right\rangle_{\mathrm{Zr}}+\frac{Z A_{\mathrm{Zr}}^{2}+Z_{\mathrm{Zr}} A^{2}}{\left(Z+Z_{\mathrm{Zr}}\right)\left(A+A_{\mathrm{Zr}}\right)^{2}}\left\langle r^{2}\right\rangle,
$$

onde $\left\langle R^{2}\right\rangle_{\mathrm{Mo}},\left\langle R^{2}\right\rangle$ e $\left\langle R^{2}\right\rangle_{\mathrm{Zr}}$ são respectivamente os raios quadráticos médios de distribuição de carga do ${ }^{94} \mathrm{Mo}$, da partícula $\alpha$ e do ${ }^{90} \mathrm{Zr}$, enquanto $\left\langle r^{2}\right\rangle$ é o raio quadrático médio intercluster dado em (3.1). Considerando que o raio rms experimental do ${ }^{94} \mathrm{Mo}$ deve estar associado com o seu estado fundamental, aplicamos

$$
\sqrt{\left\langle r^{2}\right\rangle}=\sqrt{\left\langle r^{2}\right\rangle_{0^{+}}}=5,13 \mathrm{fm} \quad, \quad \sqrt{\left\langle R^{2}\right\rangle}=1,674 \mathrm{fm} \quad \text { e } \sqrt{\left\langle R^{2}\right\rangle_{\mathrm{Zr}}}=4,224 \mathrm{fm}
$$

na eq. (3.2). Assim, obtém-se o resultado $\sqrt{\left\langle R^{2}\right\rangle_{\text {Mo }}} \approx 4,28 \mathrm{fm}$, o que representa $\approx 99 \%$ do raio rms experimental do ${ }^{94} \mathrm{Mo}(4,334 \mathrm{fm})$. Demonstra-se que o potencial intercluster adotado neste trabalho apresenta boa concordância com o raio do núcleo total. 
Outra comparação importante pode ser feita com a soma dos raios do cluster e do caroço. Usando os dados da Tabela 3.1 e os raios rms experimentais do $\alpha$ e do ${ }^{90} \mathrm{Zr}$, verificamos que

$$
\sqrt{\left\langle r^{2}\right\rangle_{0^{+}}}=0,87\left(\sqrt{\left\langle R^{2}\right\rangle}+\sqrt{\left\langle R^{2}\right\rangle_{\mathrm{Zr}}}\right)
$$

e

$$
\sqrt{\left\langle r^{2}\right\rangle_{10^{+}}}=0,82\left(\sqrt{\left\langle R^{2}\right\rangle}+\sqrt{\left\langle R^{2}\right\rangle_{\mathrm{Zr}}}\right)
$$

Portanto, há uma superposição entre o cluster- $\alpha$ e o caroço que já é significativa no estado $0^{+}$e torna-se maior nos últimos níveis da banda fundamental. Isto sugere que a banda do estado fundamental apresenta uma estrutura de cluster compacta, o que está de acordo com cálculos de S. Ohkubo [4] onde é utilizado um modelo de potencial do tipo double folding para o mesmo sistema.

Tabela 3.1: Valores teóricos e experimentais das taxas de transição $B(E 2)$ para $J \rightarrow J-2$ e valores teóricos para os raios intercluster rms, referindo-se à banda do estado fundamental $(G=16)$ do sistema $\alpha^{-90} \mathrm{Zr}$. Os valores experimentais encontram-se na Ref. [17].

\begin{tabular}{cccc}
\hline \hline & $\begin{array}{c}\sqrt{\left\langle r^{2}\right\rangle} \\
(\mathrm{fm})\end{array}$ & $\begin{array}{c}B(E 2) \\
\left(e^{2} \mathrm{fm}^{4}\right)\end{array}$ & $\begin{array}{c}B(E 2) \\
\left(e^{2} \mathrm{fm}^{4}\right)\end{array}$ \\
$J$ & 5,13 & & \\
$0^{+}$ & 5,12 & 199 & $392 \pm 6$ \\
$2^{+}$ & 5,08 & 272 & $660 \pm 102$ \\
$4^{+}$ & 5,02 & 274 & \\
$6^{+}$ & 4,95 & 250 & \\
$8^{+}$ & 4,86 & 211 & \\
$10^{+}$ & & \\
\hline \hline
\end{tabular}

\subsection{Taxas de transição $B(E 2)$}

O modelo de cluster- $\alpha$ também é usado no cálculo das probabilidades de transição reduzida de quadrupolo elétrico entre níveis consecutivos da banda. Levando em conta que não há interação spin-órbita no sistema aqui adotado (isto é, $J=L$ e $J=L)$, a taxa $B(E 2)$ para transições $J \rightarrow J-2$ é calculada por $[5,19]$

$$
B(E 2 ; G, J \rightarrow J-2)=\frac{15}{8 \pi} \beta_{2}^{2} \frac{J(J-1)}{(2 J+1)(2 J-1)}\left\langle r^{2}{ }_{-2}\right\rangle^{2},
$$

onde 


$$
\left\langle r^{2}-2\right\rangle=\int_{0}^{\infty} r^{2} u \quad(r) u \quad{ }_{-2}(r) d r
$$

e $\beta_{2}$ é mencionado como o fator de recuo, sendo dado por

$$
\beta_{2}=\frac{Z A_{\mathrm{Zr}}^{2}+Z_{\mathrm{Zr}} A^{2}}{\left(A+A_{\mathrm{Zr}}\right)^{2}} .
$$

Na fórmula (3.4), identificamos as auto-funções radiais através dos números quânti$\cos J$ (ou $L$ ) e $G$.

Os valores obtidos encontram-se na Tabela 3.1. Os resultados teóricos apresentam a mesma ordem de grandeza dos valores experimentais e fornecem uma descrição semiquantitativa satisfatória, pois não são usadas cargas efetivas nestes cálculos e os parâmetros do potencial intercluster $V(r)$ não foram ajustados com referência nos dados experimentais das probabilidades de transição. É conveniente lembrar que os dados experimentais são conhecidamente difíceis de serem reproduzidos nestas condições pelo modelo de cluster- $\alpha$ no ${ }^{94} \mathrm{Mo}$ [5].

O modelo de cluster- $\alpha$ demonstra ser mais eficiente na descrição das taxas $B(E 2)$ em comparação com cálculos baseados no modelo de camadas. A Ref. [20] mostra um cálculo detalhado usando o modelo de camadas, onde são considerados prótons e nêutrons de valência ocupando vários orbitais. Nesta referência, constatamos o uso de cargas efetivas acentuadas no cálculo das taxas $B(E 2)$ nas transições $2^{+} \rightarrow 0^{+}$e $4^{+} \rightarrow 2^{+}$do ${ }^{94} \mathrm{Mo}$, sendo que os resultados obtidos são ainda mais afastados dos dados experimentais em comparação com o modelo de cluster- $\alpha$.

\subsection{Comparação com auto-estados de oscilador harmônico}

Possuindo as funções $u \quad(r)$, temos a oportunidade de comparar os estados do sistema $\alpha^{-90} \mathrm{Zr}$ com auto-estados de oscilador harmônico esférico (OHE) adaptados para este problema. Com base nos princípios que originam a condição de Wildermuth $[9,10]$, se considerarmos que todos os núcleons do sistema movem-se independentemente num campo de OHE, tal como na forma mais simples do modelo de camadas de oscilador harmônico, podemos assumir que o centro de massa do cluster- $\alpha$ também estará submetido a um potencial do tipo OHE. A mesma conseqüência se estende para a massa reduzida do sistema cluster-caroço. Devido a esta propriedade, o potencial de OHE que descreve de forma coerente o movimento relativo do sistema cluster-caroço é aquele onde o parâmetro de oscilador harmônico $\nu$ é dado por

$$
\nu=\frac{\mu \omega}{\hbar},
$$

onde $\mu$ é a massa reduzida do sistema e $\omega$ é dado pela fórmula [13] 


$$
\hbar \omega=41 A^{-13}
$$

usada no modelo de camadas, aplicando-se o número de massa do núcleo total $(A=94)$. A comparação é executada através da expansão das funções de onda do sistema $\alpha{ }^{-90} \mathrm{Zr}$ na base ortogonal de auto-funções do OHE. No caso desta expansão, é conveniente o uso dos números quânticos $G, L$ e $M$ na identificação das funções de onda. Assim, podemos representar a expansão por

$$
\psi \quad(r, \theta, \phi)=\frac{1}{r} u \quad(r) Y \quad(\theta, \phi)=\sum_{,} c,, \quad, \psi_{,}^{\mathrm{OHE}},(r, \theta, \phi),
$$

onde $\psi \psi_{\prime}^{\mathrm{OHE}}, \quad(r, \theta, \phi)$ representa uma das auto-funções do OHE, a qual é identificada pelos números quânticos $G^{\prime}, L^{\prime}$ e $M^{\prime}$. Para os auto-estados do OHE, $G^{\prime}$ representa o número quântico principal que está associado às auto-energias $E,=\left(3 / 2+G^{\prime}\right) \hbar \omega$. A expansão resulta nos coeficientes $c$, , , dados por

$$
c,, \quad,=\delta \quad, \delta \quad, \int_{0}^{\infty} u \quad(r) u_{,}^{\mathrm{OHE}}(r) d r .
$$

Sempre que $L \neq L^{\prime}$ e/ou $M \neq M^{\prime}$ o coeficiente $c$, , , será nulo. Levando em conta apenas os coeficientes não nulos, podemos simplificar (3.9) resultando em

$$
c,=\int_{0}^{\infty} u \quad(r) u_{,}^{\mathrm{OHE}}(r) d r .
$$

O número quântico $M$ é omitido em (3.10), pois o mesmo não exerce influência sobre a parte radial das funções de onda. Como as funções $u \quad(r)$ do sistema $\alpha-{ }^{90} \mathrm{Zr}$ são normalizadas, temos que

$$
\sum_{1}|c,|^{2}=1
$$

para a expansão de um estado $|G, L\rangle$.

Os coeficientes $c$, foram calculados numericamente para os estados $|G=16, L\rangle$ da banda do estado fundamental, sendo possível a determinação das probabilidades associadas a cada auto-estado de oscilador harmônico $\left|G^{\prime}, L\right\rangle_{\mathrm{OHE}}$. Esta probabilidade é dada por

$$
P\left(G^{\prime}, L\right)=|c,|^{2} .
$$

Com os valores calculados de $P\left(G^{\prime}, L\right)$, verificamos graficamente como estas probabilidades se distribuem em cada estado da banda. Os gráficos referentes às expansões estão todos reunidos no Apêndice B. Verifica-se que todos os picos de probabilidade ocorrem nos auto-estados de OHE identificados por $G^{\prime}=16$, isto é, um número igual àquele que caracteriza a banda do estado fundamental. Este fato mostra que a descrição do sistema a partir do modelo de camadas de oscilador 
Tabela 3.2: Probabilidades $P\left(G^{\prime}=16, L=J\right)$ resultantes da expansão das funções radiais dos estados $J^{+}$da banda fundamental na base de OHE. A base de OHE é caracterizada pelo parâmetro $\nu$ dado em (3.6).

\begin{tabular}{cc}
\hline \hline$J$ & $P\left(G^{\prime}=16, L=J\right)(\%)$ \\
\hline $0^{+}$ & 89,1 \\
$2^{+}$ & 89,3 \\
$4^{+}$ & 90,0 \\
$6^{+}$ & 91,3 \\
$8^{+}$ & 93,1 \\
$10^{+}$ & 95,0 \\
\hline \hline
\end{tabular}

harmônico (e conseqüentemente a partir da condição de Wildermuth) fornece um número quântico global $G$ compatível com a banda do estado fundamental do sistema $\alpha^{-90} \mathrm{Zr}$.

As probabilidades $P\left(G^{\prime}=16, L=J\right)$ são mostradas na Tabela 3.2. Nota-se que a probabilidade associada ao auto-estado $\left|G^{\prime}=16, L=J\right\rangle_{\mathrm{OHE}}$ já é bastante acentuada na expansão do estado $0^{+}$, aumentando progressivamente conforme seguimos para os níveis de maior spin. Estes números indicam que as funções radiais $u_{16} \quad(r)$ do sistema $\alpha^{-90} \mathrm{Zr}$ tornam-se mais próximas das funções $u_{16}^{\mathrm{OHE}}(r)$ para os estados com maior $L$ (ou maior $J$ ). Este fato pode ser notado diretamente pela comparação entre as funções $u_{16} \quad(r)$ e $u_{16}^{\mathrm{OHE}}(r)$ através dos gráficos reunidos no Apêndice A. A Figura A.1 confirma o que já é constatado na Tabela 3.2, mostrando um alto grau de superposição entre a função radial do estado $0^{+}$e a componente $u_{160}^{\mathrm{OHE}}(r)$ da base de $\mathrm{OHE}$, exceto na região de superfície (situada além do raio rms) onde a função $u_{160}(r)$ se apresenta um pouco mais extensa. Como exemplo deste fato, verifica-se que $u_{160}(r) \approx 0,41 \mathrm{fm}^{-12}$ em $r=7 \mathrm{fm}$, enquanto $u_{160}^{\mathrm{OHE}}(r) \approx 0,16$ $\mathrm{fm}^{-1} 2$ no mesmo raio, havendo então uma diferença de amplitude entre as duas funções de $\approx 0,24 \mathrm{fm}^{-1} 2 \mathrm{em} r=7 \mathrm{fm}$. A variação de proximidade entre as funções $u_{16}(r)$ e $u_{16}^{\mathrm{OHE}}(r)$ na região de superfície é pouco perceptível em estados consecutivos da banda; contudo, há uma significativa aproximação entre as duas funções no estado $10^{+}$(Figura A.6) em comparação com o estado $0^{+}$. Assim, verifica-se que $u_{16}{ }_{10}(r) \approx 0,20 \mathrm{fm}^{-12}$ em $r=7 \mathrm{fm}$, enquanto $u_{1610}^{\mathrm{OHE}}(r) \approx 0,07 \mathrm{fm}^{-12}$ no mesmo raio, de modo que a diferença de amplitude entre as duas funções é de $\approx 0,13 \mathrm{fm}^{-1} 2 \mathrm{em} r=7 \mathrm{fm}$. Estes dados confirmam o aumento de superposição das duas funções e concordam com a análise das probabilidades $P\left(G^{\prime}=16, L=J\right)$.

Os resultados também podem ser analisados através do comportamento do potencial efetivo do sistema. A Figura 3.2 mostra dois gráficos que comparam os potenciais efetivos do sistema $\alpha^{-90} \mathrm{Zr}$ e do OHE nos casos $L=0$ e $L=10$, atribuindo uma certa profundidade $V_{0}$ ao potencial do OHE para que a energia do auto-estado $\left|G^{\prime}=16, L=J\right\rangle_{\mathrm{OHE}}$ seja igual à energia do estado $J^{+}$do sistema $\alpha^{-90} \mathrm{Zr}$. Considerando a faixa de energia abaixo do limiar $\alpha+{ }^{90} \mathrm{Zr}$, observamos que 
os potenciais dos dois sistemas variam de uma forma geral bastante semelhante, mesmo sem a adição da barreira centrífuga. No caso $L=0$, as diferenças entre os potenciais são mais relevantes na região do fundo do poço de potencial e alguns $\mathrm{MeV}$ abaixo e acima do limiar $\alpha+{ }^{90} \mathrm{Zr}$, enquanto o comportamento do OHE muitos $\mathrm{MeV}$ acima do limiar é incompatível com uma faixa de estados ressonantes. A adição da barreira centrífuga ameniza os efeitos das diferenças entre os dois potenciais, principalmente nas proximidades de $r=0$, onde a barreira centrífuga é predominante em ambos. No caso de barreiras centrífugas mais intensas (geradas pelo aumento de $L$ ), esta propriedade é especialmente importante no intervalo de energia onde localiza-se a banda do estado fundamental. A Figura 3.3 mostra o comportamento dos potenciais efetivos dos dois sistemas em energias próximas do limiar $\alpha+{ }^{90} \mathrm{Zr}$, onde se encontram os níveis da banda do estado fundamental, colocando em evidência a região de fronteira dos poços de potencial. No caso $L=0$, notamos que o poço de potencial do sistema $\alpha^{-90} \mathrm{Zr}$ é $\approx 0,35 \mathrm{fm}$ mais extenso do que aquele do OHE no nível de energia $0^{+}$, justificando o fato da função radial $u_{160}(r)$ se apresentar um pouco mais extensa em comparação com a região de superfície da função $u_{160}^{\mathrm{OHE}}(r)$. No entanto, no caso $L=10$, os poços de potencial efetivo dos dois sistemas elevam-se em muitos $\mathrm{MeV}$, tornando a barreira efetiva $\alpha_{-}{ }^{90} \mathrm{Zr}$ mais próxima do poço de OHE quanto ao eixo $r$. Desta forma, o poço de potencial efetivo do sistema $\alpha^{-}{ }^{90} \mathrm{Zr}$ torna-se $\approx 0,20 \mathrm{fm}$ mais extenso do que aquele do OHE no nível de energia $10^{+}$, justificando o aumento de superposição das regiões de superfície das funções $u_{16}{ }_{10}(r)$ e $u_{16}^{\mathrm{OHE}}(r)$ em comparação com o caso $L=0$. Além disto, a barreira de potencial efetivo do sistema $\alpha^{-}{ }^{90} \mathrm{Zr}$ torna-se mais alta com o aumento de $L$, se tomarmos como referência os níveis de energia $J^{+}$ correspondentes. Como conseqüência, na região de superfície, as funções radiais $u_{16}(r)$ dos estados de alto spin devem apresentar uma queda exponencial mais forte do que a registrada nas funções $u_{16}(r)$ dos estados de baixo spin e, levando em conta que as funções radiais do OHE apresentam uma diminuição de amplitude abrupta na sua região de superfície, este fato contribui para a aproximação das funções radiais $u_{16}(r)$ e $u_{16}^{\mathrm{OHE}}(r)$.

Uma relação pode ser estabelecida entre os resultados das expansões das funções radiais $u_{16}(r)$ e as constatações sobre os raios intercluster rms. Como os autoestados de $\mathrm{OHE}$ possuem um raio quadrático médio comum quando compartilham do mesmo número quântico principal $G^{\prime}$, podemos determinar um único valor de $\left\langle r^{2}\right\rangle$ para os auto-estados $\left|G^{\prime}=16, L=J\right\rangle_{\mathrm{OHE}}$. Para isso, usamos a fórmula (por exemplo, ver a Ref. [12])

$$
\left\langle r^{2}\right\rangle_{\mathrm{OHE}}=\frac{1}{\nu}\left(G^{\prime}+\frac{3}{2}\right)
$$

onde $\nu \approx 0,827 \mathrm{fm}^{-2}$ é o parâmetro dado em (3.6). Assim, obtemos os valores

$$
\left\langle r^{2}\right\rangle_{\mathrm{OHE}} \approx 21,17 \mathrm{fm}^{2} \text { e } \sqrt{\left\langle r^{2}\right\rangle_{\mathrm{OHE}}} \approx 4,60 \mathrm{fm} \text { para } G^{\prime}=16 .
$$

Se compararmos o valor de $\sqrt{\left\langle r^{2}\right\rangle_{\mathrm{OHE}}}$ com os raios intercluster rms da Tabela 


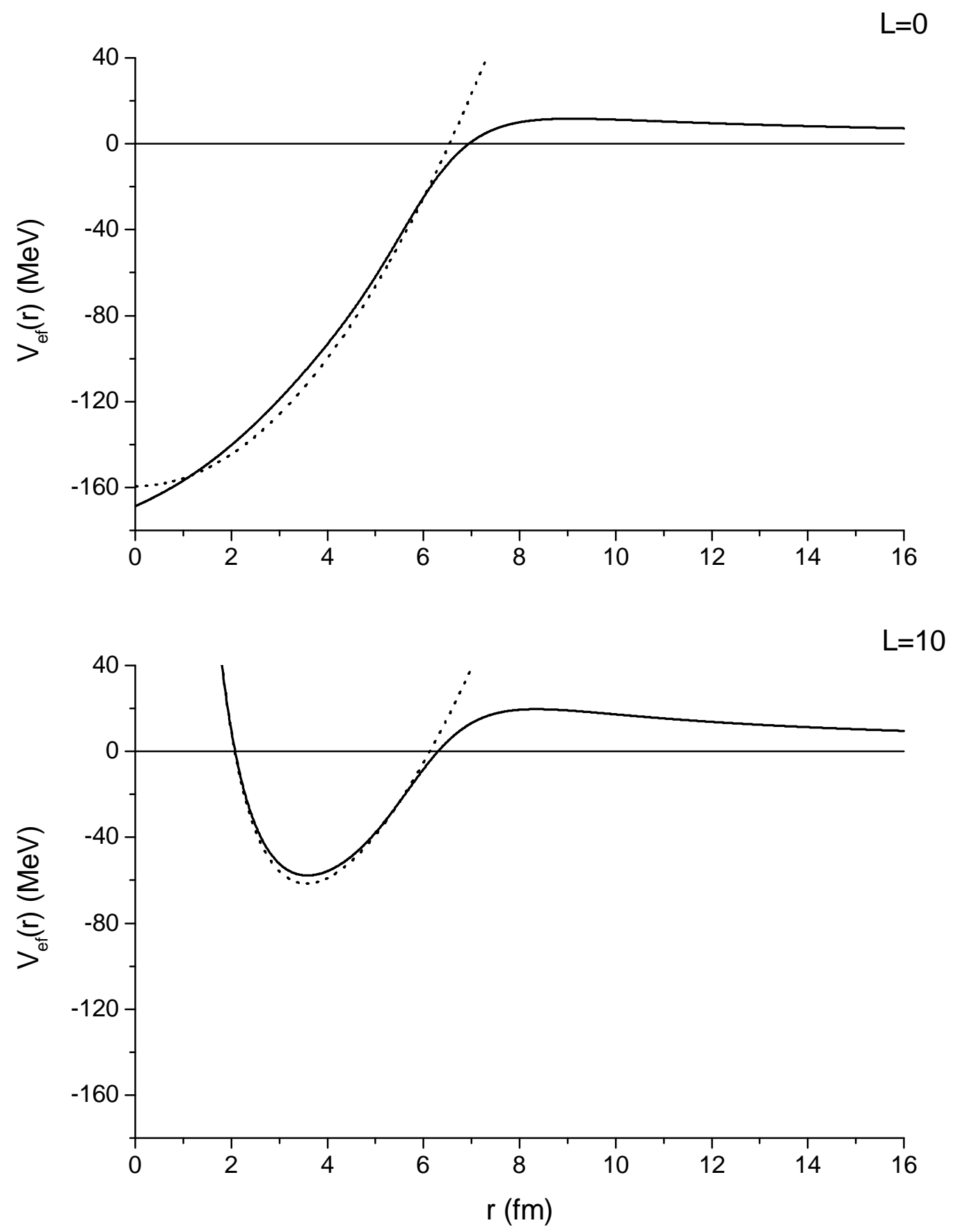

Figura 3.2: Comparação entre o potencial efetivo intercluster do sistema $\alpha{ }^{90} \mathrm{Zr}$ (linhas contínuas) e o potencial efetivo do OHE (linhas pontilhadas) com parâmetro $\nu$ dado em (3.6), nos casos de $L=0$ e $L=10$. Para cada caso, é atribuída uma certa profundidade $V_{0}$ ao potencial de OHE para que a energia do auto-estado $\left|G^{\prime}=16, L=J\right\rangle_{\mathrm{OHE}}$ seja igual à energia do estado $J^{+}$ da banda fundamental do sistema $\alpha^{-9}{ }^{90} \mathrm{Zr}$. 

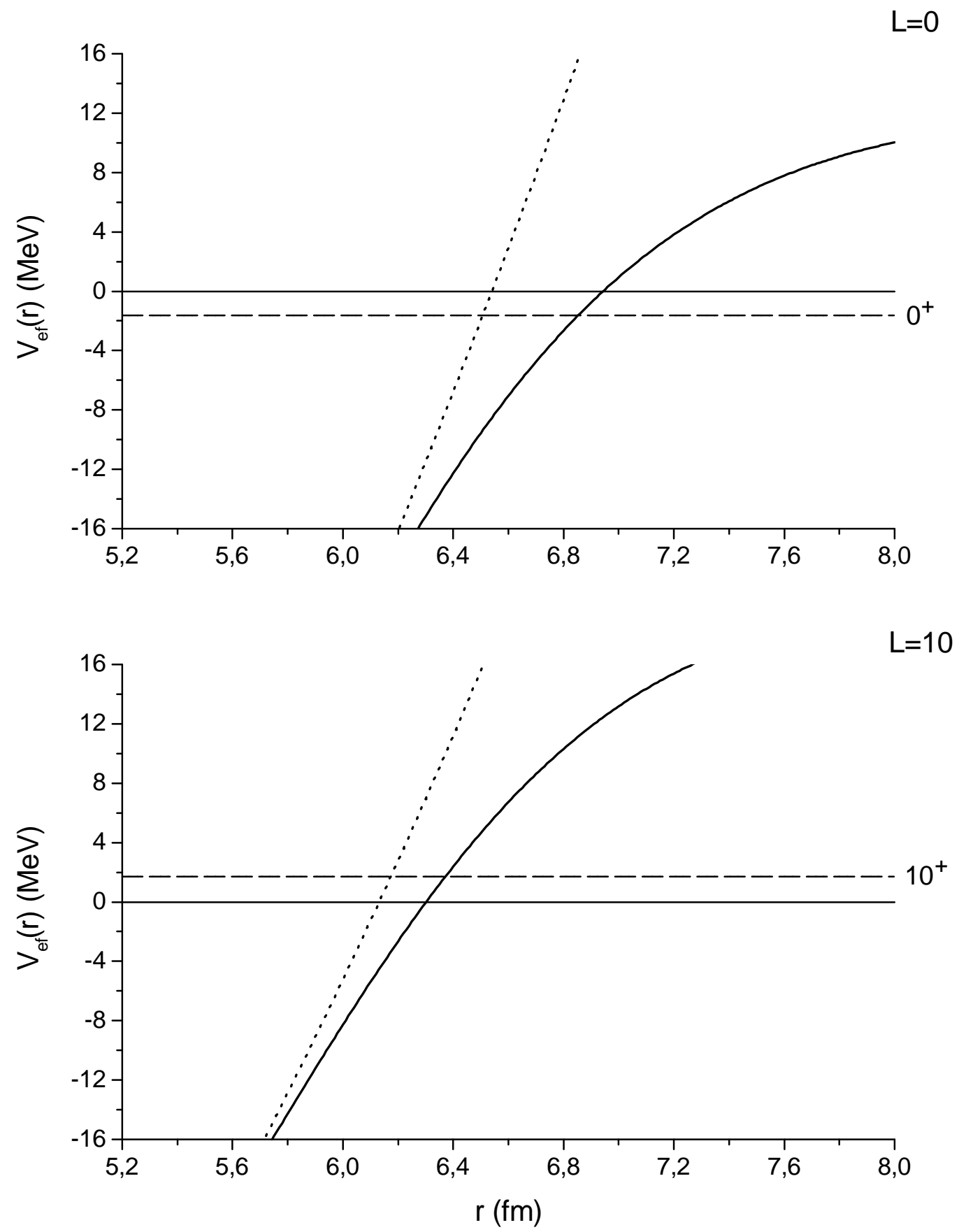

Figura 3.3: Comparação equivalente à encontrada na Figura 3.2, com destaque para a região de fronteira dos poços de potencial efetivo do OHE (linhas pontilhadas) e do sistema $\alpha^{-}{ }^{90} \mathrm{Zr}$ (linhas contínuas) em energias próximas do limiar $\alpha+{ }^{90} \mathrm{Zr}$, onde se encontram os níveis da banda fundamental. Os níveis de energia dos estados $0^{+}$e $10^{+}$são indicados em cada caso (linhas tracejadas). 
3.1, verificaremos que o raio rms do OHE com $G^{\prime}=16$ é $0,26 \mathrm{fm}$ menor do que o raio intercluster rms no estado $10^{+}$da banda fundamental, lembrando que este é o valor mais baixo de $\sqrt{\left\langle r^{2}\right\rangle}$ registrado entre os estados $0^{+}$e $10^{+}$. Este fato significa que o potencial de $\mathrm{OHE}$ com o parâmetro $\nu$ sugere uma estrutura de cluster mais compacta na banda fundamental do que aquela prevista pelo potencial intercluster $\alpha{ }^{90} \mathrm{Zr}$; por isto, o OHE pode ser entendido como um referencial de uma condição fraca de cluster- $\alpha$. Usando esta interpretação, podemos estabelecer que o aumento de proximidade das funções radiais $u_{16}(r)$ e $u_{16}^{\mathrm{OHE}}(r)$ (principalmente quanto às suas regiões de superfície) representa uma perda gradativa da aglomeração- $\alpha$ no sistema. Unindo o fato das funções $u_{16}(r)$ encontrarem-se muito próximas das funções radiais $u_{16}^{\mathrm{OHE}}(r)$ da base de OHE (mesmo no estado fundamental $0^{+}$) com as constatações obtidas através das probabilidades $P\left(G^{\prime}=16, L=J\right)$ e dos raios intercluster rms, conclui-se que a banda do estado fundamental, de acordo com o modelo proposto, apresenta uma condição de cluster- $\alpha$ moderada até o estado $10^{+}$. As expansões das funções $u_{16} \quad(r)$ na base de OHE também fornecem a estimativa na qual há uma significativa contribuição do modelo de camadas na formação dos estados da banda fundamental, sendo que tal comportamento já se manifesta no estado $0^{+}$e acentua-se nos níveis de maior $J$. Apesar da última característica mencionada, a consideração do grau de aglomeração- $\alpha$ verificado no ${ }^{94}$ Mo mostra-se importante para uma reprodução mais satisfatória das probabilidades de transição $B(E 2)$ entre os níveis desta banda. 


\section{Capítulo 4}

\section{Identificação de bandas superiores no sistema $\alpha-{ }^{90} \mathrm{Zr}$}

Neste capítulo, mostramos os procedimentos usados na identificação de bandas superiores no sistema $\alpha_{-}{ }^{90} \mathrm{Zr}$ e investigamos algumas de suas propriedades. Primeiramente, é feita uma descrição do método utilizado para o cálculo de alguns dos níveis de energia ressonantes de duas bandas superiores. A seguir, são analisados os resultados obtidos para estes níveis e suas respectivas larguras- $\alpha$.

\subsection{Procedimento para o cálculo de níveis de energia ressonantes}

A existência de bandas superiores relacionadas com a estrutura de cluster- $\alpha$ já foi mencionada para núcleos leves, tais como o ${ }^{20} \mathrm{Ne}[1]$ e o ${ }^{44} \mathrm{Ti}[2,3]$. Os cálculos descritos a seguir foram desenvolvidos com a finalidade de identificar alguns dos possíveis estados de cluster- $\alpha$ pertencentes a bandas superiores no ${ }^{94} \mathrm{Mo}$, mesmo considerando que o potencial intercluster em (1.5) não foi desenvolvido a partir de dados experimentais relacionados a tais bandas. Desta forma, assumimos que este potencial pode prever a existência de outros níveis de energia do sistema $\alpha-{ }^{90} \mathrm{Zr}$ ainda não identificados experimentalmente.

\subsubsection{Localização preliminar das bandas superiores}

O estudo das bandas superiores inicia-se com a determinação dos intervalos de energia onde devem estar situadas. Para isto, recorremos novamente ao método aplicado no cálculo dos níveis de energia da banda do estado fundamental. Levando em conta que tal método foi desenvolvido para a identificação de estados ligados ou quase-ligados, é previsto que a sua aplicação nas bandas superiores pode implicar em resultados menos precisos, no caso de níveis pouco ligados. Mesmo assim, estes resultados servem como referências para a localização destes níveis por meio de outro cálculo mais detalhado e mais apropriado para estados ressonantes. 
Os potenciais comumente usados para a descrição de sistemas do tipo $\alpha$-caroço são conhecidos por produzirem uma banda de paridade negativa, a qual tem o seu primeiro nível localizado alguns $\mathrm{MeV}$ acima do nível mais baixo da banda fundamental, e uma banda de paridade positiva excitada que tem o seu início alguns $\mathrm{MeV}$ acima do primeiro nível da banda de paridade negativa. Seguindo estas características, usamos o processo de varredura de energia para estados ligados ou quase-ligados (detalhes no Capítulo 2) na faixa de energia onde a presença destas bandas é esperada. Tomando como referência a posição da banda fundamental em relação ao limiar $\alpha+{ }^{90} \mathrm{Zr}$ (Figura 3.1), consideramos adequado o início da varredura em $E=0$. A busca pelos níveis foi executada com passo $\Delta E=0,01 \mathrm{MeV}$ nos casos $L=0,1,3$ e 5 .

O processo de varredura resultou em quatro auto-valores de energia pertencentes a bandas superiores: $E_{0^{+}}=10,14 \mathrm{MeV}, E_{1^{-}}=5,17 \mathrm{MeV}, E_{3^{-}}=5,66$ $\mathrm{MeV}$ e $E_{5^{-}}=6,45 \mathrm{MeV}$, correspondendo respectivamente aos níveis $0^{+}, 1^{-}, 3^{-}$ e $5^{-}$. A observação do número de nós internos das funções radiais associadas $u(r)$ confirma que os níveis $1^{-}, 3^{-}$e $5^{-}$pertencem à primeira banda de paridade negativa $(G=17)$ e o nível $0^{+}$pertence à segunda banda de paridade positiva $(G=18)$. Apesar das energias mencionadas serem aparentemente bem estabelecidas, elas devem ser confrontadas com cálculos específicos para a determinação de estados ressonantes. Em particular, no estado $0^{+}$, a aproximação de estado ligado não pode ser tratada como satisfatória, pois este nível encontra-se apenas $\approx 1,5 \mathrm{MeV}$ abaixo do topo da barreira de potencial e a largura da mesma barreira na energia calculada é de $\approx 3,3 \mathrm{fm}$. Por outro lado, a energia calculada para o estado $0^{+}$deve ser relativamente próxima daquela que é obtida por um cálculo de ressonância, visto que a aproximação de estado ligado produz uma função correspondente $u(r)$ a qual respeita a característica de uma função radial associada a uma energia de ressonância, isto é, aquela que apresenta um comportamento exponencial decrescente através da barreira de potencial efetivo. Quanto aos níveis $1^{-}, 3^{-}$e $5^{-}$, a aproximação de estado ligado é mais adequada, pois estes níveis encontram-se respectivamente $\approx 6,6 \mathrm{MeV}, 6,8 \mathrm{MeV}$ e 7,3 MeV abaixo do topo da barreira de potencial efetivo, enquanto as larguras da barreira de potencial efetivo nestas energias são respectivamente de $\approx 15,1 \mathrm{fm}, 13,7 \mathrm{fm}$ e 12,0 fm.

\subsubsection{Tratamento para estados ressonantes}

Os resultados preliminares mostram que os estados da banda de paridade negativa e da banda de paridade positiva excitada são do tipo ressonante e, por isto, estas bandas devem ser tratadas por um método que considere tal propriedade. Uma forma de tratamento se baseia na interpretação dos estados destas bandas como ressonâncias produzidas no espalhamento do cluster- $\alpha$ pelo potencial de interação com o núcleo de ${ }^{90} \mathrm{Zr}$. O potencial intercluster $V(r)$ pode ser aplicado de forma coerente nesta situação.

Seguindo esta proposta, foi desenvolvido um processo de determinação de estados ressonantes, o qual também depende da resolução da equação radial para 
o sistema, porém, com adaptações para este caso. Este processo não é igual à varredura de energia usada na procura de estados ligados, mas também se baseia no respeito às condições de contorno e à continuidade da derivada logarítmica de $u(r)$. O método RKF é novamente aplicado com os parâmetros internos (aqueles relacionados apenas com o método numérico) semelhantes aos especificados no cálculo dos estados da banda fundamental. A função $u(r)$ é calculada em duas partes $u_{\mathrm{I}}(r)$ e $u_{\mathrm{II}}(r)$ associadas às regiões I e II, tal como na resolução da equação radial para estados ligados (detalhes na Seção 2.4), sendo que as duas regiões são delimitadas por um raio $r_{\mathrm{f}}$ localizado na fronteira externa da barreira de potencial efetivo, para uma certa energia $E$.

A condição de contorno em $r \gg 0$ deve caracterizar a superposição de uma onda incidente e outra emergente no processo de espalhamento do cluster- $\alpha$. Esta condição de contorno é baseada na forma assintótica das funções de Coulomb esféricas

$$
u(r) \underset{\rightarrow \infty}{\sim} \sin \left[k r-\gamma \ln (2 k r)-\frac{1}{2} L \pi+\sigma+\delta\right],
$$

onde $\sigma$ é o deslocamento de fase coulombiano, $k=\mu v / \hbar$ é o número de onda associado à massa reduzida do sistema e $\gamma$ é dado por

$$
\gamma=\left(\frac{e^{2}}{4 \pi \varepsilon_{0}}\right) \frac{Z Z_{\mathrm{Zr}}}{\hbar v}
$$

com $v$ sendo a velocidade relativa entre o caroço e o cluster- $\alpha$ no infinito. O deslocamento de fase $\delta$, que é provocado pela presença do potencial nuclear, deve ser calculado numericamente. Assim, a condição inicial do método RKF a ser aplicada na região II (em $\left.r_{0} \gg 0\right)$ será

$$
u_{\mathrm{II}}\left(r_{0}\right)=B \sin \left[k r_{0}-\gamma \ln \left(2 k r_{0}\right)-\frac{1}{2} L \pi+\sigma+\delta\right],
$$

onde $B$ é um coeficiente a ser calculado para que seja mantida a continuidade da solução completa $u(r)$ no raio $r_{\mathrm{f}}$. A condição inicial $u_{\mathrm{I}}\left(r_{0}\right)$ aplicada na região I (em $r_{0}=0$ ou próximo de 0 ) é a mesma indicada na eq. (2.6), visto que a função $u(r)$ se comporta de forma similar às funções radiais de estados ligados quanto à região interna do poço atrativo e nas proximidades da origem.

A continuidade da derivada logarítmica de $u(r)$ em $r_{\mathrm{f}}$ depende não somente da energia $E$, mas também do deslocamento de fase $\delta$. Para um certo valor de $E$, haverá um valor de $\delta$ correspondente que satisfaz tal continuidade, surgindo então uma função $\delta(E)$ que respeita a condição de existência de $u(r)$. Com isto, a energia de ressonância $E$ é definida como aquela onde $\delta(E)=(\pi / 2+n \pi)$, isto é, a energia onde $\delta$ passa por $(\pi / 2+n \pi)$, sendo $n$ um número inteiro. O cálculo da função $\delta(E)$ é feito através da resolução da equação radial repetidas vezes com a variação dos parâmetros $\delta$ e $E$, visando sempre a identificação de combinações $(\delta, E)$ que respeitem a condição $(2.10)$. 
O cálculo de $\delta$ é influenciado pela escolha do raio $r_{0}$ onde é aplicada a condição inicial (4.2). Levando em conta que o potencial nuclear é praticamente inexistente em $r \gg 0$, assumimos que (4.2) deve ser aplicado num raio $r_{0}$ o qual satisfaz a desigualdade

$$
k r_{0} \gg L(L+1)+\gamma^{2}
$$

de acordo com a condição de validade da forma assintótica das funções de Coulomb esféricas sem a presença de interações de curto alcance [21]. A condição (4.3) foi empregada com a seguinte adaptação:

$$
r_{0}=\frac{c\left[L(L+1)+\gamma^{2}\right]}{k}, \quad \text { onde } c=60 .
$$

Verifica-se que a variação de $c$ pode alterar o valor de $\delta$, porém, de forma pouco significativa. Por exemplo, foi constatado que $\delta$ sofre uma diminuição inferior a 0,02 rad quando $c$ é aumentado de 20 para 60. Após os testes mencionados, decidiu-se pelo uso de $c=60 \mathrm{em}$ (4.4), pois tal escolha resulta em valores de $\delta$ que se tornam praticamente nulos para energias afastadas da ressonância e próximas do limiar $\alpha+{ }^{90} \mathrm{Zr}$, onde a barreira coulombiana é predominante no processo de espalhamento. Nestas condições, o valor de $r_{0}$ situa-se na ordem de $10^{3} \mathrm{fm} \mathrm{em}$ energias próximas do topo da barreira de potencial efetivo, e alcança a ordem de $10^{6} \mathrm{fm}$ para a menor energia usada $(0,2 \mathrm{MeV})$ no cálculo de $\delta$.

Para energias afastadas de $E$, a busca pelas combinações $(\delta, E)$ que satisfazem a (2.10) foi executada com passo de energia $\Delta E=0,4 \mathrm{MeV}$ e passo angular $\Delta \delta=0,02 \mathrm{rad}$. Nas proximidades da ressonância, onde a função $\delta(E)$ tem um aumento abrupto de $\pi$ (nos casos onde as energias $E$ são próximas da altura máxima da barreira efetiva, o aumento pode ser inferior a $\pi$ ), o passo $\Delta E$ deve ser reduzido em ordens de grandeza para a identificação do ponto de ressonância $\delta(E)=(\pi / 2+n \pi)$. Os níveis de energia obtidos com a aproximação de estado ligado (ver subseção anterior) tornam-se úteis na determinação das funções $\delta(E)$, pois estes valores preliminares são usados para a localização dos intervalos de energia onde se encontram as energias $E$. Com isto, temos previamente o conhecimento dos intervalos onde o passo $\Delta E$ necessita ser reduzido para a determinação mais precisa da função $\delta(E)$ nas proximidades da ressonância.

As funções $\delta(E)$ obtidas para $L=0,1,3$ e 5 encontram-se no Apêndice C. As propriedades relacionadas com estas funções são discutidas na próxima seção. O processo para o cálculo de $\delta(E)$ também permite a determinação da função radial $u(r)$ associada a uma certa energia acima do limiar $\alpha+{ }^{90} \mathrm{Zr}$. As Figuras 4.1 e 4.2 mostram duas funções radiais associadas às energias de ressonância $E$ encontradas respectivamente nos casos $L=0$ e 1 . As duas funções apresentam o comportamento esperado para estados ressonantes onde a amplitude dentro do poço atrativo é maior do que a amplitude além da barreira de potencial efetivo. Assim, demonstra-se que o processo de determinação das energias $E$ através das funções $\delta(E)$ é coerente com o comportamento das funções radiais em tais energias. Ao contrário da situação de ressonância, a Figura 4.3 mostra a função 
$u(r)$ associada a uma energia $\approx 5 \mathrm{MeV}$ abaixo de $E$ no caso $L=0$. Observamos nesta figura que a maior amplitude encontra-se além da barreira de potencial efetivo, enquanto a amplitude dentro do poço atrativo é várias ordens de grandeza menor. Tal comportamento é esperado em energias afastadas de $E$, onde a onda incidente praticamente não penetra na região interna.

\subsection{Propriedades dos níveis ressonantes calculados}

Os dados experimentais disponíveis sobre o espectro do ${ }^{94}$ Mo não mostram níveis de energia que possam ser identificados como pertencentes a bandas superiores do sistema $\alpha^{-90} \mathrm{Zr}$. Por isto, os poucos níveis calculados para estas bandas e suas respectivas propriedades devem ser interpretados como referências teóricas.

O procedimento descrito na Seção 4.1 resultou em algumas das energias de ressonância pertencentes às bandas $G=17$ e $G=18$ (Figura 4.4). Os níveis $8^{+}$ e $10^{+}$da banda do estado fundamental também podem ser considerados estados ressonantes, visto que localizam-se acima do limiar $\alpha+{ }^{90} \mathrm{Zr}$. Entretanto, como já foi mencionado no Capítulo 2, a aproximação de estado ligado para estes níveis é bastante adequada, de modo que o procedimento para o cálculo de energias de ressonância não foi usado para a banda $G=16$. Verifica-se que o primeiro nível $1^{-}$da banda de paridade negativa localiza-se $\approx 7 \mathrm{MeV}$ acima do estado fundamental teórico (o nível teórico $0^{+}$da banda do estado fundamental). O primeiro nível $0^{+}$da banda de paridade positiva excitada está situado próximo da

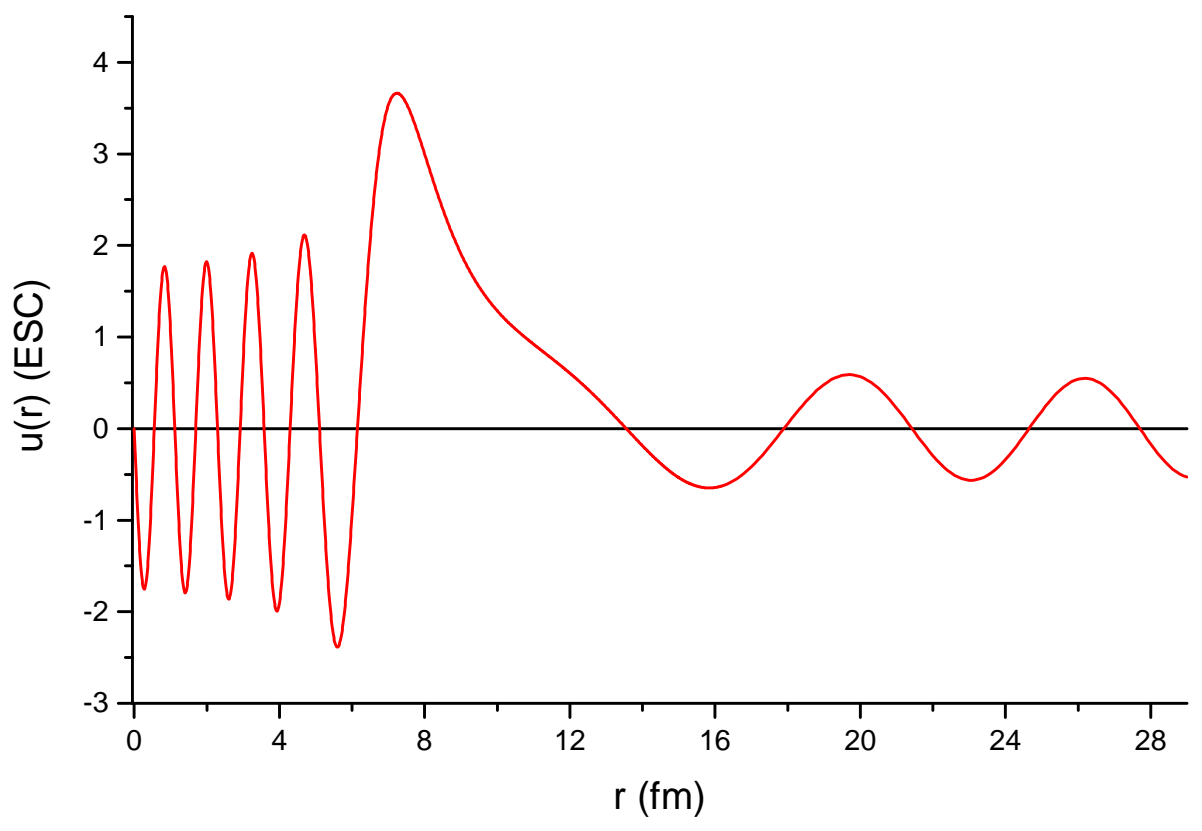

Figura 4.1: Função radial $u(r)$ associada à ressonância no estado $0^{+}$da banda de paridade positiva excitada $(G=18)$. A escala ESC é arbitrária. 


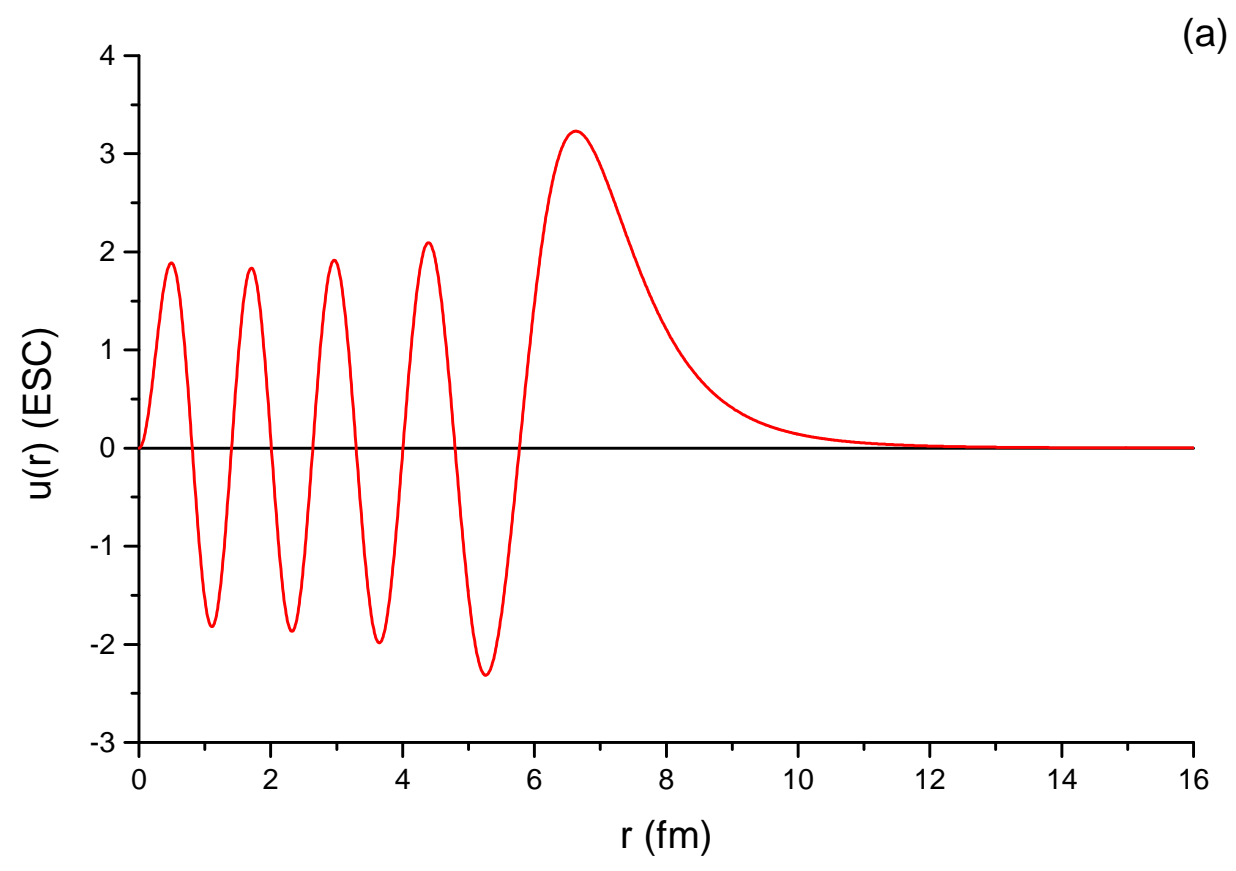

a)

(b)

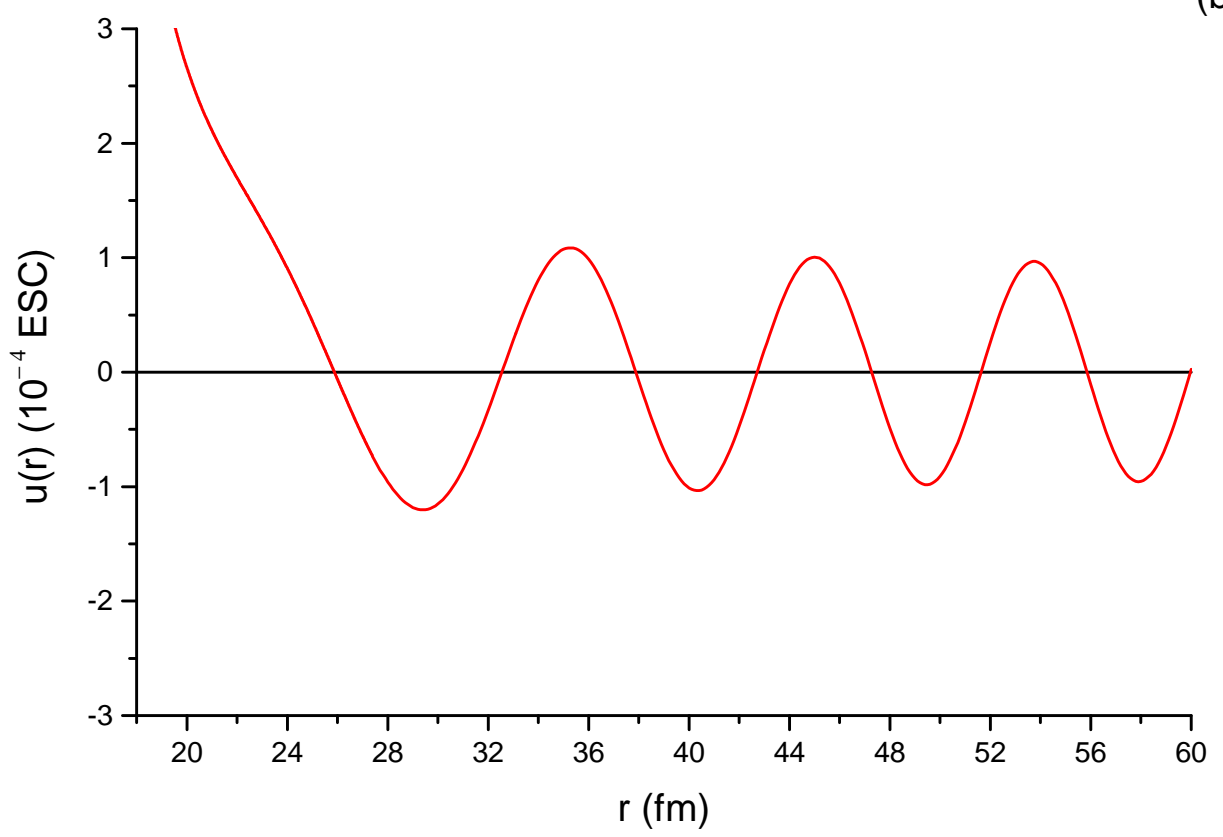

Figura 4.2: Função radial $u(r)$ associada à ressonância no estado $1^{-}$da banda de paridade negativa $(G=17)$. O gráfico (a) destaca o trecho de $u(r)$ dentro do poço atrativo e através da barreira efetiva, enquanto o gráfico (b) coloca em evidência a mesma função na região além da barreira. Os dois gráficos se relacionam por uma escala ESC arbitrária. 
(a)

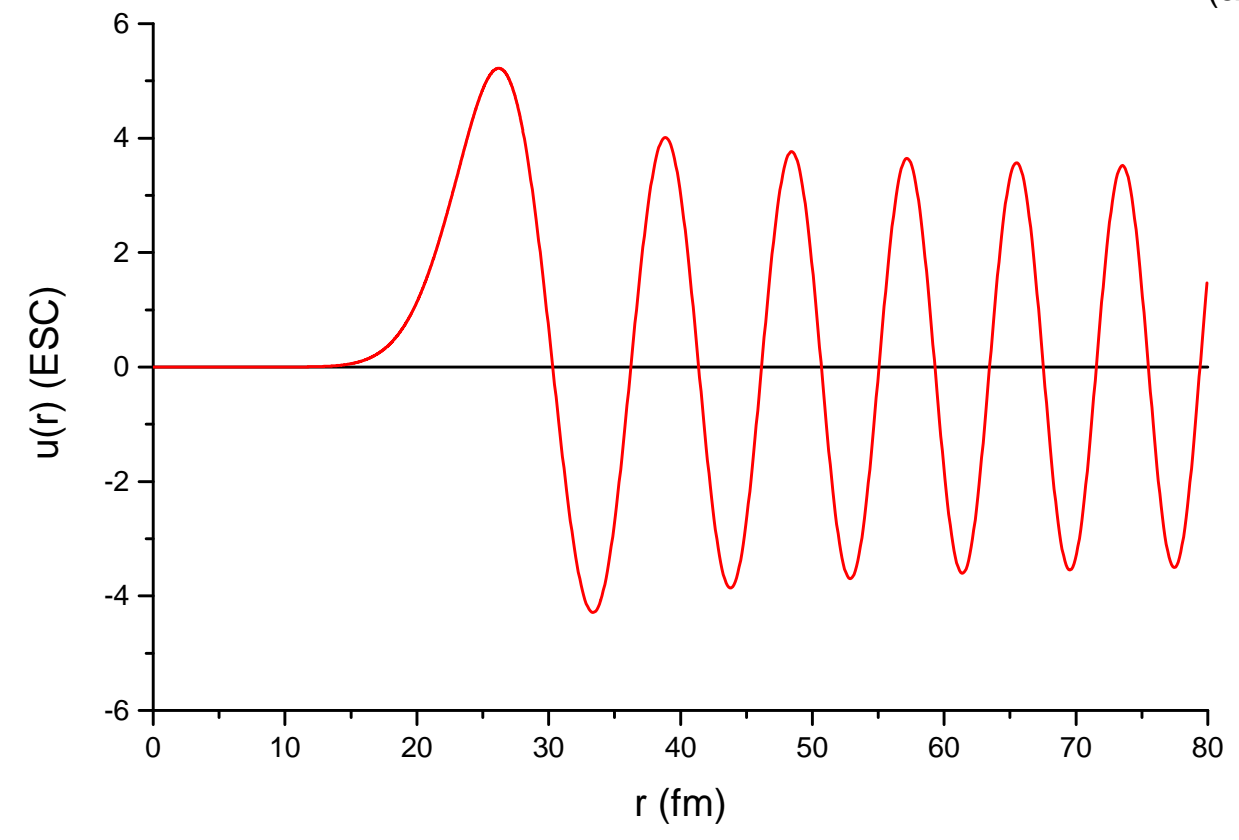

(b)

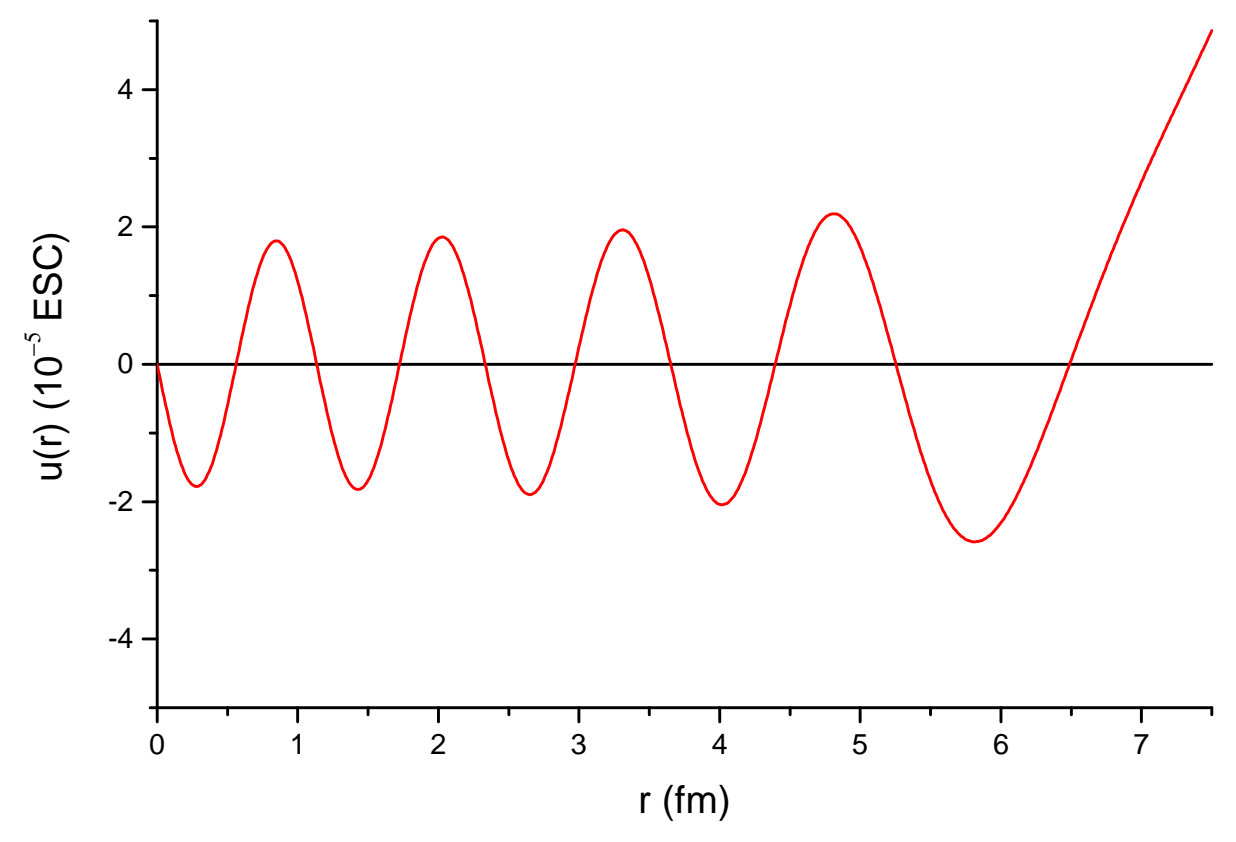

Figura 4.3: Função radial $u(r)$ associada a uma energia afastada da ressonância $(E=5 \mathrm{MeV})$ para $L=0$. O gráfico (a) mostra o comportamento de $u(r)$ dentro e fora do poço atrativo, incluindo a região além da barreira de potencial. O gráfico (b) coloca em evidência o trecho dentro do poço atrativo. Os dois gráficos se relacionam por uma escala ESC arbitrária. 


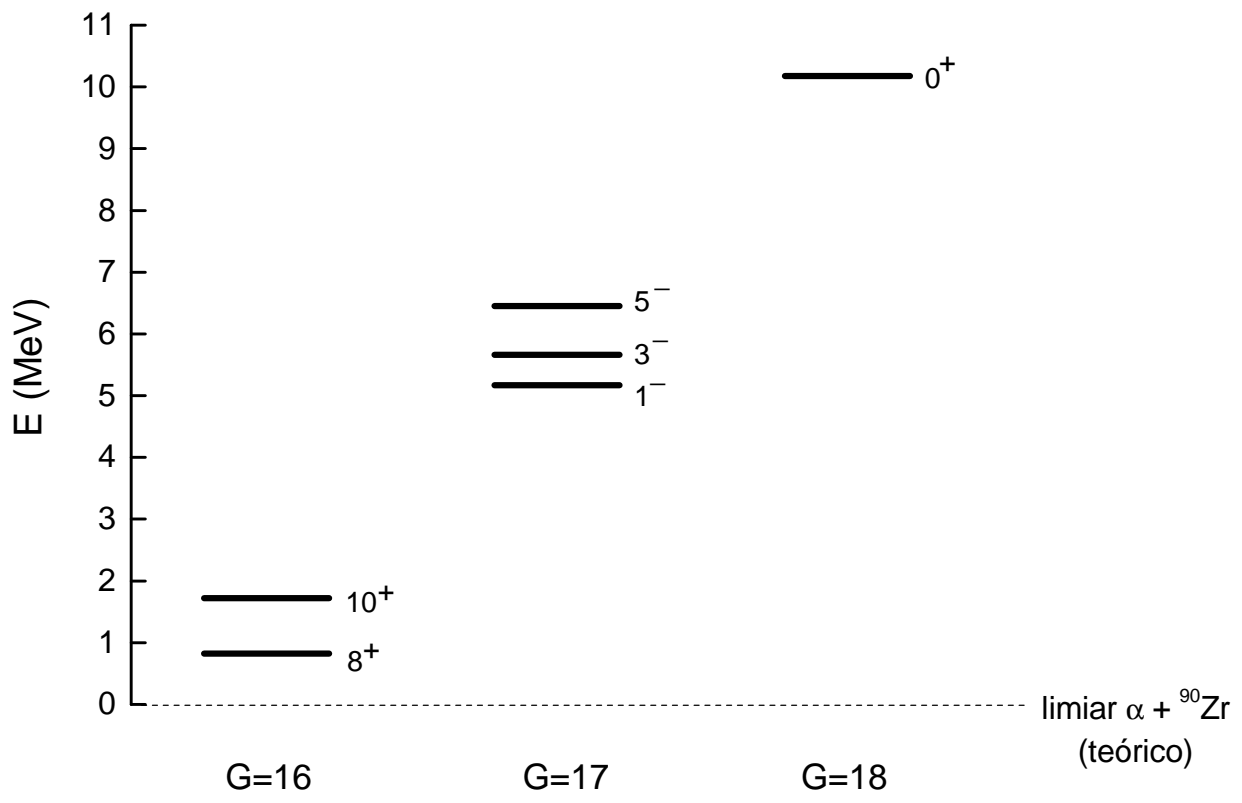

Figura 4.4: Níveis de energia calculados para alguns estados ressonantes do sistema $\alpha_{-}{ }^{90} \mathrm{Zr}$. O número da banda $G$ é indicado.

altura máxima da barreira de potencial $(\approx 1,5 \mathrm{MeV}$ abaixo do topo da barreira) e $\approx 12 \mathrm{MeV}$ acima do estado fundamental teórico. Estes resultados são compatíveis com cálculos de Ohkubo [4] executados com o modelo double folding para o mesmo sistema. Levando em conta os espectros teóricos produzidos por outros cálculos de estrutura de cluster- $\alpha$, é prevista a existência de níveis consecutivos de maior spin e paridade negativa logo acima do nível calculado $5^{-}$, constituindo a banda $G=17$. Da mesma forma, níveis de maior spin com paridade positiva são previstos logo acima do nível calculado $0^{+}$, constituindo a banda $G=18$.

As energias de ressonância calculadas encontram-se numericamente na Tabela 4.1. Comparando os cálculos preliminares da Subseção 4.1.1 e o tratamento específico para estados ressonantes da Subseção 4.1.2, constatamos que as autoenergias resultantes da aproximação de estado ligado reproduzem de forma muito satisfatória os valores obtidos para as energias $E$ da banda $G=17$, levando-se em conta a precisão de centésimo de $\mathrm{MeV}$ da Tabela 4.1. No caso do nível $0^{+}$da banda $G=18$, há uma diferença de $0,04 \mathrm{MeV}$ entre a energia $E$ e a respectiva auto-energia resultante da aproximação de estado ligado, sendo este um resultado ainda satisfatório, visto que a aproximação de estado ligado na banda $G=18$ serve apenas como um guia para a localização da vizinhança da ressonância. A eficácia desta aproximação na banda $G=17$ também é notada no comportamento das funções $u(r)$ dos estados de paridade negativa (ver Figura 4.2), onde a amplitude além da barreira efetiva é várias ordens de grandeza menor do que a amplitude dentro do poço atrativo.

O conhecimento das funções $\delta(E)$ também permite o cálculo das larguras- $\alpha$ totais associadas aos níveis ressonantes. A largura $\Gamma$ é extraída da função $\delta(E)$ por meio de $[22,3]$ 
Tabela 4.1: Níveis de energia teóricos e respectivas larguras- $\alpha$ totais para alguns estados de bandas superiores do sistema $\alpha^{-}{ }^{90} \mathrm{Zr}$. O grau de precisão em cada largura é definido a partir do erro previsto no cálculo numérico de $d \delta_{L} / d E$ em $E_{R}$.

\begin{tabular}{cccc}
\hline \hline & & $E$ & $\Gamma$ \\
$J$ & $G$ & $(\mathrm{MeV})$ & $\left(10^{-3} \mathrm{eV}\right)$ \\
\hline $1^{-}$ & 17 & 5,17 & 3,1 \\
$3^{-}$ & 17 & 5,66 & 13,3 \\
$5^{-}$ & 17 & 6,45 & 53 \\
$0^{+}$ & 18 & 10,18 & $8,7 \times 10^{7}$ \\
\hline \hline
\end{tabular}

$$
\Gamma=\frac{2}{\left.(d \delta / d E)\right|_{{ }_{R}}} .
$$

A determinação da derivada $d \delta / d E$ nas energias $E$ resultou nas larguras mostradas na Tabela 4.1. As larguras muito pequenas encontradas nos primeiros níveis da banda de paridade negativa (entre as ordens de $10^{-3}$ e $10^{-2} \mathrm{eV}$ ) confirmam que tais estados podem ser tratados coerentemente pela aproximação de estado ligado, assim como os níveis $8^{+}$e $10^{+}$da banda $G=16$. Com isso, é sugerida uma equivalência entre a forma adequada para o tratamento da banda $G=17$ e o tratamento dado por Michel, Reidemeister e Ohkubo $[2,3]$ para a banda de paridade negativa do sistema $\alpha^{-}{ }^{40} \mathrm{Ca}$. A proximidade entre o nível $0^{+}$da banda $G=18$ e o topo da barreira efetiva resulta numa largura- $\alpha$ muito maior $(87 \mathrm{keV})$ para o estado mencionado, indicando que os níveis desta banda devem apresentar uma característica típica de ressonância.

O comportamento peculiar das funções $\delta(E)$ na vizinhança de $E$ nos motiva a fazer uma comparação com fórmulas usadas comumente para a descrição de ressonâncias. Verifica-se que as funções calculadas $\delta(E)$ apresentam boa concordância com a fórmula

$$
\delta(E)=-\arctan \left[\frac{\Gamma}{2(E-E)}\right]
$$

nas vizinhanças das ressonâncias, sendo $\Gamma$ a largura- $\alpha$ total para um certo $L$. A equação (4.6) surge diretamente da fórmula de Breit-Wigner sem a presença do termo de fundo. No Apêndice C, é feita uma comparação entre as funções calculadas $\delta(E)$ e os gráficos previstos pela eq. (4.6) aplicando-se as larguras- $\alpha$ e energias $E$ mencionadas na Tabela 4.1. Os pontos calculados numericamente encontram-se sempre próximos das curvas teóricas, considerando as vizinhanças das ressonâncias dos níveis $1^{-}, 3^{-}$e $5^{-}$, sendo que o módulo da diferença entre os pontos e as curvas não ultrapassa poucos centésimos de rad. Na maioria dos pontos pertencentes ao intervalo aproximado $\pi / 6<\delta<5 \pi / 6$, tal diferença é 
menor ou pouco maior que o erro $(\Delta \delta) / 2$ estimado para os pontos calculados, sendo $\Delta \delta=0,02 \mathrm{rad}$ o passo angular mencionado na Subseção 4.1.2. Quanto à ressonância no estado $0^{+}$da banda $G=18$ (Figura C.1), observa-se o mesmo comportamento registrado nos estados de paridade negativa, com excessão dos pontos calculados acima de $\approx 5 \pi / 6$, onde há um desvio em relação à curva teórica que torna-se significativo para as energias mais afastadas de $E$. Sabe-se que a eq. (4.6) descreve satisfatoriamente apenas as ressonâncias onde as larguras são estreitas e não dependentes da energia (ou fracamente dependentes de $E$ ); como a ressonância no estado $0^{+}$já não é suficientemente estreita e está localizada logo abaixo do topo da barreira de potencial, o desvio ocorrido neste caso é previsível. O comportamento decrescente da função calculada $\delta_{0}(E)$ em energias acima da ressonância de $0^{+}$é uma indicação da impossibilidade do surgimento de outras ressonâncias em energias mais altas com $L=0 .{ }^{1}$

O fato das funções calculadas $\delta_{3}(E)$ e $\delta_{5}(E)$ passarem por $3 \pi / 2$ indica a existência de outras ressonâncias pertencentes a uma banda de paridade negativa excitada correspondendo a $G=19$. Contudo, estas ressonâncias estão localizadas acima da barreira efetiva e, por conseqüência, tornam-se muito largas e sobrepostas. Apesar da eq. (4.5) não ser adequada para ressonâncias muito largas e assimétricas como as observadas na banda $G=19$, usamos a fórmula mencionada para uma estimativa da ordem de grandeza das larguras associadas, resultando em valores da ordem de $10 \mathrm{MeV}$. Tais resultados sugerem que a banda $G=19$ deve apresentar um comportamento no qual suas ressonâncias já não podem ser tratadas individualmente no processo de espalhamento do cluster- $\alpha$.

\footnotetext{
${ }^{1}$ Como exemplo, este tipo de comportamento pode ser notado mais claramente através da Ref. [3], onde são mostradas as funções $\delta_{L}(E)$ do sistema $\alpha-{ }^{40} \mathrm{Ca}$.
} 


\section{Conclusões e perspectivas}

Foi mostrado neste trabalho que o modelo de cluster- $\alpha$, o qual já demonstrou eficiência na reprodução de dados espectroscópicos em núcleos leves, pode ser estendido para o ${ }^{94} \mathrm{Mo}$ da região dos núcleos meio-pesados com uma boa reprodução dos dados experimentais disponíveis. A seguir, são citados os principais resultados obtidos através da análise do sistema $\alpha^{-}{ }^{90} \mathrm{Zr}$ :

- Constatou-se que o potencial intercluster $\alpha{ }^{90} \mathrm{Zr}$ proposto por Buck, Merchant e Perez [5] fornece uma descrição satisfatória dos espaçamentos entre os níveis de energia experimentais da banda do estado fundamental $(G=16)$, levando-se em conta que tal potencial teve os seus parâmetros ajustados para a reprodução de espectros e meias-vidas de decaimento- $\alpha$ em vários núcleos de diferentes regiões de massa e que estes parâmetros não são dependentes da energia de excitação do sistema ou do número quântico $L$. Os níveis de energia calculados neste trabalho são totalmente compatíveis com o espectro teórico da Ref. [5].

- Os raios intercluster rms calculados para a banda do estado fundamental indicam a presença do efeito antistretching, o qual já foi constatado em outros sistemas $\alpha$-caroço $[1,3,4]$ e no próprio sistema $\alpha^{-90} \mathrm{Zr}$ [4] com outras formas de potencial intercluster. A comparação dos raios intercluster rms com a soma dos raios rms experimentais de $\alpha$ e ${ }^{90} \mathrm{Zr}$ demonstra que a banda do estado fundamental possui uma estrutura de cluster- $\alpha$ compacta, o que está de acordo com cálculos de Ohkubo [4]. O valor calculado para o raio intercluster rms do estado fundamental $0^{+}$, em associação com os raios rms experimentais de $\alpha$ e ${ }^{90} \mathrm{Zr}$, demonstra que o potencial intercluster da Ref. [5] apresenta ótima concordância com o raio rms experimental do ${ }^{94} \mathrm{Mo}$.

- As taxas de transição $B(E 2)$ calculadas para a banda do estado fundamental apresentam a mesma ordem de grandeza dos poucos dados experimentais disponíveis e mostram uma concordância semiquantitativa satisfatória, pois não há o uso de cargas efetivas nos cálculos e os parâmetros do potencial intercluster não foram ajustados com referência nas taxas $B(E 2)$ experimentais. Deve-se levar em conta a existência de cálculos detalhados com base no modelo de camadas [20] que resultam em valores de $B(E 2)$ muito distantes dos respectivos dados experimentais referentes ao ${ }^{94} \mathrm{Mo}$, mesmo com a introdução de altas cargas efetivas. Deste modo, os resultados sugerem que 
a consideração da aglomeração- $\alpha$ no ${ }^{94}$ Mo favorece uma reprodução mais realista das taxas de transição.

- A expansão das funções de onda radiais da banda do estado fundamental na base de oscilador harmônico com parâmetro $\nu=\mu \omega / \hbar$ e $\hbar \omega=41 A^{-13}$ mostra que há um alto grau de superposição entre tais funções e as respectivas funções radiais de oscilador harmônico com mesmo $L$ e número quântico principal $G^{\prime}=16$. Também verificou-se que este nível de superposição aumenta de $89,1 \%$ no estado $0^{+}$para $95,0 \%$ no estado $10^{+}$. Os resultados obtidos através desta expansão e dos raios intercluster rms indicam que a banda do estado fundamental do sistema $\alpha^{-}{ }^{90} \mathrm{Zr}$ apresenta uma condição de aglomeração- $\alpha$ moderada até o estado $10^{+}$. A expansão também sugere que há uma significativa contribuição do modelo de camadas na formação dos estados da banda fundamental, sendo que tal condição já se manifesta no estado $0^{+}$e acentua-se para os níveis de maior spin.

- Os cálculos referentes à banda de paridade negativa $(G=17)$ indicam que a mesma se inicia em $\approx 5 \mathrm{MeV}$ acima do limiar $\alpha+{ }^{90} \mathrm{Zr}$, em compatibilidade com cálculos de Ohkubo [4], e seus três primeiros níveis possuem larguras- $\alpha$ entre as ordens de $10^{-3}$ e $10^{-2} \mathrm{eV}$. O fato de tais larguras serem muito estreitas mostra que estes estados podem ser tratados adequadamente pela aproximação de estado ligado. Assim, é sugerida uma analogia entre o tratamento adequado para a banda $G=17$ e o tratamento dado para a banda de paridade negativa do sistema $\alpha-{ }^{40} \mathrm{Ca}[3]$.

- Os cálculos referentes à banda de paridade positiva excitada $(G=18)$ mostram que a mesma se inicia logo abaixo da altura máxima da barreira de potencial $(\approx 1,5 \mathrm{MeV}$ abaixo do topo da barreira) e $\approx 12 \mathrm{MeV}$ acima do estado fundamental teórico do sistema $\alpha^{-}{ }^{90} \mathrm{Zr}$, em compatibilidade com cálculos de Ohkubo [4]. A largura de $87 \mathrm{keV}$ calculada para o nível $0^{+}$indica que a banda $G=18$ deve apresentar uma característica típica de ressonância.

Portanto, conclui-se que o modelo de cluster- $\alpha$ oferece uma contribuição importante para a interpretação de dados espectroscópicos no ${ }^{94} \mathrm{Mo}$ e sugere a persistência da estrutura de cluster- $\alpha$ na região de $A=90$. Mais conclusões podem ser extraídas deste trabalho com possíveis novos dados experimentais relacionados ao intervalo de energia das bandas superiores $G=17$ e $G=18$.

O prosseguimento deste trabalho ainda pode fornecer previsões sobre estados de maiores spins nas bandas $G=16,17$ e 18 . Outra possibilidade relacionada ao ${ }^{94}$ Mo é o aperfeiçoamento do potencial fenomenológico de interação $\alpha{ }^{-}{ }^{90} \mathrm{Zr}$ por meio de novos ajustes e/ou novos dados experimentais.

Os métodos de cálculo aplicados ao sistema $\alpha_{-}{ }^{90} \mathrm{Zr}$ podem ser adaptados para o estudo de outros sistemas de cluster. Vários trabalhos têm sido publicados sobre este tema, tais como a procura por diferentes estruturas de cluster em núcleos pesados $[8,25]$ e estudos sobre estados do tipo molecular em núcleos leves [23, 24]. 
Com isto, a pesquisa em estruturas de cluster ainda pode ser estendida para a investigação de propriedades espectroscópicas em núcleos de diferentes regiões de massa. Este trabalho serve como uma base para o desenvolvimento de estudos futuros nesta área. 


\section{Apêndice A}

\section{Funções de onda radiais da banda do estado fundamental}

Neste apêndice, são apresentadas graficamente as funções de onda radiais $u \quad(r)$ associadas aos estados da banda fundamental $(G=16)$ do sistema $\alpha^{-}{ }^{90} \mathrm{Zr}$. O conhecimento prévio do número quântico $G$ também permite a caracterização das funções radiais na forma $u \quad(r)$, onde $N$ é o número de nós internos. Os gráficos mostram a comparação entre as funções $u \quad(r)$ (linhas contínuas) e as respectivas funções radiais $u_{1}^{\mathrm{OHE}}(r)$ (linhas pontilhadas) associadas aos auto-estados $\left|G^{\prime}=16, L\right\rangle_{\mathrm{OHE}}$ da base de oscilador harmônico esférico com parâmetro $\nu=\mu \omega / \hbar$ (definição em (3.6)). 


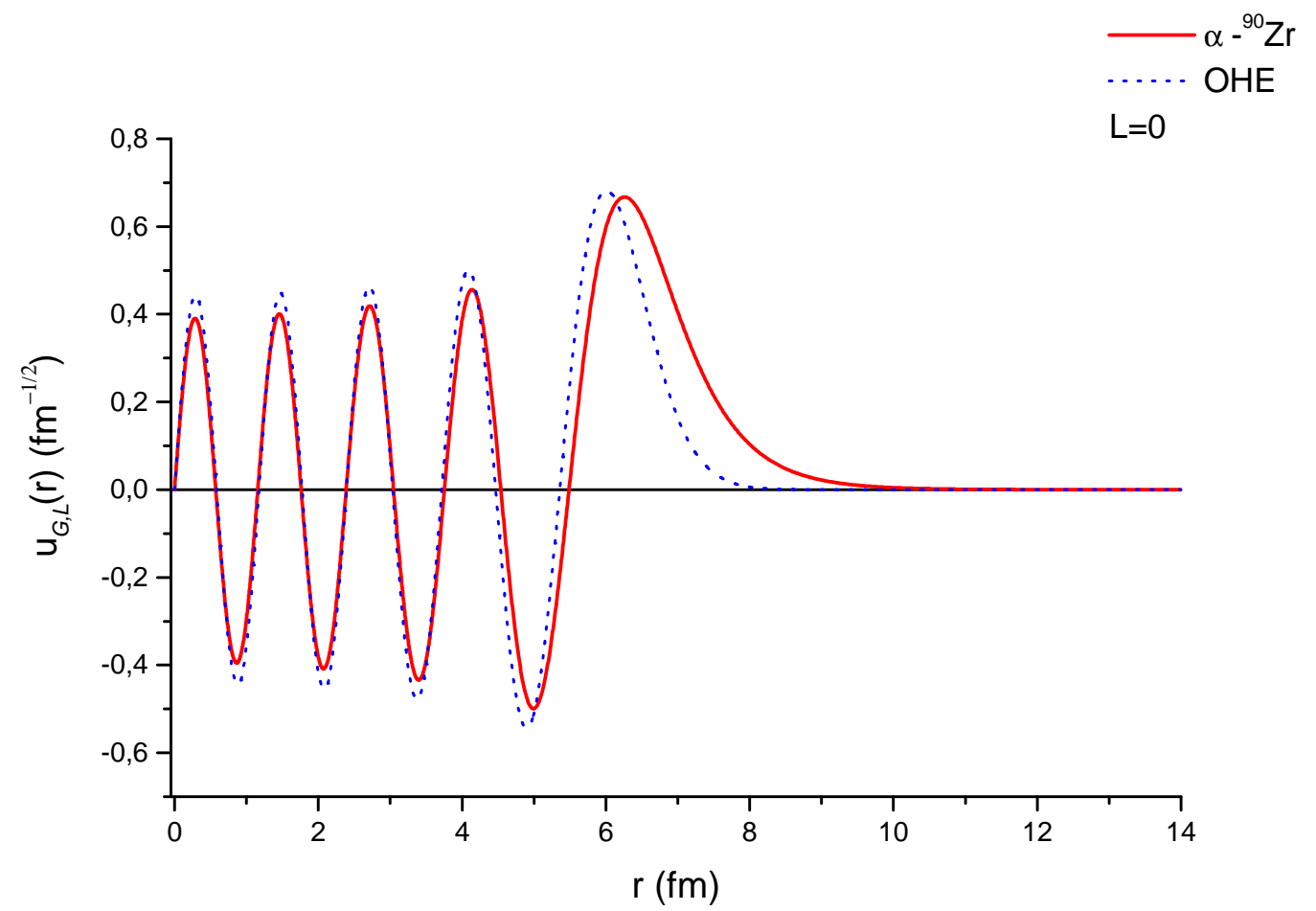

Figura A.1: Função radial $u_{G, L}(r)$ associada ao estado $0^{+}(N=8)$.

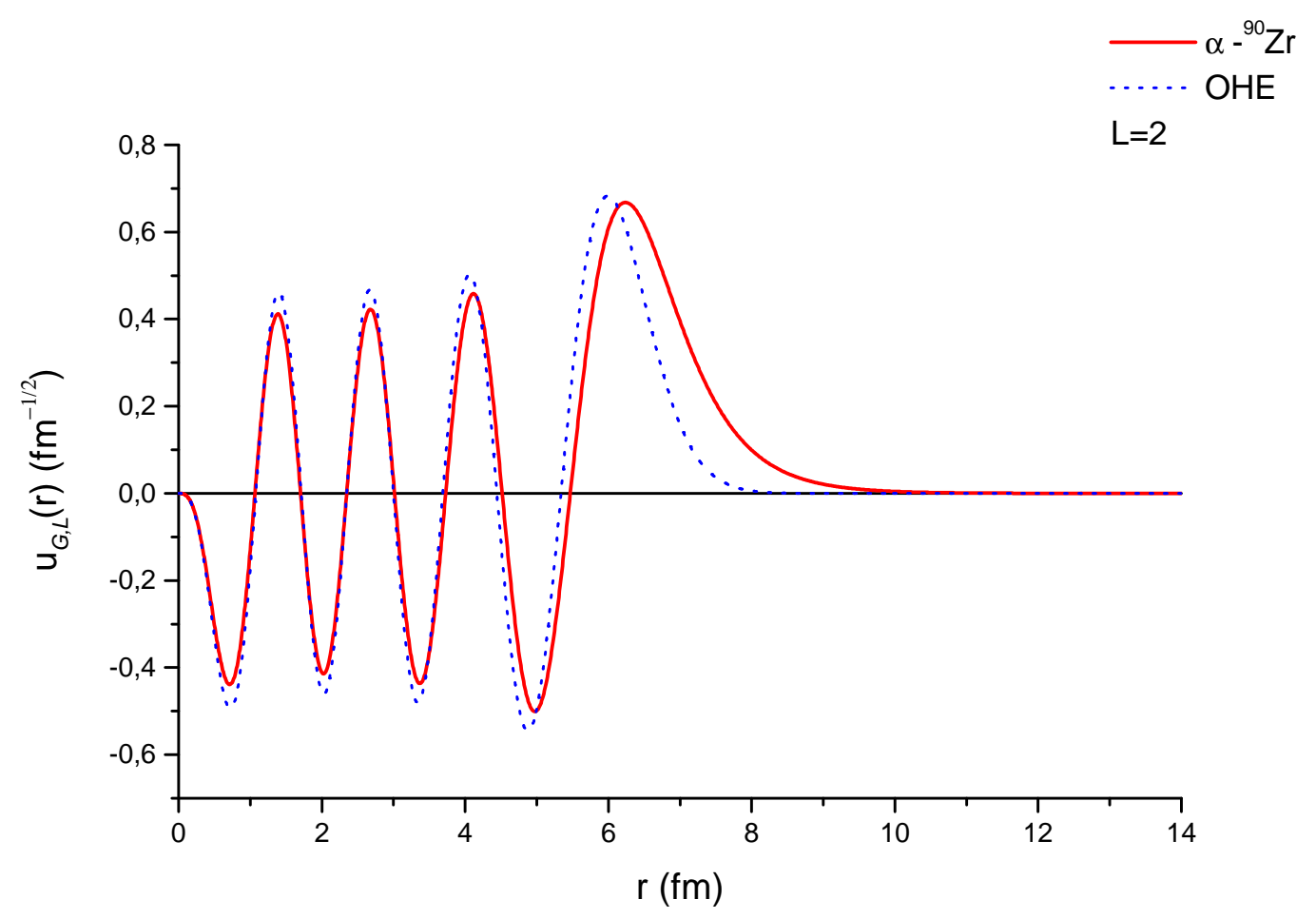

Figura A.2: Função radial $u_{G, L}(r)$ associada ao estado $2^{+}(N=7)$. 


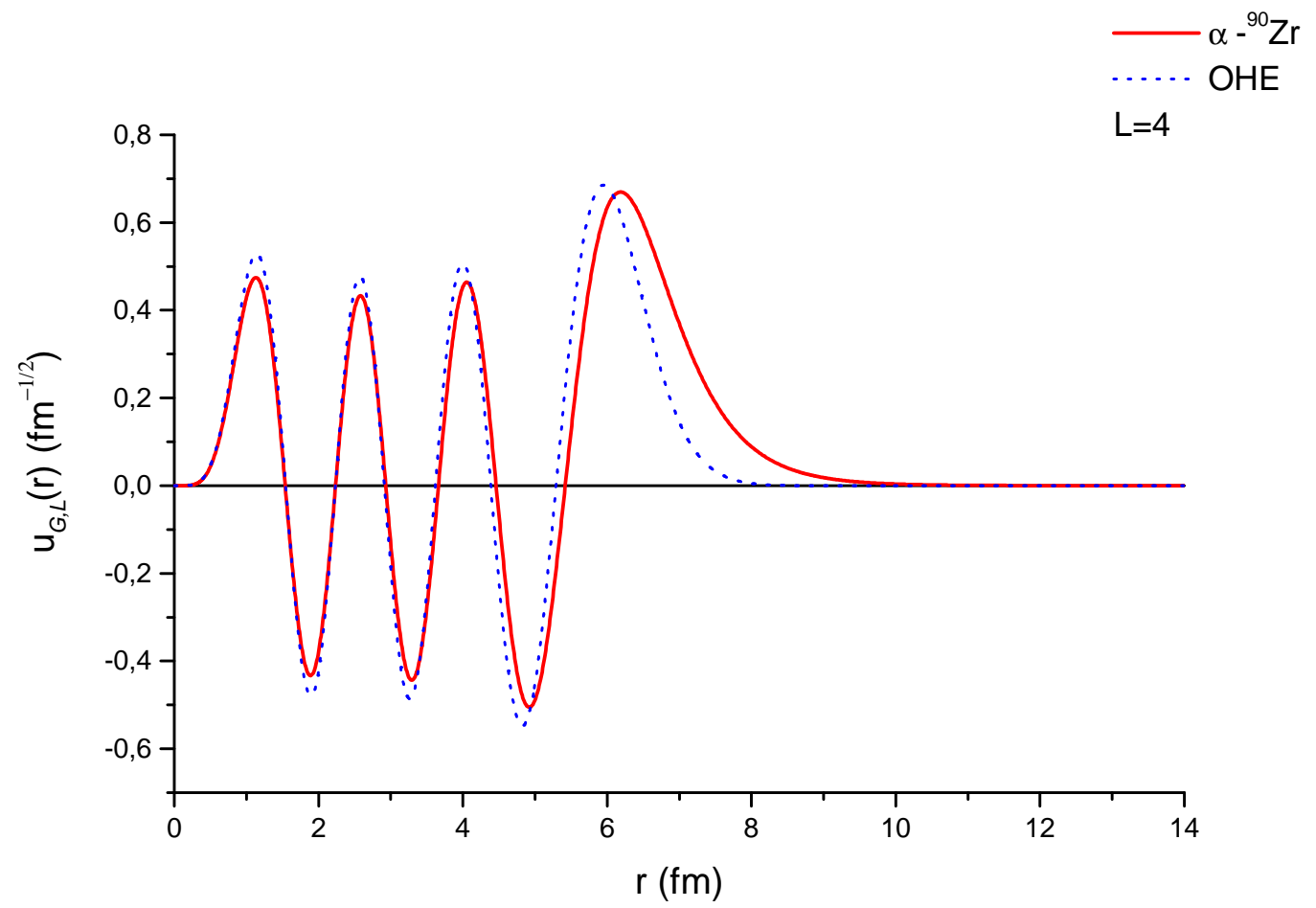

Figura A.3: Função radial $u_{G, L}(r)$ associada ao estado $4^{+}(N=6)$.

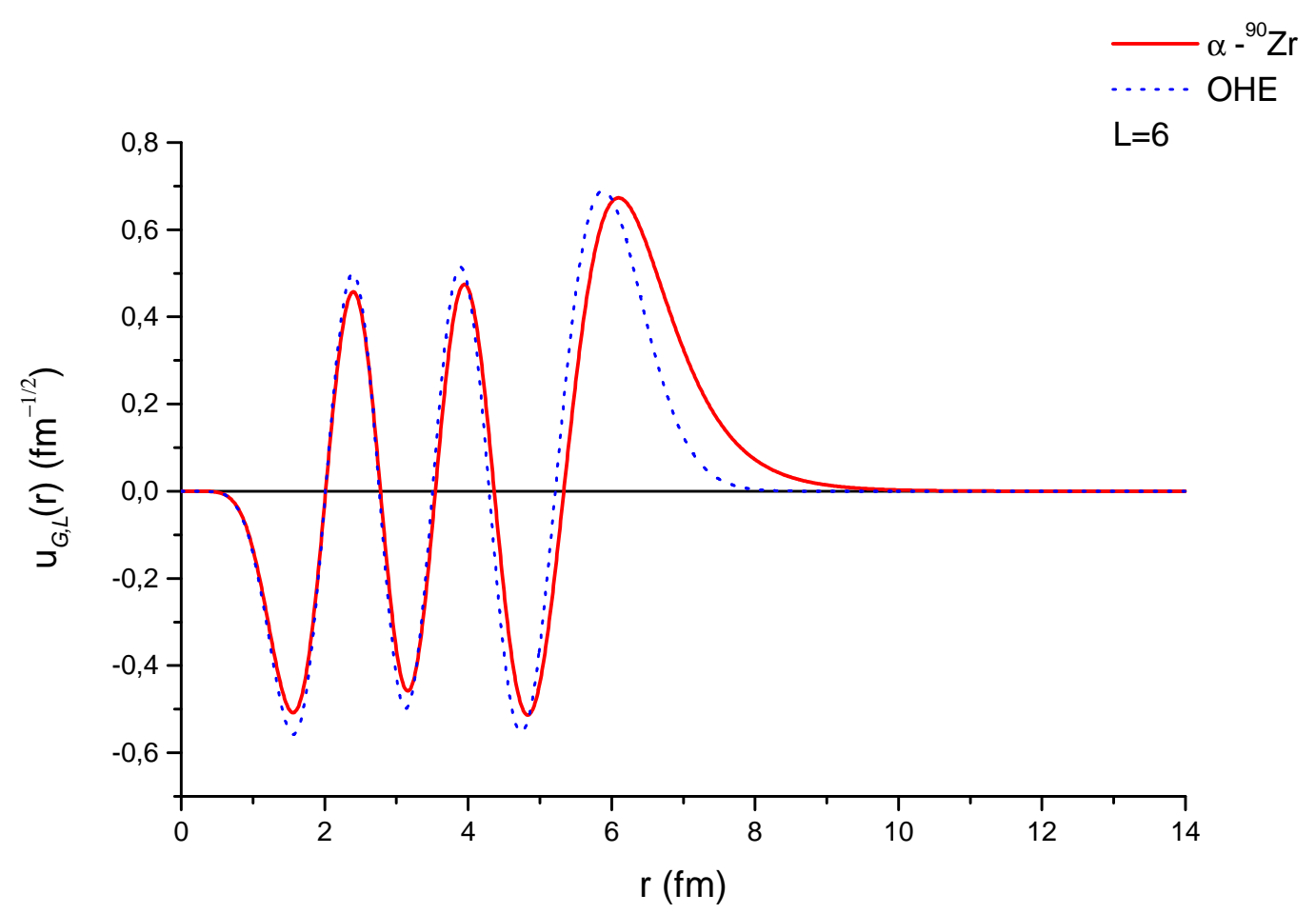

Figura A.4: Função radial $u_{G, L}(r)$ associada ao estado $6^{+}(N=5)$. 


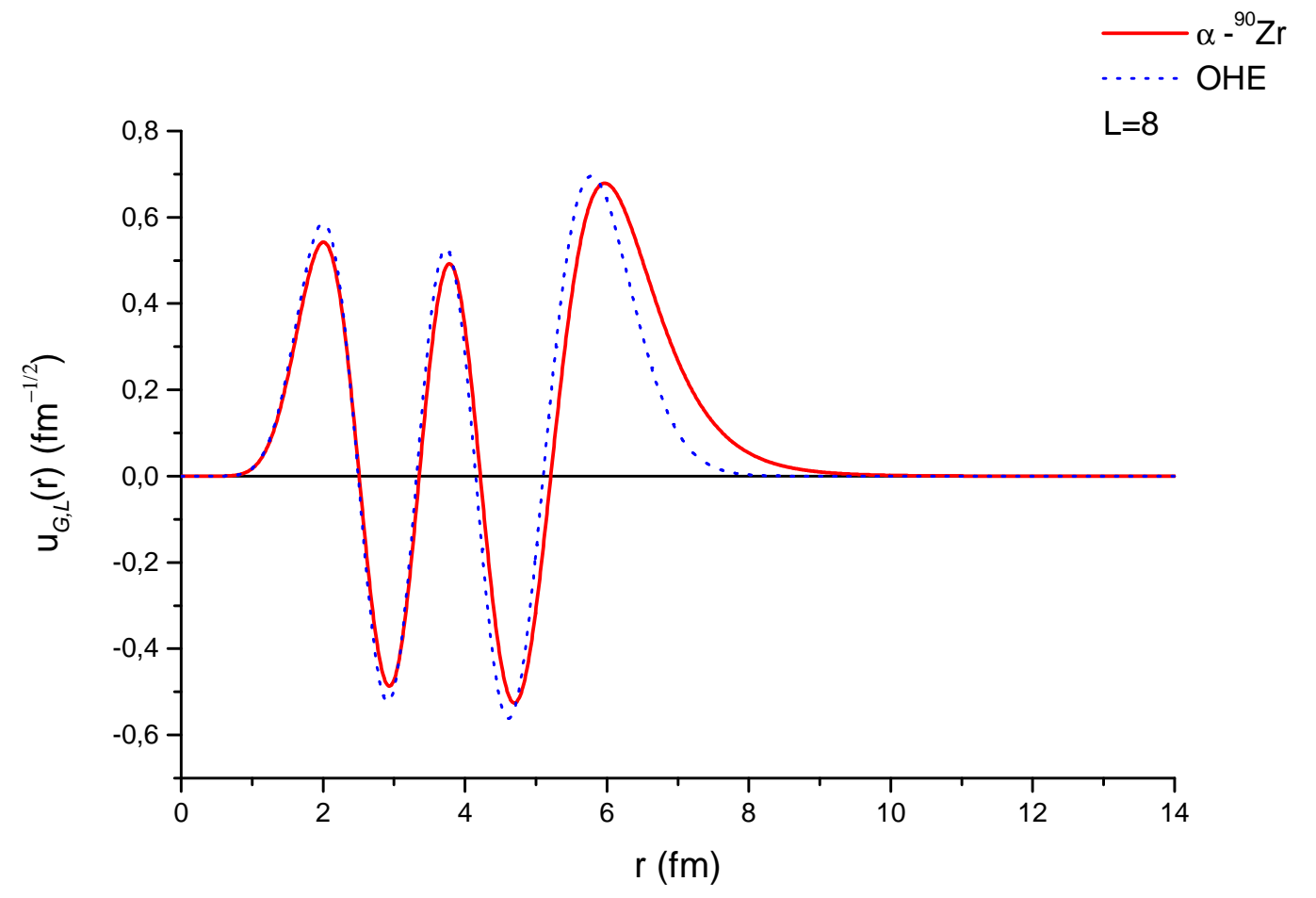

Figura A.5: Função radial $u_{G, L}(r)$ associada ao estado $8^{+}(N=4)$.

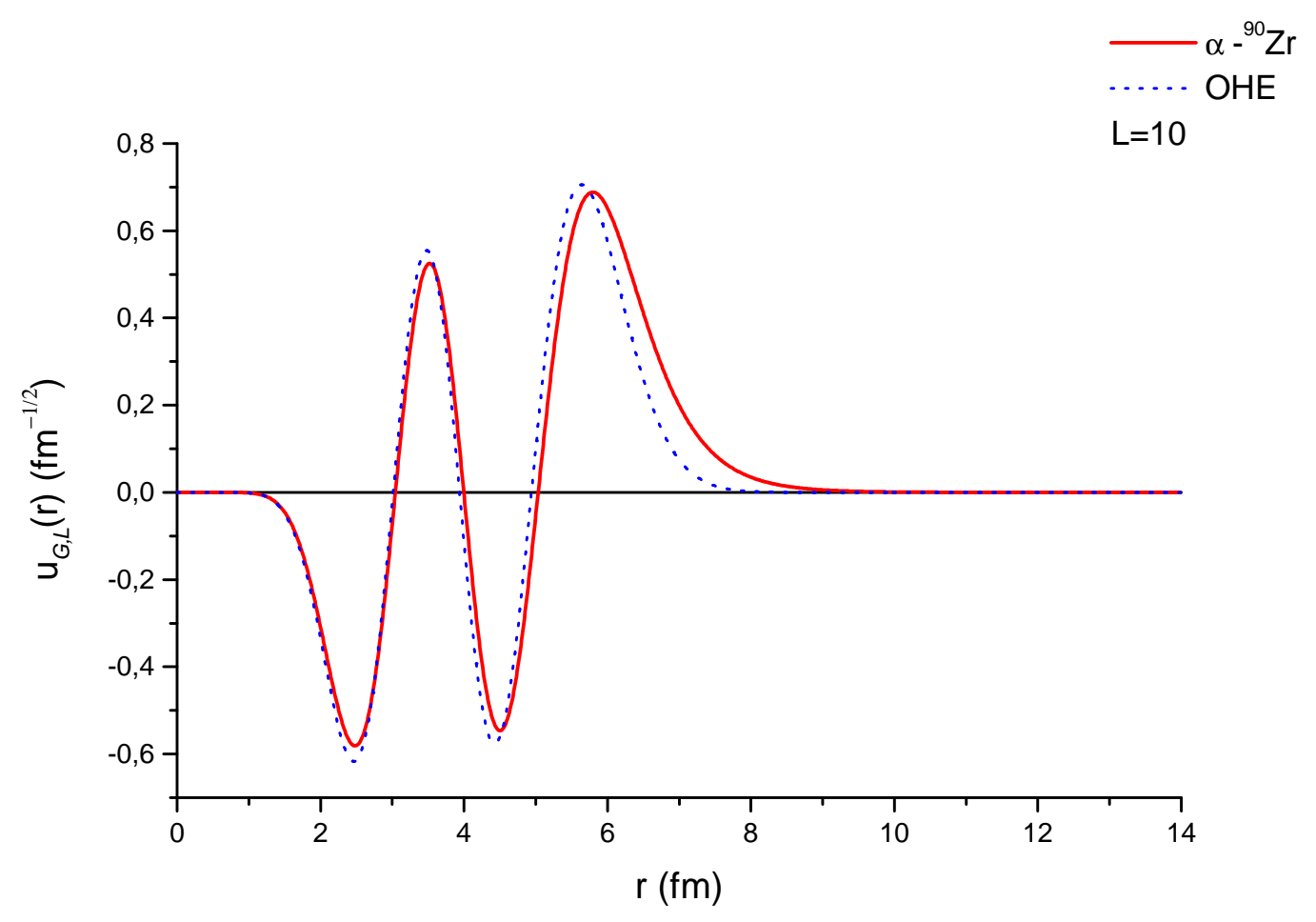

Figura A.6: Função radial $u_{G, L}(r)$ associada ao estado $10^{+}(N=3)$. 


\section{Apêndice B}

\section{Expansão das funções de onda radiais da banda fundamental na base de OHE}

Neste apêndice, são apresentadas as distribuições de probabilidades obtidas pela expansão das funções de onda radiais $u \quad(r)$ da banda do estado fundamental $(G=16)$ na base de oscilador harmônico esférico (OHE) com parâmetro $\nu=\mu \omega / \hbar$ (definição em (3.6)). A altura de cada coluna representa a probabilidade $P\left(G^{\prime}, L\right)$ associada ao auto-estado de oscilador harmônico $\left|G^{\prime}, L\right\rangle_{\mathrm{OHE}}$, sendo $G^{\prime}$ o número quântico principal do OHE. Para cada pico de probabilidade registrado, é colocado o valor numérico de $P\left(G^{\prime}, L\right)$ (em \%) acima da coluna correspondente. 


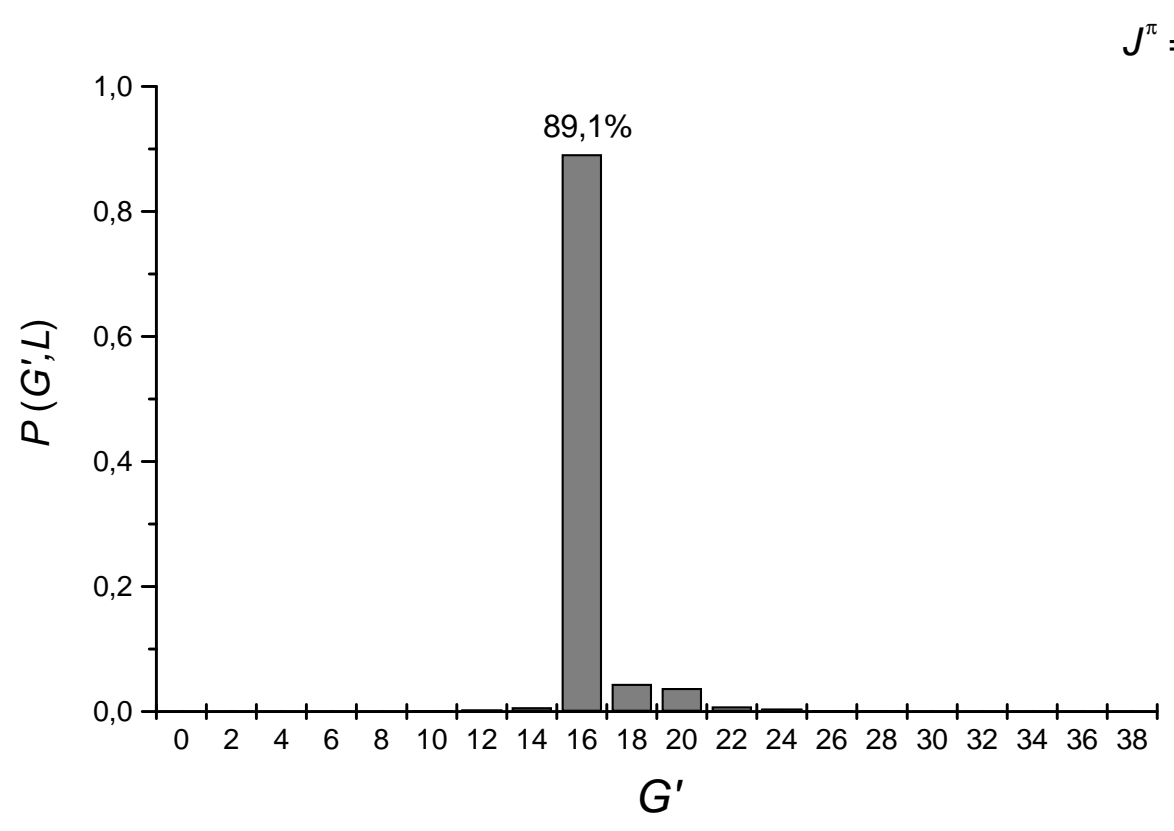

Figura B.1: Expansão da função radial $u_{G, L}(r)$ associada ao estado $0^{+}$.

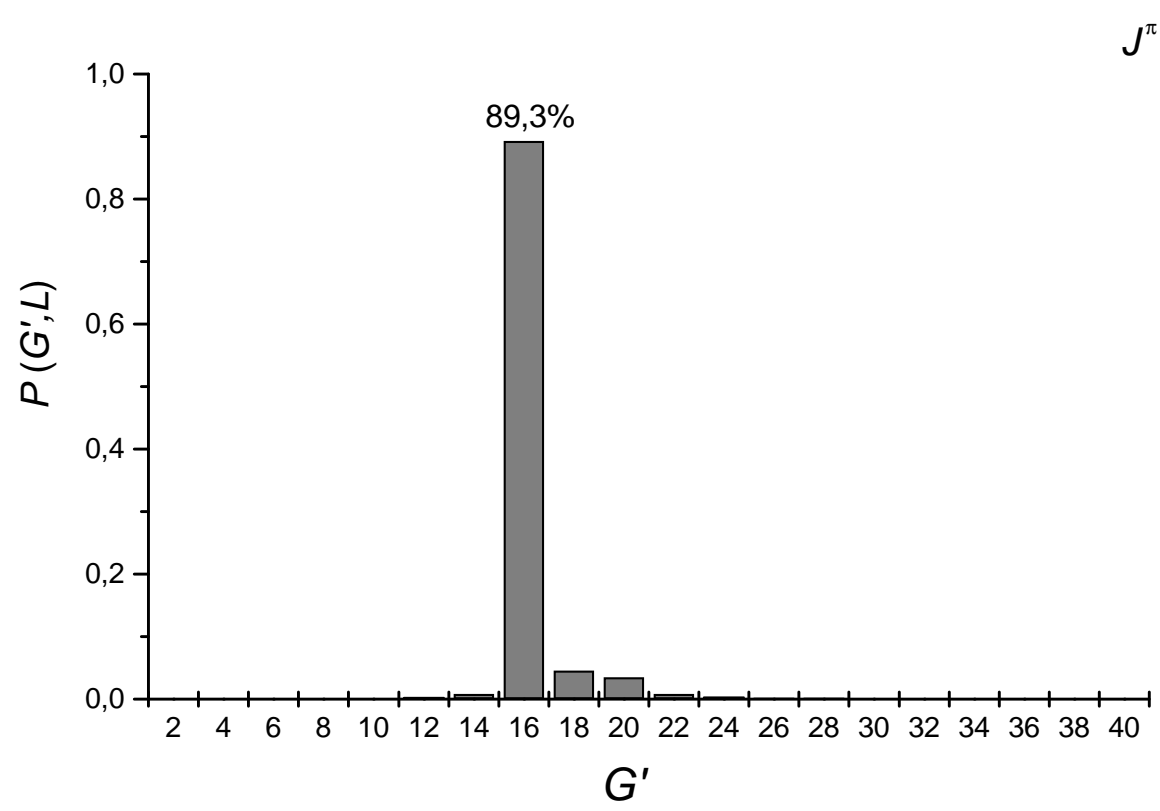

Figura B.2: Expansão da função radial $u_{G, L}(r)$ associada ao estado $2^{+}$. 


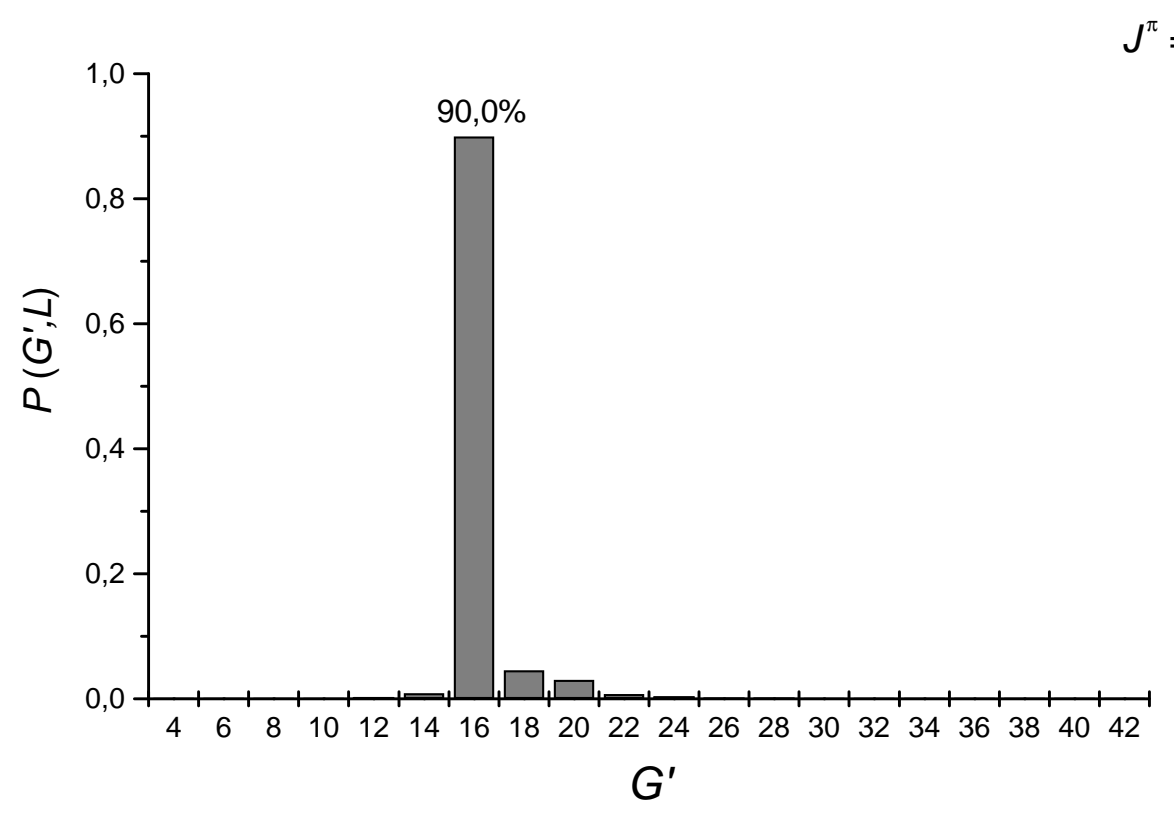

Figura B.3: Expansão da função radial $u_{G, L}(r)$ associada ao estado $4^{+}$.

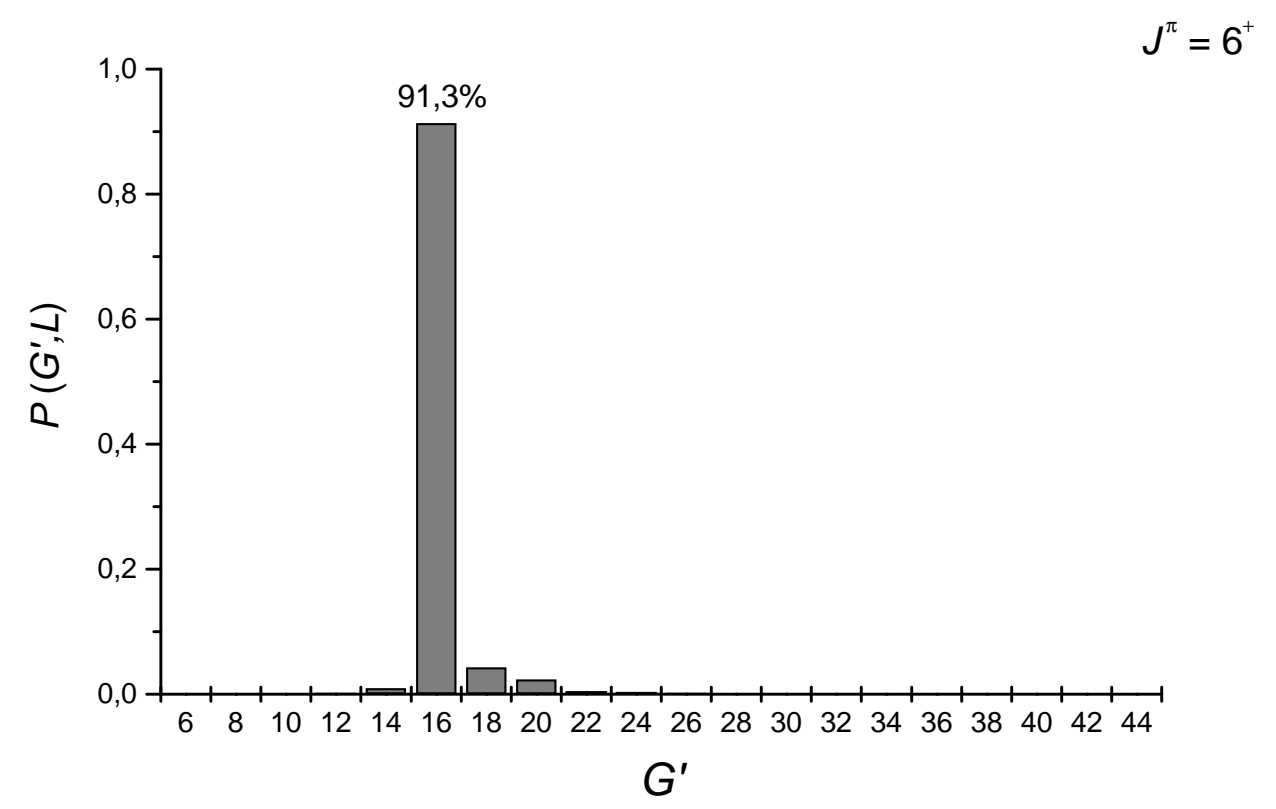

Figura B.4: Expansão da função radial $u_{G, L}(r)$ associada ao estado $6^{+}$. 


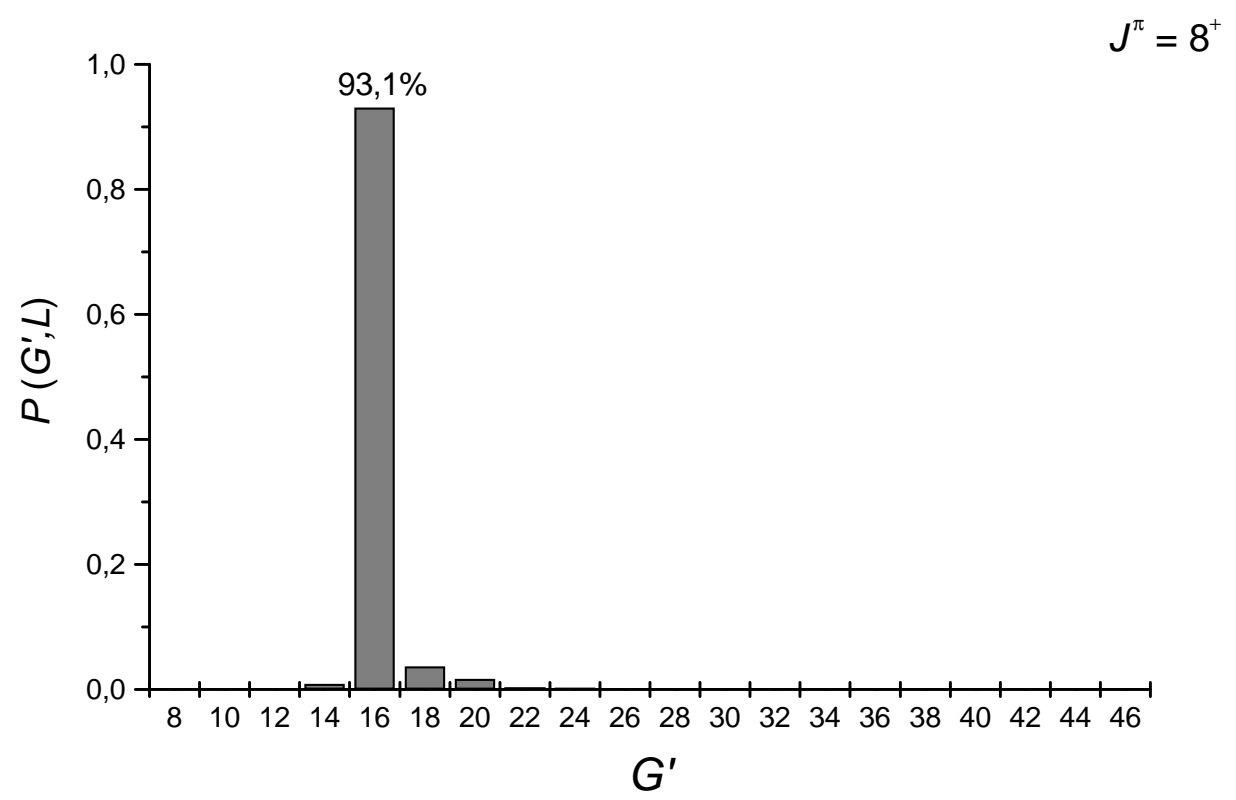

Figura B.5: Expansão da função radial $u_{G, L}(r)$ associada ao estado $8^{+}$.

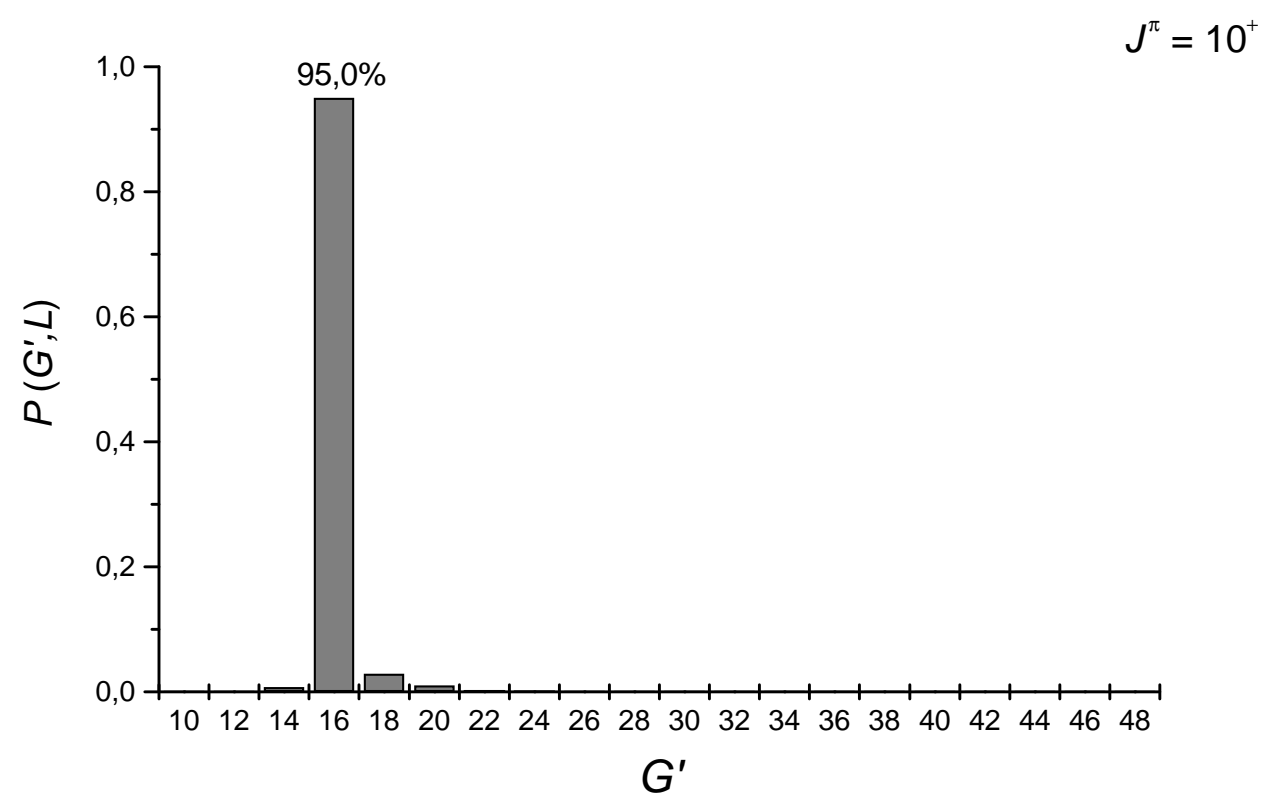

Figura B.6: Expansão da função radial $u_{G, L}(r)$ associada ao estado $10^{+}$. 


\section{Apêndice C}

\section{Funções de deslocamento de fase $\delta_{L}(E)$}

Este apêndice apresenta graficamente as funções de deslocamento de fase $\delta(E)$ obtidas através do método descrito no Capítulo 4 , sendo tratados os casos $L=0$, 1, 3 e 5. Nos gráficos identificados por (a), são mostrados os pontos calculados numericamente no intervalo de 0 a $21 \mathrm{MeV}$ que constituem as funções $\delta(E)$. Em cada gráfico identificado por (b), são colocados em evidência os pontos localizados na vizinhança da energia de ressonância a qual está associada a um dos estados de bandas superiores do sistema $\alpha^{-}{ }^{90} \mathrm{Zr}$. As linhas contínuas presentes nos gráficos (b) representam as previsões feitas através da eq. (4.6) para o comportamento do deslocamento de fase nas proximidades da ressonância. 


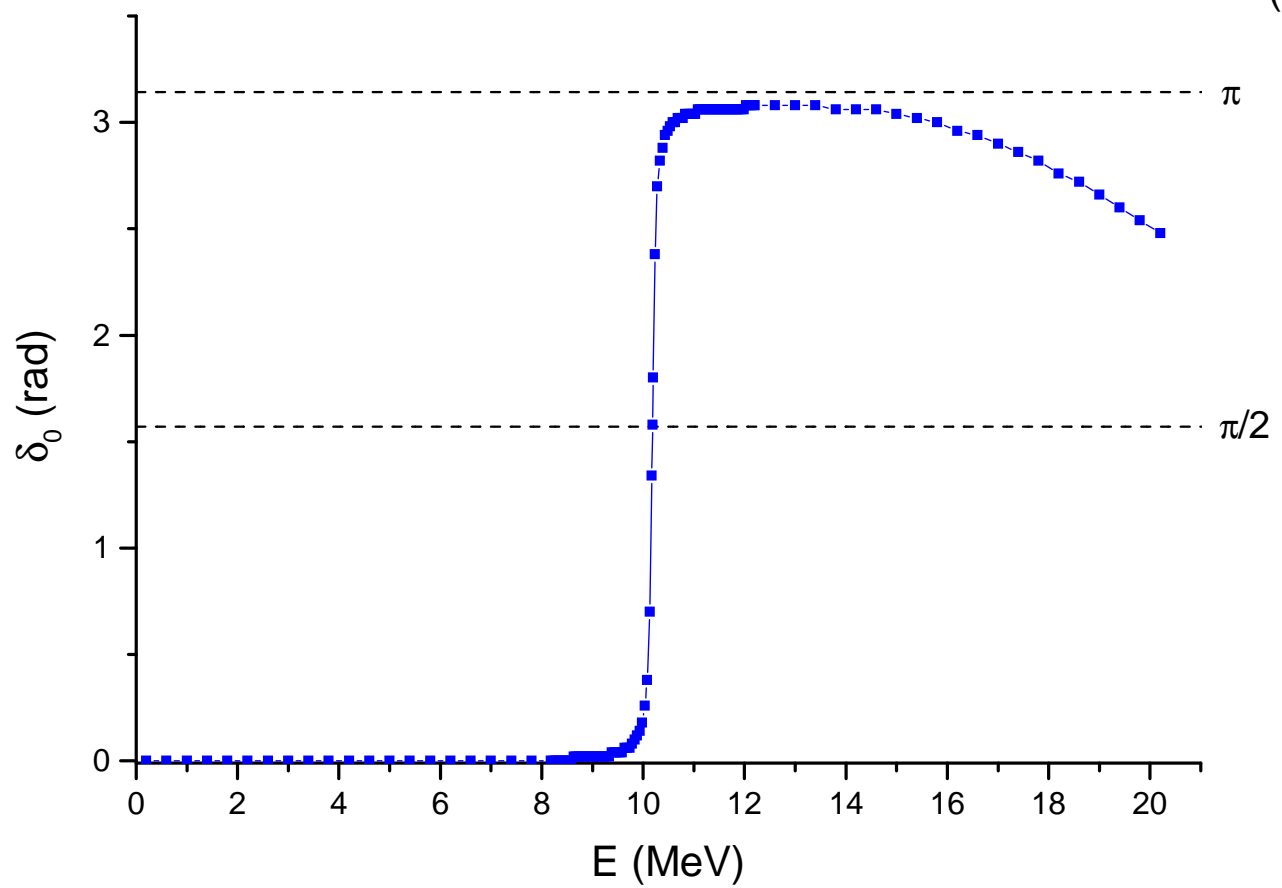

(a) $\pi / 2$

(b)

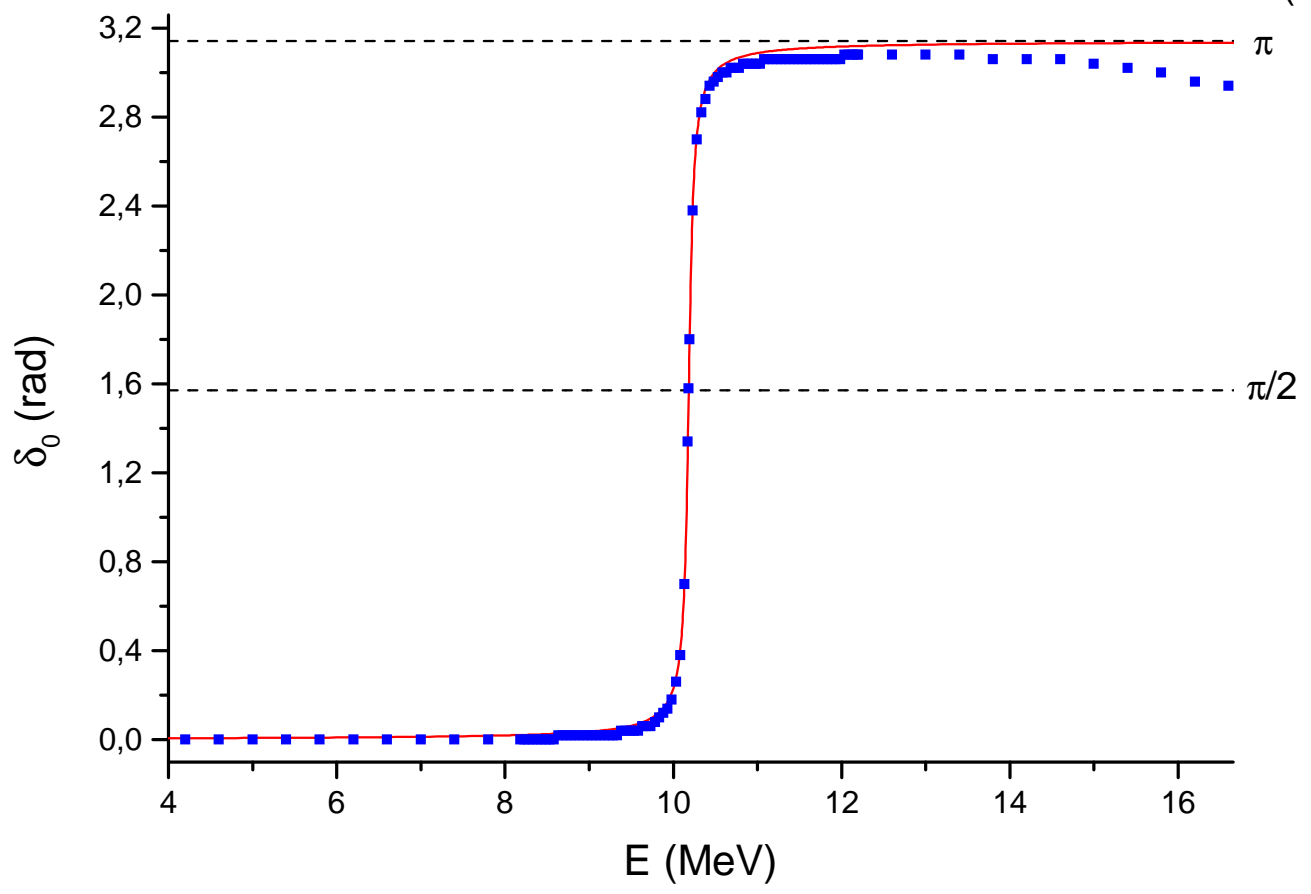

Figura C.1: Função $\delta_{0}(E)$ correspondente ao caso $L=0$. O gráfico (b) destaca a ressonância no estado $0^{+}$da banda $G=18$. 


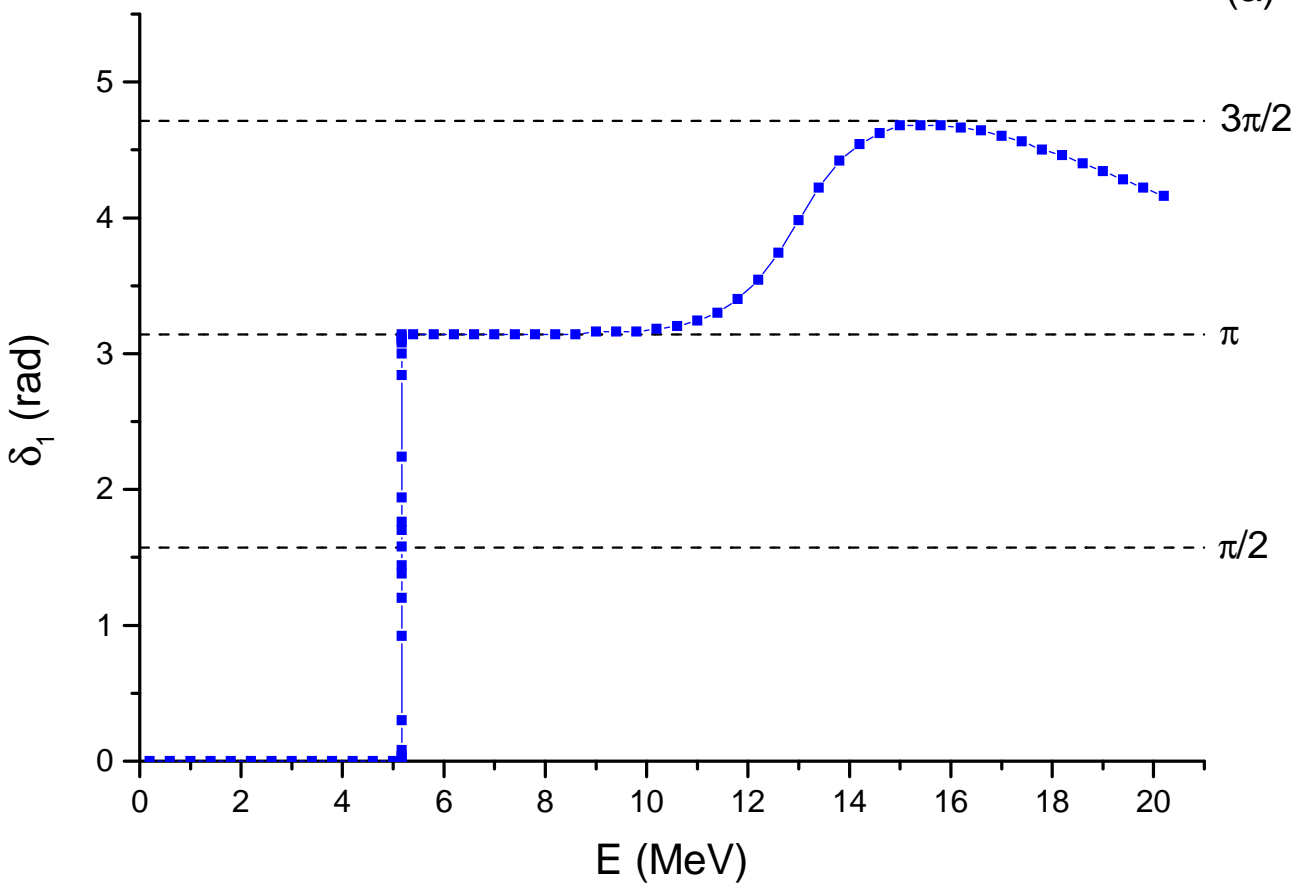




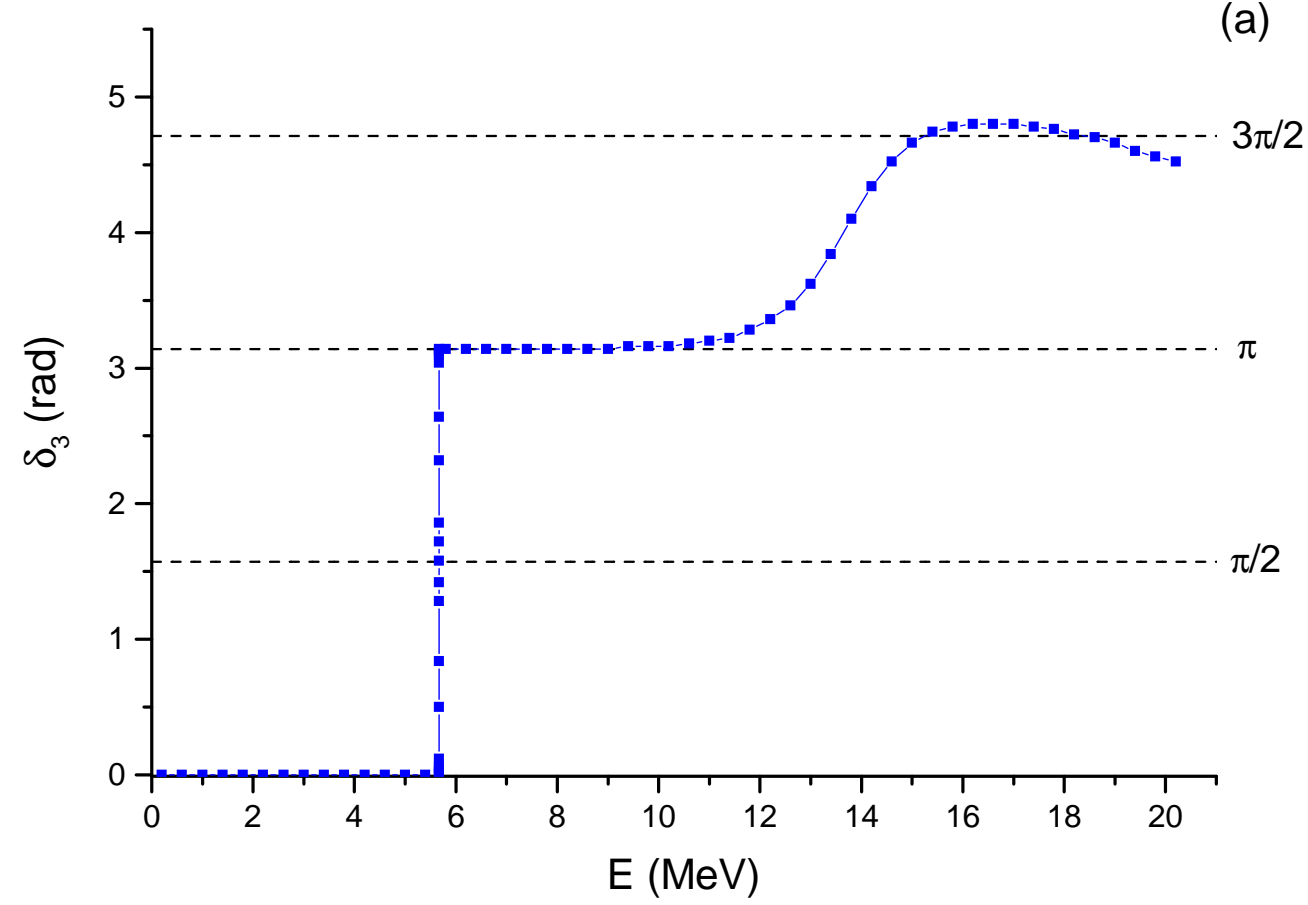

(b)

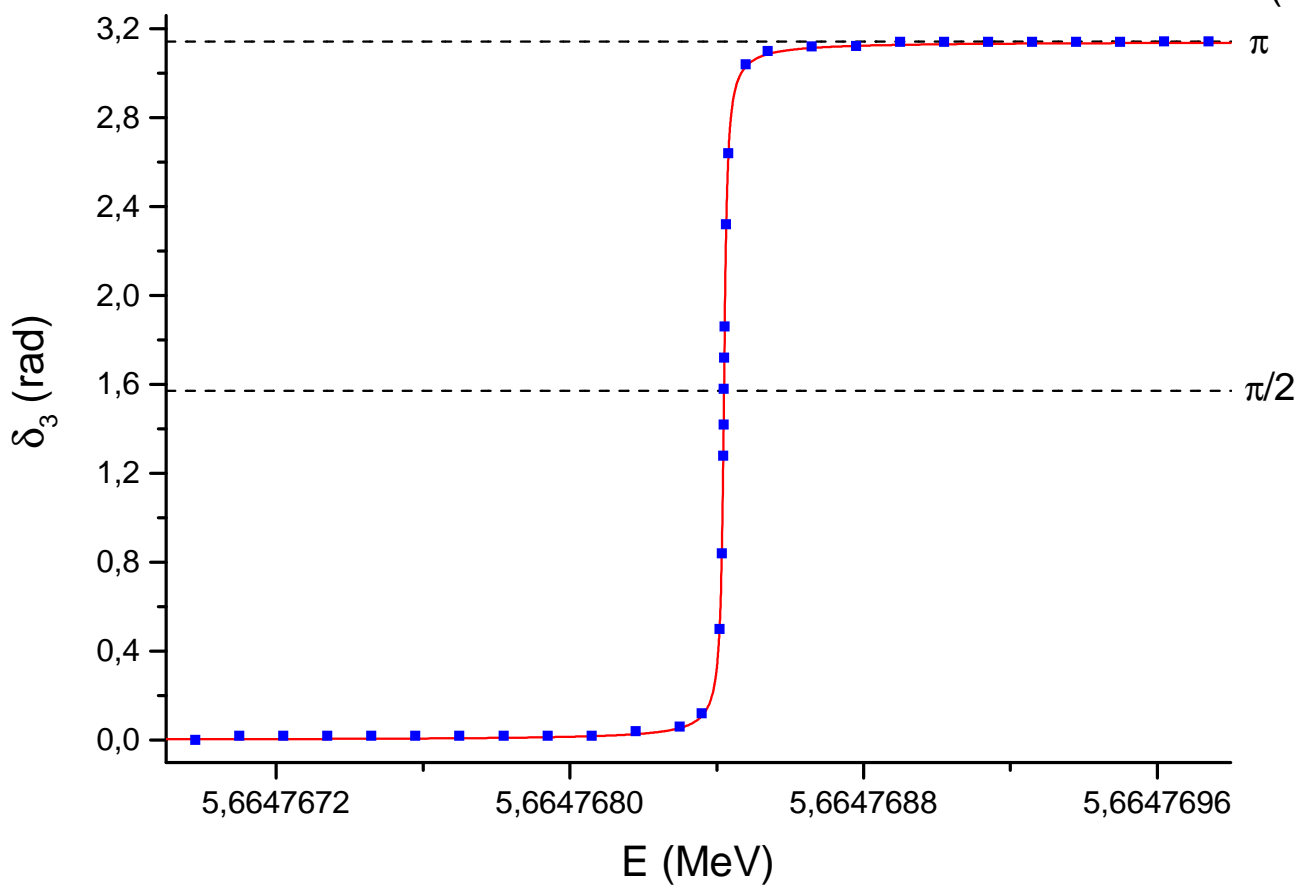

Figura C.3: Função $\delta_{3}(E)$ correspondente ao caso $L=3$. O gráfico (b) destaca a ressonância no estado $3^{-}$da banda $G=17$. 


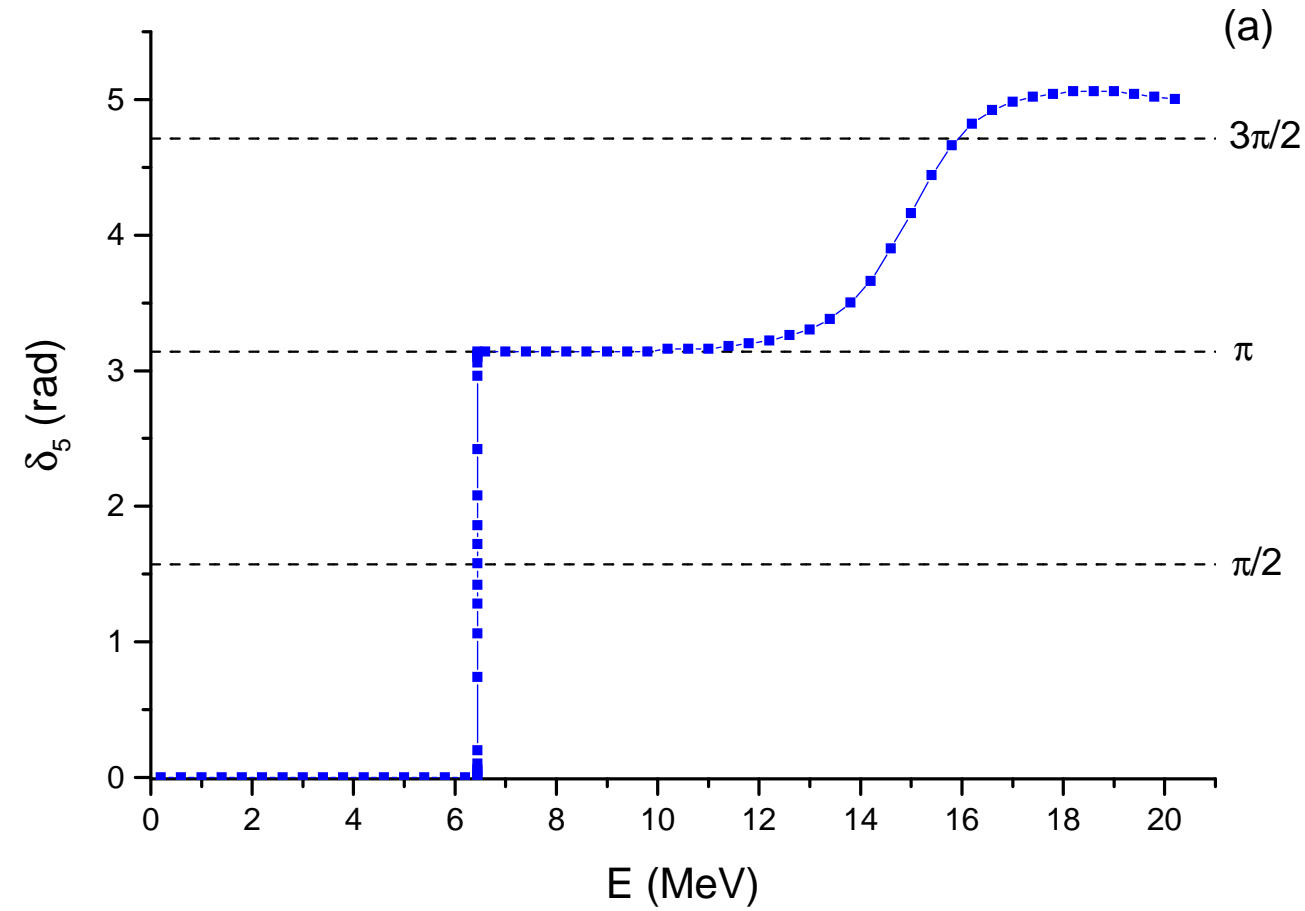

(b)

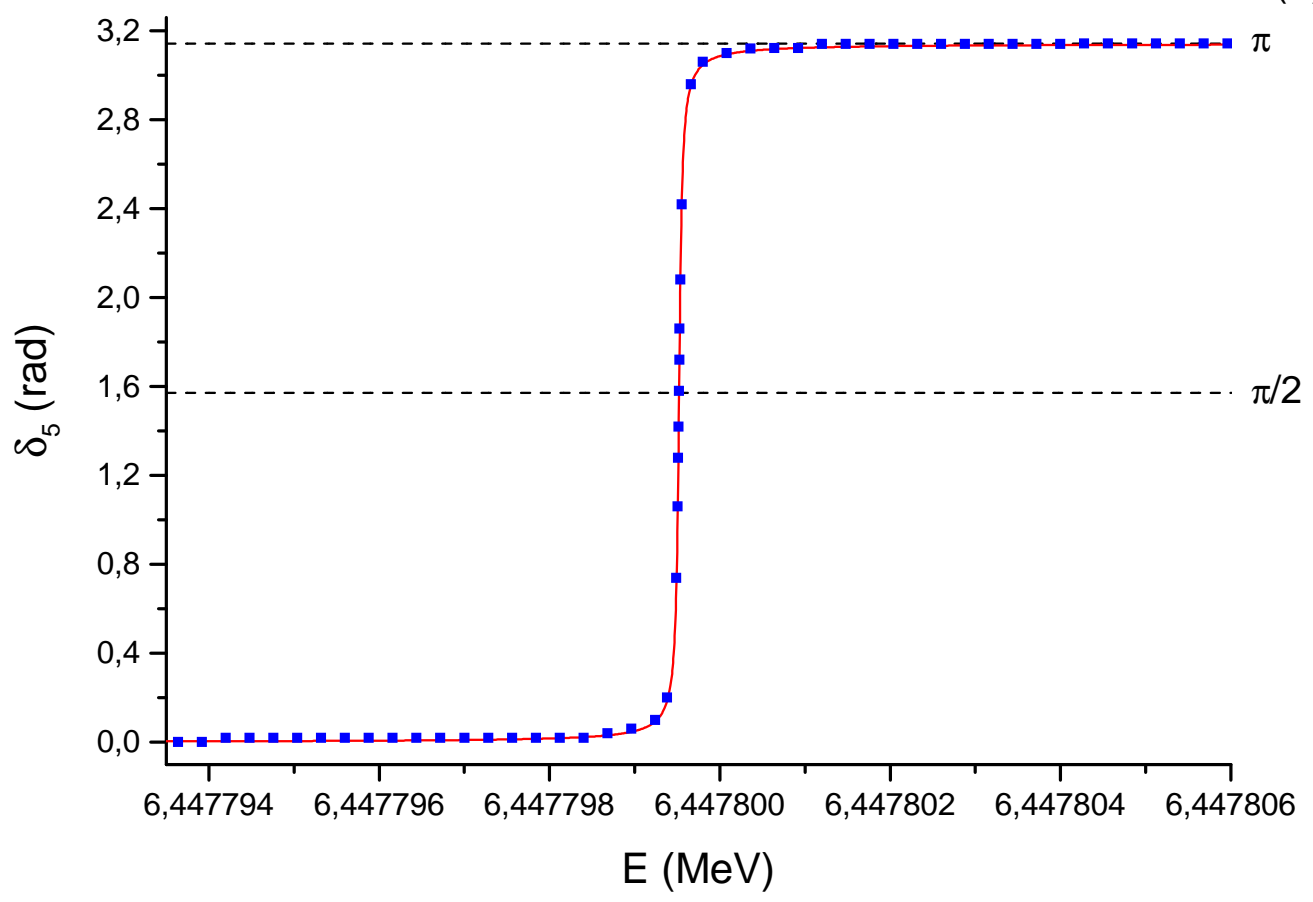

Figura C.4: Função $\delta_{5}(E)$ correspondente ao caso $L=5$. O gráfico (b) destaca a ressonância no estado $5^{-}$da banda $G=17$. 


\section{Referências Bibliográficas}

[1] B. Buck, C.B. Dover and J.P. Vary, Phys. Rev. C 11, 1803 (1975).

[2] F. Michel, G. Reidemeister and S. Ohkubo, Phys. Rev. Lett. 57, 1215 (1986).

[3] F. Michel, G. Reidemeister and S. Ohkubo, Phys. Rev. C 37, 292 (1988).

[4] S. Ohkubo, Phys. Rev. Lett. 74, 2176 (1995).

[5] B. Buck, A.C. Merchant and S.M. Perez, Phys. Rev. C 51, 559 (1995).

[6] F. Michel, G. Reidemeister and S. Ohkubo, Phys. Rev. C 61, 041601 (2000).

[7] F. Hoyler, P. Mohr and G. Staudt, Phys. Rev. C 50, 2631 (1994).

[8] B. Buck, A.C. Merchant, M.J. Horner e S.M. Perez, Nucl. Phys. A673, 157 (2000).

[9] K. Wildermuth and Y.C. Tang, A Unified Theory of the Nucleus (Academic Press, New York, 1977).

[10] K. Wildermuth and Th. Kanellopoulos, Nucl. Phys. 7, 150 (1958).

[11] G.R. Satchler, Direct Nuclear Reactions (Oxford University Press, New York, 1983).

[12] S.S.M. Wong, Introductory Nuclear Physics (Prentice-Hall, New Jersey, 1990).

[13] A. deShalit and H. Feshbach, Theoretical Nuclear Physics, vol. 1 (John Wiley \& Sons, Inc., New York, 1974).

[14] A.M. Kobos et al., Nucl. Phys. A425, 205 (1984).

[15] P.L. DeVries, A First Course in Computational Physics (John Wiley \& Sons, Inc., Oxford, 1994).

[16] G. Audi and A.H. Wapstra, Nucl. Phys. A595, 409 (1995).

[17] J.K. Tuli, Nucl. Data Sheets 66, 1 (1992).

[18] R.C. Barrett and D.F. Jackson, Nuclear Sizes and Structure (Clarendon Press, Oxford, 1977). 
[19] B. Buck and A.A. Pilt, Nucl. Phys. A280, 133 (1977).

[20] Chang-hua Zhang, Shun-jin Wang and Jin-nan Gu, Phys. Rev. C 60, 054316 (1999).

[21] A. Messiah, Quantum Mechanics, vol. 1 (John Wiley \& Sons, Inc., New York, 1976).

[22] A. Arima and S. Yoshida, Nucl. Phys. A219, 475 (1974).

[23] S. Ohkubo and K. Yamashita, Phys. Rev. C 66, 021301(R) (2002).

[24] S. Ohkubo and K. Yamashita, Phys. Lett. B 578, 304 (2004).

[25] B. Buck, A.C. Merchant and S.M. Perez, Phys. Rev. C 71, 014311 (2005). 